Review

\title{
A survey of photocatalytic materials for environmental remediation
}

\author{
Agatino Di Paola a,b,* Elisa García-López ${ }^{\mathrm{a}, \mathrm{b}}$, Giuseppe Marcì ${ }^{\mathrm{a}, \mathrm{b}}$, Leonardo Palmisano ${ }^{\mathrm{a}, \mathrm{b}, * *}$

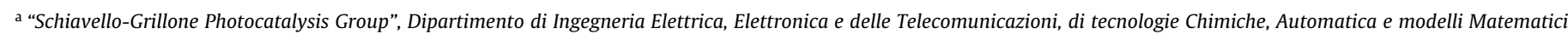 \\ (DIEETCAM), Università di Palermo, Viale delle Scienze, 90128 Palermo, Italy \\ b Consorzio Interuniversitario "La Chimica per l'Ambiente" (INCA), Via delle Industrie 21/8, 30175 Marghera, Italy
}

\section{A R T I C L E I N F O}

\section{Article history:}

Received 10 June 2011

Received in revised form

14 November 2011

Accepted 14 November 2011

Available online 22 November 2011

\section{Keywords:}

Heterogeneous photocatalysis

Environmental remediation

Water treatment

Air cleaning

Photocatalyic materials

\begin{abstract}
A B S T R A C T
Heterogeneous photocatalysis is an advanced oxidation process which has been the subject of a huge amount of studies related to air cleaning and water purification. All these processes have been carried out mainly by using $\mathrm{TiO}_{2}$-based materials as the photocatalysts and ca. $75 \%$ of the articles published in the last 3 years is related to them. This review illustrates the efforts in the search of alternative photocatalysts that are not based on $\mathrm{TiO}_{2}$, with some exceptions concerning particularly innovative modifications as nanoassembled $\mathrm{TiO}_{2}$ or $\mathrm{TiO}_{2}$ composites with active carbon, graphite and fullerene. Papers reporting preparation, characterization and testing of binary, ternary and quaternary compounds, have been reviewed. Despite many of these photocatalysts being effective for the photodecomposition of many pollutants, most of them do not allow a complete mineralization of the starting compounds, differently from $\mathrm{TiO}_{2}$.
\end{abstract}

(c) 2011 Elsevier B.V. All rights reserved.

\section{Contents}

1. Introduction.

2. Modified and nanoassembled $\mathrm{TiO}_{2}$

2.1. Modified $\mathrm{TiO}_{2} \ldots$

2.2. Nanoassembled $\mathrm{TiO}_{2}$

2.3. $\mathrm{TiO}_{2} / \mathrm{CNTS}$ composites

2.4. Conjugated carbon materials deposited on $\mathrm{TiO}_{2}$

2.5. N-doped $\mathrm{TiO}_{2}$

3. Binary compounds .

3.1. Binary oxides .

3.1.1. $\mathrm{ZnO}$.

3.1.2. $\mathrm{Cu}_{2} \mathrm{O}$

3.1.3. $\mathrm{WO}_{3}$

3.1.4. $\mathrm{V}_{2} \mathrm{O}_{5}$

3.1.5. Iron oxides

3.1.6. $\mathrm{Bi}_{2} \mathrm{O}_{3} \ldots$

3.1.7. $\mathrm{NiO}, \mathrm{Nb}_{2} \mathrm{O}_{5}, \mathrm{Ta}_{2} \mathrm{O}_{5} \ldots$

3.1.8. $\mathrm{ZrO}_{2}, \mathrm{CeO}_{2}, \mathrm{Ga}_{2} \mathrm{O}_{3}$

3.2. Binary sulfides...

4. Ternary compounds.

4.1. Ternary oxides

4.1.1. Vanadates.

4.1.2. $\mathrm{Bi}_{2} \mathrm{WO}_{6}, \mathrm{BiMoO}_{6}$

\footnotetext{
* Corresponding author. Tel.: +39 0912386374629 ; fax: +39 0917025020 .

** Corresponding author. Tel. +39091 23863746; fax: +39091 7025020.

E-mail addresses: agatino.dipaola@unipa.it (A. Di Paola), leonardo.palmisano@unipa.it (L. Palmisano).
} 


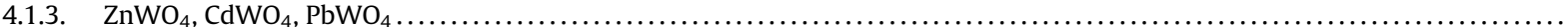

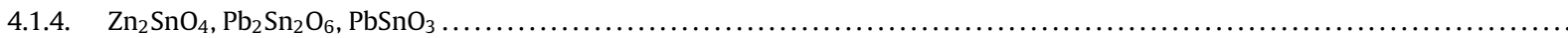

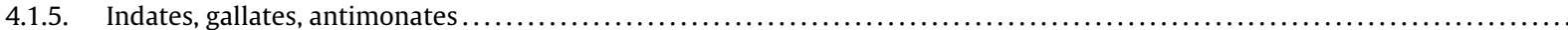

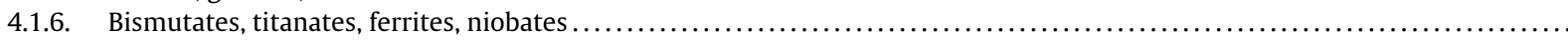

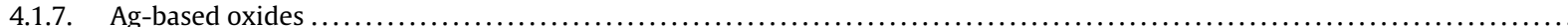

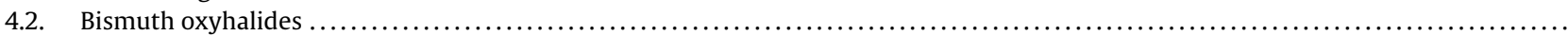

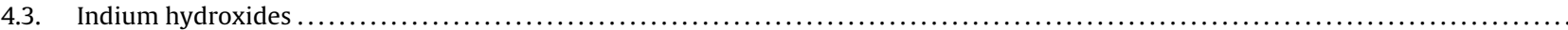

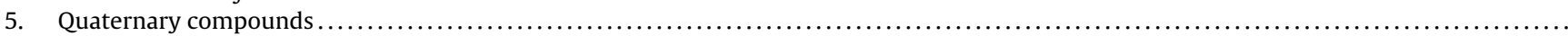

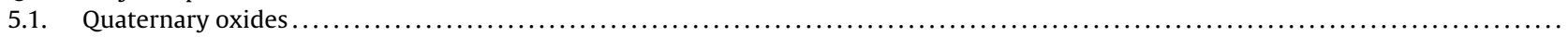

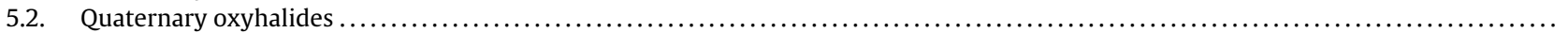

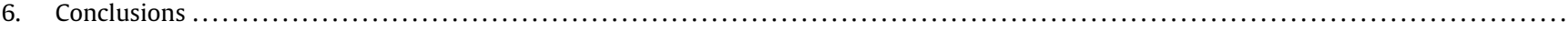

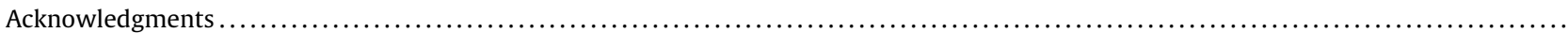

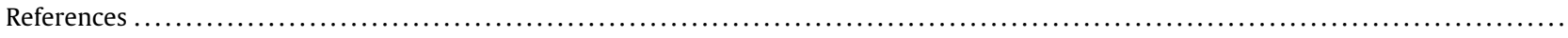

\section{Introduction}

Since the first pioneering papers in the seventies, the interest of scientists in heterogeneous photocatalysis has grown very much and thousands of papers have been published. Many topics have been tackled and this technology has been successfully applied to water splitting, hydrogen formation, dye sensitized cells production, environmental remediation by abatement of organic and inorganic pollutants, inactivation/killing of bacteria, and organic syntheses. In this review, our attention will be devoted only to environmental remediation in gas-solid and liquid-solid systems.

The present literature reports information on a huge amount of photocatalysts prepared with this aim as powders or supported as films on various types of materials. Most of these materials were bare $\mathrm{TiO}_{2}$ samples in the main polymorphic phases (anatase, rutile or brookite) or $\mathrm{TiO}_{2}$-based samples, doped or loaded with transition or rare earth metal species or sensitized with metal and metal free phthalocyanines, porphyrins and various dyes. The most used $\mathrm{TiO}_{2}$ photocatalyst was Degussa P25 that showed the best performances, especially under UV irradiation, probably due to the contemporary presence of anatase and rutile. Materials prepared by coupling two or more types of oxides to obtain mixed particles showing improved photocatalytic efficiency with respect to the single oxides have been also prepared, characterized and tested. In most but not all cases, $\mathrm{TiO}_{2}$ was one of the constituents.

The results of these studies, although important by a scientific point of view, do not prove for many reasons that these complex systems are more convenient than the bare $\mathrm{TiO}_{2}$ phases. Indeed, especially in aqueous liquid-solid systems, photocorrosion phenomena giving rise to release of pollutant species can occur, the enhancement of the photocatalytic activity is low, deactivation of the materials is observed, etc. On the other hand, the use of the bare $\mathrm{TiO}_{2}$ phases presents some drawbacks as (i) small amount of photons absorbed in the visible region with the consequent need to irradiate with UV light, (ii) high recombination rate for the photoproduced electron-hole pairs (iii) difficulty to significantly improve the performances by loading or doping with foreign species that often work as recombination centers, (iv) deactivation in the absence of water vapour observed in gas-solid systems when aromatic molecules must be abated, (v) difficulty to support powdered $\mathrm{TiO}_{2}$ on some materials. As a consequence, the research in heterogeneous photocatalysis has been addressed to modify some morphological and electronic properties of $\mathrm{TiO}_{2}$ in order to enhance its photoefficiency. In particular, powdered samples with high specific surface areas, nanosized particles and films on glasses or other supports have been prepared to increase the possibility for the reacting species to adsorb or to avoid the separation step. Doping, loading and sensitization of $\mathrm{TiO}_{2}$ were mainly aimed to shift the light absorption towards visible light and/or to increase the lifetime of the photoproduced electron-holes pairs.
Many review papers on the photocatalytic materials have been published in the past, but only a few have been concerned with the application of these photocatalysts for environmental remediation [1-8]. In this review, works on binary, ternary and quaternary compounds as possible alternatives to $\mathrm{TiO}_{2}$ are reported, even if the first part concerns innovative nanoassembled $\mathrm{TiO}_{2}$ or $\mathrm{TiO}_{2}$ composited with electronic conductors as active carbon, graphite and fullerene. A particular attention has been dedicated to papers dealing with nanostructured materials. Only papers dealing with compounds that are pure phase and their XRD patterns match well with the published JCPDS files have been described. A short section has been reserved to $\mathrm{N}$-doped $\mathrm{TiO}_{2}$ materials that are increasingly studied as typical visible light-responsive photocatalysts.

\section{Modified and nanoassembled $\mathrm{TiO}_{2}$}

\subsection{Modified $\mathrm{TiO}_{2}$}

Activated carbons (AC) have been reported to increase remarkably the photoactivity of $\mathrm{TiO}_{2}$ for the degradation of organic pollutants such as phenol [9-12], 4-chlorophenol [10], 4-aminophenol [11], salicylic acid [11] and 2,4-dichlorophenoxyacetic acid [10]. The synergistic effect was ascribed to the creation of a common contact interface between both solid phases and to the continuous transfer of the species from $\mathrm{AC}$ to $\mathrm{TiO}_{2}$. The interface was spontaneously created by a mere mixture of both phases in suspension [9].

Araña et al. [11] prepared catalysts by mixing $\mathrm{TiO}_{2}$ and activated carbon at different proportions. The results showed that the AC not only increased the surface area but also modified the acid-base properties and the UV spectrum of $\mathrm{TiO}_{2}$. Another interesting result was the efficiency of these catalysts under solar irradiation.

Binary materials composed by mixtures of home-prepared AC and commercial $\mathrm{TiO}_{2}$ Degussa P25 were employed for the photooxidization of 2-propanol in gas-solid regime [13]. The synergy between $\mathrm{TiO}_{2}$ and $\mathrm{AC}$ enormously increased the photocatalytic ability of the bare semiconductor to completely mineralize the substrate. Probably, the majority of the substrate and of the intermediates were reversibly adsorbed onto the AC surface, avoiding the deactivation of $\mathrm{TiO}_{2}$ that occurred when the bare semiconductor was used.

$\mathrm{TiO}_{2} /$ carbon composites have generally shown better performances than bare $\mathrm{TiO}_{2}$. Two types of composites have been prevalently studied: carbon-coated $\mathrm{TiO}_{2}$ and $\mathrm{TiO}_{2}$ loaded on activated carbon. Carbon-coated anatase-type $\mathrm{TiO}_{2}$ prepared by heat treatment of mixtures of $\mathrm{TiO}_{2}$ and various carbon precursors (poly(vinyl alcohol), hydroxyl propyl cellulose or poly(ethylene terephthalate)) showed high adsorptivity, and high efficiency for the photodecomposition of methylene blue (MB) [14-17]. No detectable reduction in photocatalytic activity was observed after 
cyclic usage of the most active carbon-coated sample obtained by $\mathrm{TiO}_{2}$ and poly(vinyl alcohol) [15].

A remarkable improvement of the visible light photodegradation of acid orange 7 and 2,4-dichlorophenol was obtained with carbon-deposited $\mathrm{TiO}_{2}$ samples prepared by hydrothermal dehydration of glucose [18]. Carbon coating $\mathrm{TiO}_{2}$ particles stabilizes the anatase phase and gives adsorptivity to the catalyst surface. Anatase particles coated by porous carbon were employed for the decomposition of phenol in water [19]. The presence of carbon on the $\mathrm{TiO}_{2}$ surface increased phenol adsorption on the catalyst but the decomposition rate of phenol was higher for the bare $\mathrm{TiO}_{2}$.

The photoactivity of the $\mathrm{TiO}_{2} /$ carbon composites obtained by loading $\mathrm{TiO}_{2}$ on activated carbon is generally higher than that of carbon-coated $\mathrm{TiO}_{2}$ samples or mixed suspensions of $\mathrm{TiO}_{2}$ and activated carbon. The AC matrix not only acts as a support for the $\mathrm{TiO}_{2}$ deposition but also counterworks the growth of the $\mathrm{TiO}_{2}$ particles and the transformation from anatase to rutile phase.

Torimoto et al. [20-22] loaded $\mathrm{TiO}_{2}$ on activated carbon by addition of carbon to a $\mathrm{TiO}_{2}$ colloid obtained by hydrolysis of titanium tetraisopropoxide. The $\mathrm{TiO}_{2} / \mathrm{AC}$ composites were more active than bare $\mathrm{TiO}_{2}$ for the photocatalytic degradation of gaseous propionaldehyde [20] and propyzamide [21] but less efficient for the photodecomposition of dichloromethane [22].

High efficiency of phenol removal under UV irradiation was obtained with $\mathrm{TiO}_{2}$ particles precipitated onto the surface of activated carbon through the hydrolysis of tetraisopropyl orthotitanate [23]. Two processes, adsorption and decomposition were involved in the removal of phenol. Although adsorption was dominant, combination of these two processes increased phenol removal from water by comparison with activated carbon and $\mathrm{TiO}_{2}$ alone.

Nagaoka et al. [24] prepared $\mathrm{TiO}_{2}$-loaded carbon microsphere composites by carbonization of cellulose microspheres coated by $\mathrm{TiO}_{2}$. The removal efficiency of acetaldehyde was increased by mixing the carbon microspheres with $\mathrm{TiO}_{2}$ powder, but the enhancement was not so great as that obtained with the carbon $/ \mathrm{TiO}_{2}$ microsphere composites. This indicates that the carbon surface was efficient in concentrating acetaldehyde around the $\mathrm{TiO}_{2}$ anchored on the composite surface.

$\mathrm{TiO}_{2}$ immobilized on activated carbon filter was investigated for the photodegradation of indoor air pollutants at the ppb level [25]. The results showed that the combination of $\mathrm{TiO}_{2}$ and AC significantly increased the removal of NO, benzene, toluene, ethylbenzene and $o$-xylene, due to the large adsorption capacity of AC.

Liu et al. [26] prepared $\mathrm{TiO}_{2} / \mathrm{AC}$ composites with high activity and easy separability using a hydrothermal method. Phenol, methyl orange (MO) and $\mathrm{Cr}(\mathrm{VI})$ were used as target pollutants to test the activity and decantability of the samples. The activity of the sample containing $5 \mathrm{wt}$.\% of AC was much higher than that of P25 and naked $\mathrm{TiO}_{2}$.

$\mathrm{TiO}_{2}$-coated active carbon composites prepared from tetrabutylorthotitanate were more efficient than pure $\mathrm{TiO}_{2}$ particles in the photodegradation of methylene blue [27] and rhodamine $\mathrm{B}(\mathrm{RhB})$ [28]. The composites were used repeatedly preserving their high photoactivity [28].

Wang et al. [29] prepared $\mathrm{TiO}_{2} / \mathrm{AC}$ composites by a diphydrothermal method at $180^{\circ} \mathrm{C}$ using peroxotitanate as a precursor. The samples were tested for the degradation of $\mathrm{MO}$ and showed a higher efficiency than mixtures of AC and commercial P25 or synthetic $\mathrm{TiO}_{2}$. The composites were easily separated from the bulk solution and the photocatalytic ability was hardly decreased after a five-cycle reaction.

\subsection{Nanoassembled $\mathrm{TiO}_{2}$}

Nanostructured materials can be used with the aim to enhance the photoactivity of $\mathrm{TiO}_{2}$. The different shapes of $\mathrm{TiO}_{2}$ nanomaterials include not only nanoparticles, nanofibers and nanotubes but also nanocombs, nanorings, nanosprings, nanobowls, nanobelts, nanosheets, nanocages, nanorods, etc.

The photocatalytic activity of $\mathrm{TiO}_{2}$ nanotubes [30] annealed at different temperatures was evaluated by the degradation of the reactive blue 69 dye and compared with that of $\mathrm{TiO}_{2}$ Degussa P25. The nanotubes were prepared from an anatase precursor by an alkali thermal reflux treatment at atmospheric pressure with $\mathrm{NaOH}$. When the $\mathrm{TiO}_{2}$ nanotubes were used without any annealing treatment, their photocatalytic performance was lower than that of $\mathrm{P} 25$. Annealing the nanotubes at $300^{\circ} \mathrm{C}$ the photoactivity was very close to that of the commercial sample but it decreased at higher temperatures because the dehydration induced the collapse of the nanotubular array reducing the specific surface area of the anatase particles.

$\mathrm{TiO}_{2}$ nanotube array films prepared by electrochemical anodic oxidation were investigated for the photodegradation of phenol [31], methyl orange [32,33], acid orange 7 [32], methylene blue [34-36] or gaseous acetaldehyde [37,38]. The nanotube arrays were more active than anatase or $\mathrm{P} 25 \mathrm{TiO}_{2}$ nanoparticulate films with similar thickness and geometric area. The enhanced photoactivity was ascribed to a more effective separation of the photogenerated electron-hole pairs occurring in the well-ordered $\mathrm{TiO}_{2}$ nanotube array film and to the higher internal surface area of the nanotube structure. The photoactivity of the $\mathrm{TiO}_{2}$ nanotube films was strongly influenced by the thickness and very slightly by the tube diameter $[32,36,37]$. With increasing the thickness, the photodegradation efficiency increased till a maximum and then decreased to an almost steady value. When the film is thicker than the light penetration depth, the active thickness is practically constant and the bottom film serves only as support. The active species have a longer diffusion path in the longer nanotubes and this may cause the decrease of the photocatalytic degradation rate.

Schulte et al. [38] studied the effect of the crystal phase composition of the $\mathrm{TiO}_{2}$ nanotube array on the photocatalytic reduction of $\mathrm{CO}_{2}$ and oxidation of acetaldehyde. The nanotube films were amorphous as prepared but their phase composition (anatase or mixtures of anatase and rutile) was directly tunable by annealing at varying temperature. Under UV the photoreduction of $\mathrm{CO}_{2}$ decreased with increasing rutile content but increased under visible and near visible light. For oxidation, the mixed phase samples showed enhanced reactivity that depended on the anatase to rutile ratio.

Similar results were found by Bouazza et al. [39] who prepared $\mathrm{TiO}_{2}$ nanotubes with different crystalline structures using carbon nanotubes (CNTs) as templates. A thin film of $\mathrm{TiO}_{2}$ deposited on multi-walled carbon nanotubes with the aid of benzyl alcohol as a linking agent was heat treated in argon to obtain the desired crystalline phase. Subsequently the CNTs were removed by oxidation in air at $520^{\circ} \mathrm{C}$. The samples were tested for the photocatalytic oxidation of propene and the activity followed the order: rutile < anatase < anatase/rutile mixture. It is worth noting that higher values of propene conversion and photoactivity were obtained with the precursor $\mathrm{TiO}_{2} / \mathrm{CNTs}$ consisting of $70 \% \mathrm{TiO}_{2}$ (100\% anatase) and 30\% CNTs. The improved performance was attributed to a reduced electron-hole pair recombination due to the presence of the carbon nanotubes which act as an electron acceptor, promoting interfacial electron-transfer processes from the attached oxide to the CNT.

\section{3. $\mathrm{TiO}_{2} / \mathrm{CNTS}$ composites}

The CNTs are materials particularly interesting because they have unique electronic properties associated with their special 1D structure that facilitates the charge transfer [40]. The CNTs are described as tubular structures made entirely of rolled-up layers 


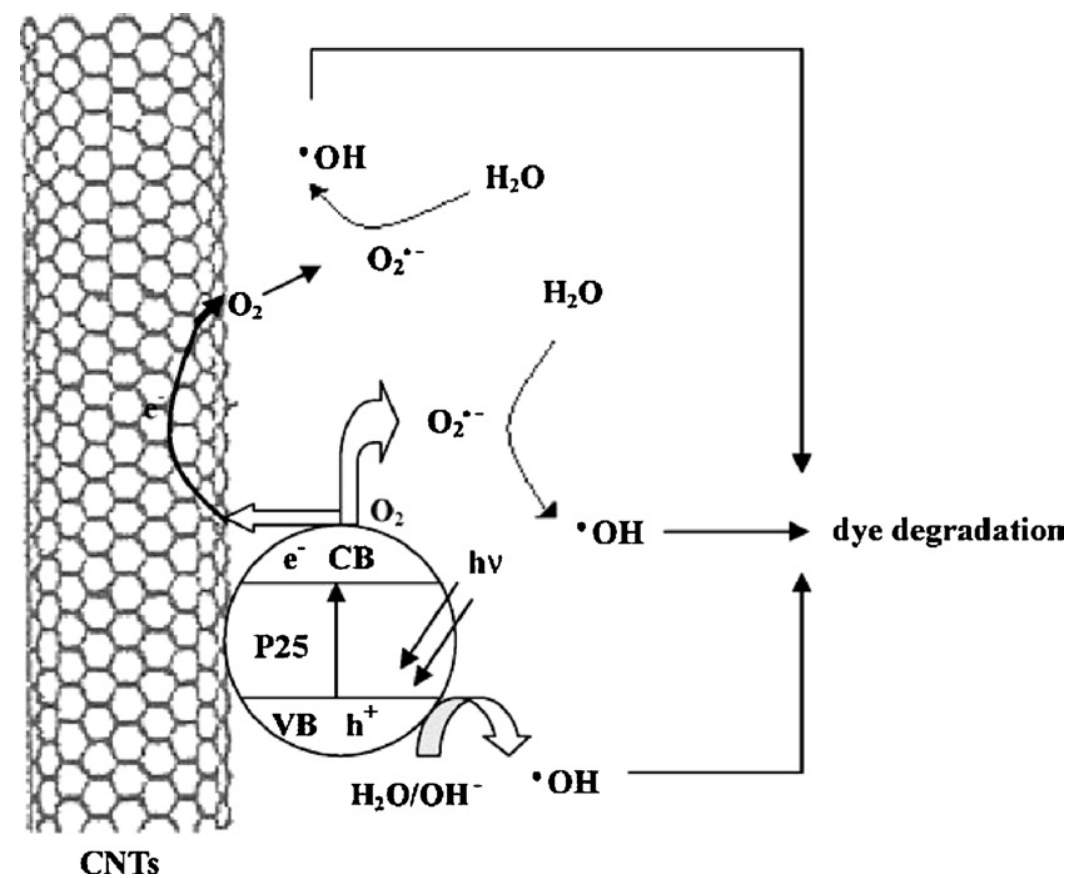

Fig. 1. Schematic illustration of the mechanism of the activation of photocatalytic activity for P25 by CNTs. Reproduced with permission from ref. [51].

of interconnected carbon atoms. They are classified as "singlewalled" nanotubes (SWCNTs) which consist of a single layer of graphene sheet rolled into a cylindrical tube or multi-walled nanotubes (MWCNTs), which comprise multiple concentric tubes. In general, the CNTs possess large specific surface areas due to their hollow geometry.

CNTs- $\mathrm{TiO}_{2}$ hybrids have been tested for the photodegradation of acetone [41], propene [39], phenol [42-47], methylene blue [48-50]. All these studies have revealed that the addition of CNTs enhanced the photocatalytic efficiency of $\mathrm{TiO}_{2}$.

Yen et al. [46] found that the synthesis procedures affected the morphology and the physico-chemical properties of the (MWCNTs) $/ \mathrm{TiO}_{2}$ nanocomposites influencing the photoactivity of the catalysts. In particular, the samples prepared by the sol-gel method were more efficient for the photodegradation of phenol and $\mathrm{NO}_{x}$ than those prepared by hydrothermal treatment.

Yu et al. [51] studied the effect of MWCNTs on the adsorption and the photocatalytic properties of $\mathrm{TiO}_{2} \mathrm{P} 25$. The results showed that the mixture of CNTs and $\mathrm{TiO}_{2}$ greatly increased the photocatalytic activity of $\mathrm{TiO}_{2}$ for the treatment of three azo dyes and was more efficient of the mixture of $\mathrm{TiO}_{2}$ with activated carbon. Fig. 1 shows a schematic illustration of the mechanism proposed for the enhanced photocatalytic activity of P25 by CNTs. Although the CNTs were not composited with P25, the two components can interact with each other so that the electrons excited in the conduction band of P25 may migrate into the nanocylinder of MWCNT and the possibility of recombination of the electron/hole pairs decreases. $\mathrm{O}_{2}$ adsorbed on the surface of the CNTs may accept the electron and form the ${ }^{\bullet} \mathrm{OH}$ radical which oxidizes the adsorbed dye directly on the surface.

The same mechanism could explain the enhanced photocatalytic activity of $\mathrm{TiO}_{2} / \mathrm{CNTs}$ composites tested for the degradation of acetone in air [41]. The CNTs were boiled with concentrated $\mathrm{HNO}_{3}$ to get oxygenated functionalities as hydroxyl, carboxyl and carbonyl groups on the surface of the nanotube. The treated CNTs were combined with $\mathrm{TiO}_{2}$ through sonochemical and calcination methods. The photoactivity of these samples was much higher than that of P25 or of an activated carbon/ $\mathrm{TiO}_{2}$ composite. The presence of a small amount of CNTs enhanced the photoefficiency of $\mathrm{TiO}_{2}$ greatly, but an excess amount of CNTs shielded $\mathrm{TiO}_{2}$ from absorbing UV.

Faria and coworkers prepared $\mathrm{MWCNTs} / \mathrm{TiO}{ }_{2}$ composite catalysts that were tested for the degradation of phenol under UV $[42,44]$ and visible light $[43,44]$ irradiation. In both cases, the introduction of MWCNTs into $\mathrm{TiO}_{2}$ remarkably increased the rate of phenol disappearance. The maximum activity was observed for a weight ratio $\mathrm{MWCNTs} / \mathrm{TiO}_{2}$ equal to $20 \%$ and was considerably higher than a mechanical mixture of MWCNTs and $\mathrm{TiO}_{2}$ with the same MWCNTs content. The synergetic effect, induced by a strong interphase interaction between MWCNT and $\mathrm{TiO}_{2}$, was ascribed to MWCNT acting as photosensitizer rather than as adsorbent or dispersing agent in the composite catalysts. As shown in Fig. 2, the hypothesized mechanism was an electron transfer from MWCNT

a $h v$

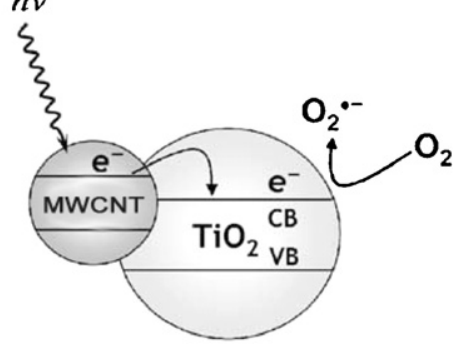

b

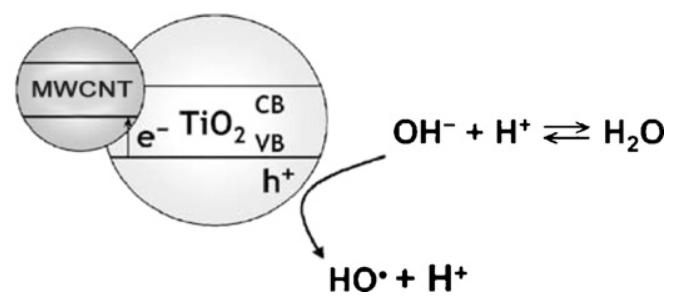

Fig. 2. Mechanism for the enhanced photoactivity of the $\mathrm{MWCNTs} / \mathrm{TiO}_{2}$ composites. Reproduced with permission from ref. [43]. 


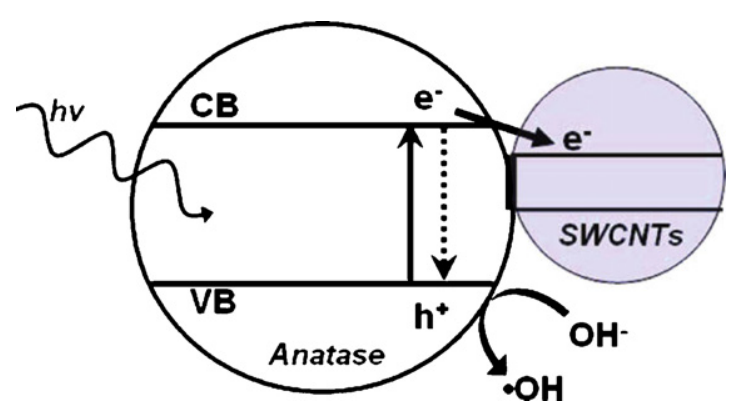

Fig. 3. Schematic representation of the charge transfer between SWCNTs and anatase.

Reproduced with permission from ref. [45].

to the conduction band of $\mathrm{TiO}_{2}$ and a simultaneous electron backtransfer to MWCNT with the formation of a hole in the valence band of $\mathrm{TiO}_{2}$. The photogenerated electrons and holes triggered the formation of $\mathrm{O}_{2}{ }^{-}$and hydroxyl ${ }^{\bullet} \mathrm{OH}$ radicals which are responsible for the degradation of the organic compound.

Yao et al. [45] investigated the photoreactivity of single or multi-walled CNTs/anatase composites prepared using a simple low-temperature process. The nanostructured composite assembled from anatase and $100 \mathrm{~nm}$ single-walled CNTs exhibited enhanced and selective photocatalytic oxidation of phenol in comparison to both pure anatase and Degussa P25. The anatase/100 nm multi-walled CNTs composite was more active than pure anatase but less efficient than the anatase/single-walled CNTs. Fig. 3 shows the mechanism proposed to justify the high activity of the anatase/single-walled CNTs system. The relative position of the conduction band edges permits the transfer of electrons from the conduction band of anatase to the conduction band of the SWCNTs allowing charge separation, stabilization, and hindered recombination. As shown in Fig. 4, the lower efficiency of the anatase/multi-walled CNTs composites with respect to the anatase/single-walled CNTs systems was attributed to the less individual contact between multi-walled $\mathrm{CNT}$ and $\mathrm{TiO}_{2}$ surface.

The conduction band edge of $\mathrm{TiO}_{2}$ (anatase, brookite or rutile) ranges between -0.46 and $-0.37 \mathrm{~V}$ [52] whilst that of SWCNTs was found to be $+0.3 \mathrm{~V}$ [53]. The charge transfer from the $\mathrm{TiO}_{2}$ conduction band to the SWCNT conduction band is therefore energetically favorable as proposed by Yao et al. [45].

The raw MWCNTs are usually highly tangled with one another and their ends are rarely visible. Luo et al. [54] prepared short MWCNTs that can be suspended, sorted and manipulated more easily so that the light can well penetrate into the inner tubes. The short MWCNTs were used as starting materials to fabricate $\mathrm{TiO}_{2}$ /short MWCNTs nanocomposites that were tested for the photodegradation of Reactive Brilliant Red X-3B. The photoactivity
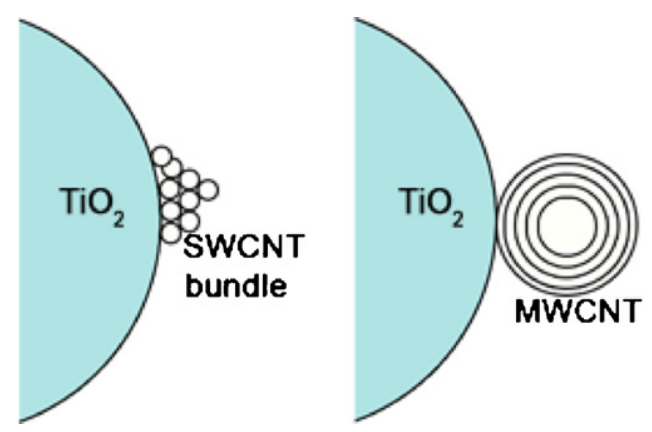

Fig. 4. Schematic representation of a SWCNT bundle and a MWCNT in contact with a $\mathrm{TiO}_{2}$ particle (not to scale).

The figure has been adapted from ref. [45]. of the $\mathrm{TiO}_{2} /$ short MWCNTs samples with optimum weight ratio $(1: 100)$ was much higher than that of various active photocatalysts $\left(\mathrm{TiO}_{2} /\right.$ short MWCNTs $\left.>\mathrm{TiO}_{2} / \mathrm{MWCNTs}>\mathrm{TiO}_{2}>\mathrm{P} 25\right)$.

Gao et al. [55] demonstrated the feasibility of a novel surfactant wrapping sol-gel method for coating a uniform and well-defined nanometer-scale $\mathrm{TiO}_{2}$ layer on individual MWCNTs, producing a mesoporous anatase nanocomposite film. Irradiation of the MWCNTs $/ \mathrm{TiO}_{2}$ composite or a $\mathrm{TiO}_{2}$-coated electrode at a sufficiently positive potential resulted in enhanced MB degradation. The best performance of the composite was attributed to the capability of the CNTs and the applied potential to facilitate the separation of the photogenerated electron/hole pairs at the $\mathrm{CNTs}-\mathrm{TiO}_{2}$ interface.

Conventional sol-gel methods usually lead to a heterogeneous, non-uniform coating of CNTs by $\mathrm{TiO}_{2}$, showing bare CNTs surfaces and random aggregation of $\mathrm{TiO}_{2}$ onto the CNTs surface. The MWCNTs $/ \mathrm{TiO}_{2}$ nanocomposites prepared by the surfactant wrapping sol-gel method exhibited much higher activity for the degradation of MB than that of samples prepared by a conventional sol-gel method, and a onefold rate enhancement with respect to $\mathrm{TiO}_{2}$ alone [56].

\subsection{Conjugated carbon materials deposited on $\mathrm{TiO}_{2}$}

An attractive method to improve the photocatalytic efficiency of $\mathrm{TiO}_{2}$ is to modify the $\mathrm{TiO}_{2}$ surface with conjugated carbon materials such as graphite, fullerene or graphene. The delocalized conjugated $\pi$ structures have been proven to cause a rapid photoinduced charge separation and a relatively slow charge recombination in electron-transfer processes [57].

Shanmugam et al. [58] synthesized $\mathrm{TiO}_{2} @ \mathrm{C}$ core-shell composite nanoparticles by a simple and efficient single-step method. HRTEM results revealed that a few graphitic layers were wrapped on the surface of $\mathrm{TiO}_{2}$, and these carbon layers were responsible for suppressing the transformation from anatase to rutile even at high temperature. The sample prepared at $700^{\circ} \mathrm{C}$ showed an activity comparable to that of P25 for the degradation of 4-chlorophenol under UV irradiation. The photoactivity of the $\mathrm{TiO}_{2} @ \mathrm{C}$ samples was higher than that of the commercial $\mathrm{TiO}_{2}$ for the photobleaching of MB under sunlight.

Efficient photocatalysts were prepared by surface hybridization of $\mathrm{TiO}_{2}$ particles with few molecular thick layers of graphitelike carbon [59]. $\mathrm{TiO}_{2} /$ carbon core-shell structures were obtained through a hydrothermal method at $180^{\circ} \mathrm{C}$, using commercial P25 and glucose as starting materials, and the carbonaceous cages were graphitized by calcination at $800^{\circ} \mathrm{C}$ in a $\mathrm{N}_{2}$ atmosphere. The catalysts were tested for the degradation of formaldehyde under UV light irradiation. The sample with a carbon shell of three molecular layers thickness $(\sim 1 \mathrm{~nm})$ showed the highest photocatalytic activity which was about two times higher than that of P25. The enhanced photoactivity was ascribed to the high migration efficiency of photoinduced electrons at the graphite-like carbon $/ \mathrm{TiO}_{2}$ interface due to the electronic interaction between $\mathrm{TiO}_{2}$ and the conjugated structure of graphite. The samples exhibited a high activity under visible light irradiation because graphite-like carbon absorbs visible light and the excited electrons are subsequently injected into the conduction band (d-orbital) of $\mathrm{TiO}_{2}$ due to the $\mathrm{d}-\pi$ interaction.

Three-dimensionally ordered macroporous $\mathrm{TiO}_{2} /$ graphitized carbon were obtained by catalytic graphitization of polystyrene arrays, which were used as both template and carbon source [60]. The graphitization degree and the content of graphitic carbon in the composite were dependent on the pyrolysis temperature and confinement effect of the macroporous oxide skeleton. The $\mathrm{TiO}_{2}$ /graphitized carbon showed higher activity than $\mathrm{TiO}_{2}$ /amorphous carbon and P25 in the degradation of RhB and activity comparable to that of P25 in the degradation of eosin Y. 
a

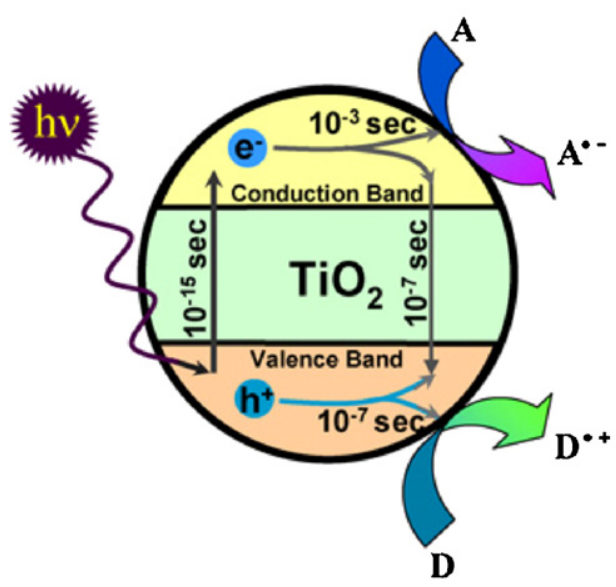

b $\quad$ A

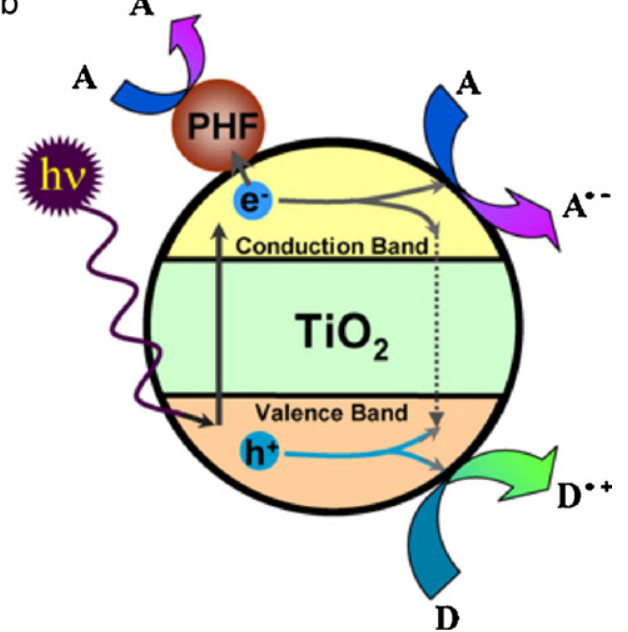

Fig. 5. Hypothetical photocatalytic reactions occurring upon UV irradiation. (a) With $\mathrm{TiO}_{2}$ alone and (b) in presence of adsorbed PHF molecules.

Reproduced with permission from ref. [64].

Yang et al. [61] combined carbon nanotubes and $\mathrm{TiO}_{2}$ nanotubes by carbonizing poly(ethylene glycol) 6000 at $600^{\circ} \mathrm{C}$ on $\mathrm{TiO}_{2}$ nanotube arrays obtained by anodization of Ti foils. Compared with the unmodified $\mathrm{TiO}_{2}$ nanotubes, the coupled $\mathrm{C} / \mathrm{TiO}_{2}$ photocatalyst showed an enhanced efficiency for the photodecomposition of MO, due to the increased carrier rate and stronger adsorbability of the tube-in-tube carbon-coated $\mathrm{TiO}_{2}$ arrays.

Fullerene supported on silica or $\gamma$-alumina has been successfully used for the photooxygenation of olefins [62,63]. Apostolopoulou et al. [64] developed an impregnation method for dispersing various amounts of $\mathrm{C}_{60}(1-4 \% \mathrm{w} / \mathrm{w})$ onto a titania surface. Kamat et al. [65] demonstrated the transfer of photogenerated electrons from titanium dioxide to fullerenes with ethanol/benzene mixture as solvent.

Fullerenes are extremely hydrophobic so that their use in aqueous media is quite limited. The water solubility of fullerenes can be improved by functionalizing the molecules with hydroxyl groups. Krishna et al. [66] employed polyhydroxy fullerenes (PHF) to enhance the photocatalytic efficacy of $\mathrm{TiO}_{2}$ for the degradation of the Procion red dye. Fig. 5 shows the hypothetical photocatalytic reactions occurring upon UV irradiation. The PHF molecules adsorbed on the surface of $\mathrm{TiO}_{2}$ by electrostatic forces enabled the scavenging of the photogenerated electrons decreasing the electron/hole recombination. The surface coverage of the $\mathrm{TiO}_{2}$ nanoparticles by the PHF molecules $\left(\mathrm{C}_{60}(\mathrm{OH})_{n}, n=18-24\right)$ determined the extent of enhancement in dye degradation, with an optimum $\mathrm{PHF} / \mathrm{TiO}_{2}$ weight ratio equal to 0.001 .

A fullerene/ $/ \mathrm{TiO}_{2}$ composite was prepared by heating at $700{ }^{\circ} \mathrm{Ca}$ mixture of titanium(IV) n-butoxide and surface oxidized fullerene [67]. The excellent results obtained for the photodegradation of MB were attributed to both the effects between the photocatalysis of the supported $\mathrm{TiO}_{2}$ and the absorptivity of the fullerene.

$\mathrm{Mu}$ et al. [68] modified the surface of $\mathrm{TiO}_{2}$ Degussa P25 with a home-prepared $\mathrm{C}_{60}$ derivative, i.e. $\mathrm{C}_{60}(\mathrm{CHCOOH})_{2}$. In comparison to the pure P25 or to a mixture of $\mathrm{C}_{60}$ and P25, the modified $\mathrm{TiO}_{2}$ nanoparticles displayed a higher photocatalytic activity for the reduction of $\operatorname{Cr}(\mathrm{VI})$ ions in aqueous solution. The UV-vis spectrum of the modified P25 revealed a stronger absorption in the range of $400-800 \mathrm{~nm}$, indicating some electron interactions between $\mathrm{C}_{60}(\mathrm{CHCOOH})_{2}$ and $\mathrm{TiO}_{2}$. As shown in Fig. 6, the increased photoefficiency was ascribed to the effective separation of the electron-hole pairs in P25 due to the formation of covalent bonds between $\mathrm{C}_{60}$ and $\mathrm{P} 25$.

Choi workgroup proposed a new approach to develop visible light-active photocatalysts by a sensitization mechanism based on the charge transfer between surface adsorbate and semiconductor particle [69]. Differently from the common dye sensitization that is mediated through the excited dye state, the visible light irradiation excites an electron from the ground state of the adsorbate to the semiconductor conduction band and subsequently the electron can be transferred to electron acceptors present in the solution. Water-soluble fullerol $\left(\mathrm{C}_{60}(\mathrm{OH})_{x}\right)$ was well adsorbed on $\mathrm{TiO}_{2}$ Degussa P25 and the adsorbed fullerol activated $\mathrm{TiO}_{2}$ in the visible region through a ligand-to-metal charge transfer mechanism, that is absent by using $\mathrm{C}_{60} / \mathrm{TiO}_{2}$ systems prepared by impregnation. Fullerol/ $/ \mathrm{TiO}_{2}$ exhibited marked visible photocatalytic activity for the redox conversion of 4-chlorophenol, iodide anion and $\mathrm{Cr}(\mathrm{VI})$.

Carbon was also used in graphene-like form to prepare graphene $/ \mathrm{TiO}_{2}$ photocatalysts [70]. Graphene is an atomic sheet of $\mathrm{sp}^{2}$-bonded carbon atoms with unique properties, such as high conductivity, large specific surface area and high transparency

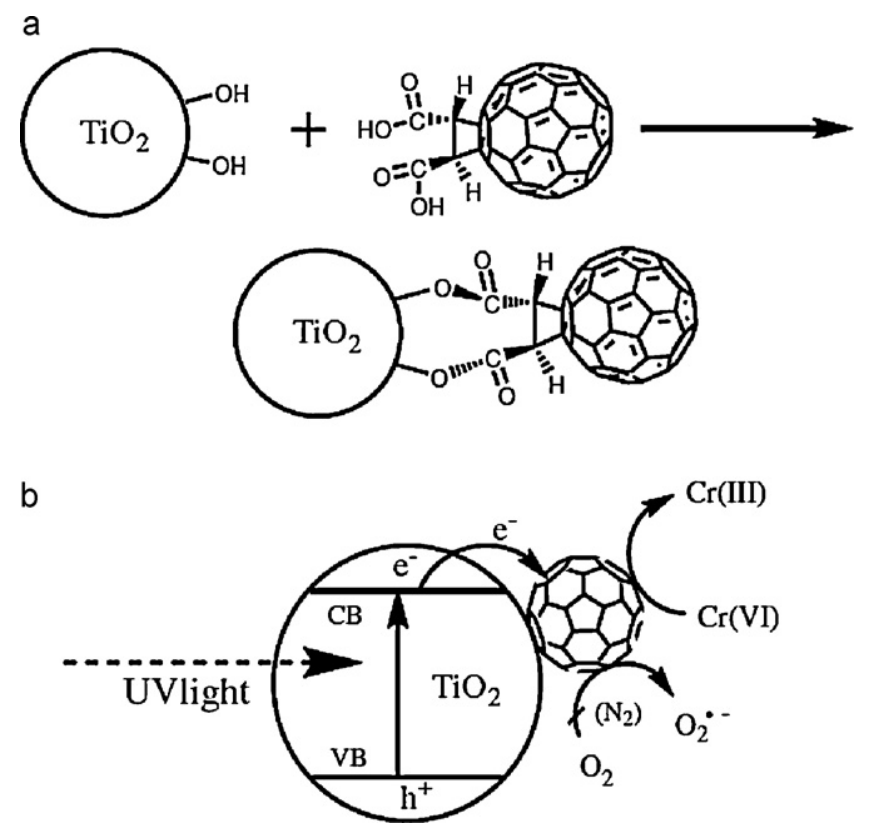

Fig. 6. (a) Formation of the $\mathrm{C}_{60}(\mathrm{CHCOOH})_{2}$ modified Degussa P25; (b) possible photocatalytic reduction mechanism of the $\mathrm{Cr}(\mathrm{VI})$ ions using the modified P25 as a photocatalyst.

Reproduced with permission from ref. [66]. 


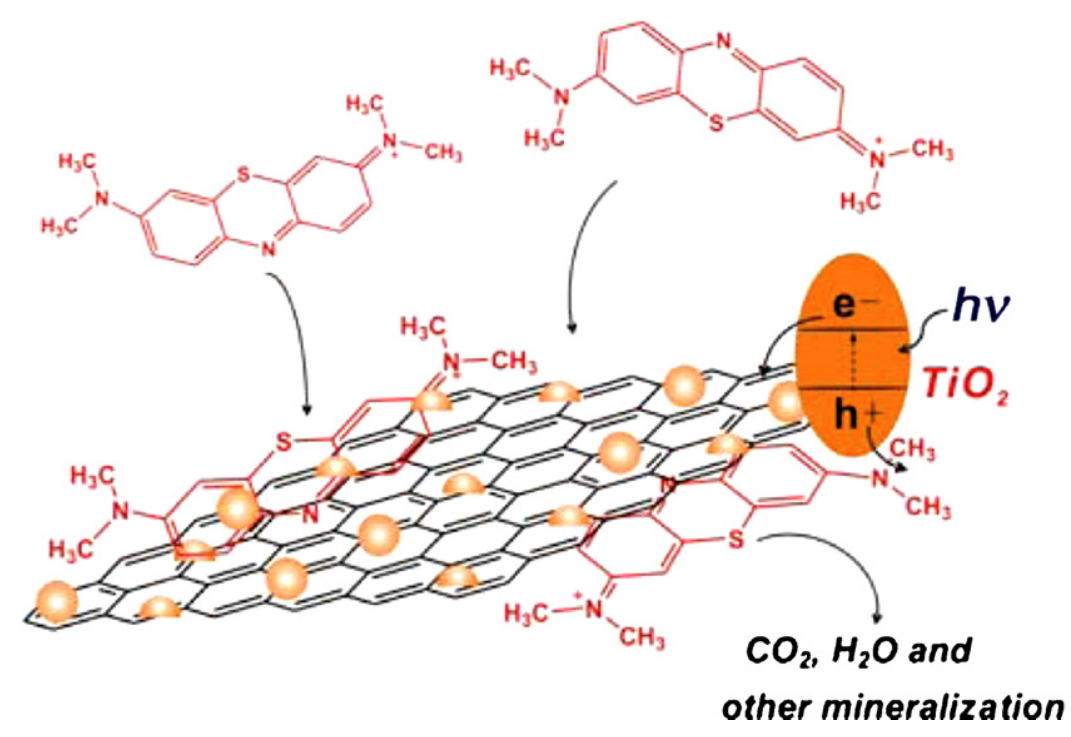

Fig. 7. Schematic structure of P25-graphene and tentative processes of the photodegradation of MB. Reproduced with permission from ref. [70]

due to its one-atom thickness [71]. Zhang et al. [72] prepared a P25-graphene composite by hydrothermal treatment of a suspension of graphene oxide and P25. In the reaction process, graphene oxide was reduced to graphene and simultaneously P25 nanoparticles were deposited on the graphene sheet. The P25-graphene composite was more active than P25 in the photodegradation of MB and its high performance was attributed to an enhanced adsorptivity and a reduction of the charge recombination. As illustrated in Fig. 7, graphene acts as an acceptor of the electrons photogenerated by irradiation of P25 and ensures fast charge transportation in view of its high conductivity. The P25-graphene composite exhibited higher efficiency than P25-CNTs with the same carbon content, due to its giant two-dimensional planar structure, which facilitated a better platform for the adsorption of the dye and charge transportation.

Graphene-like carbon/ $/ \mathrm{TiO}_{2}$ photocatalysts were recently obtained by melamine and P25 via a facile in situ graphitization approach [70]. The presence of graphene increased the photoefficiency of $\mathrm{TiO}_{2}$ and the sample with a monolayer carbon shell $(0.468 \mathrm{~nm})$ showed the highest photocatalytic activity which was about 2.5 times higher than that of the bare P25. Authors ascribed the enhanced photoactivity to the synergistic effect between graphene-like carbon and $\mathrm{TiO}_{2}$ that causes a rapid photoinduced charge separation and decreases the possibility of recombination of the photogenerated electron-hole pairs.

$\mathrm{TiO}_{2}$-based photocatalysts are usually in the form of powder so that for being used in practical applications there is the need to conform or support the $\mathrm{TiO}_{2}$. Lillo-Ródenas et al. [73] employed $\mathrm{TiO}_{2}$ Degussa P25 to prepare pure $\mathrm{TiO}_{2}$ pellets and $\mathrm{TiO}_{2} / \mathrm{C}$ pellets obtained using several carbonaceous materials. The results showed that P25 exhibited the best photoactivity for propene oxidation at room temperature but its efficiency strongly decreased when it was agglomerated in form of pellets, either with or without carbon. The activity of the $\mathrm{TiO}_{2} / \mathrm{C}$ pellets was very different depending on the carbon material. The samples containing carbon materials with high surface area and especially high electric conductivity were more active than the pure $\mathrm{TiO}_{2}$ pellets. Pelletized $\mathrm{TiO}_{2}$-based photocatalysts incorporating "white additives" such as mesoporous amorphous silica MCM-41, zeolites, $\mathrm{SiO}_{2}, \mathrm{Al}_{2} \mathrm{O}_{3}$, glass wool and quartz wool were also examined [74]. The performance of $\mathrm{TiO}_{2} / \mathrm{MCM}-41$ was higher than that of the P25-pellets and better than the best $\mathrm{TiO}_{2} /$ carbon pellet obtained in the previous work.

\section{5. $\mathrm{N}$-doped $\mathrm{TiO}_{2}$}

A significant drawback in the practical application of $\mathrm{TiO}_{2}$ is its wide band gap which requires the use of UV light during the photocatalytic reactions thus limiting the possibility of employing the solar light. In 1986, Sato [75] found that modification of $\mathrm{TiO}_{2}$ with $\mathrm{N}$ allowed to extend the adsorption light from UV to the visible area. In 2001, Asahi et al. [76] reported the synthesis of films and powders of $\mathrm{N}$-doped $\mathrm{TiO}_{2}$ that were more active than $\mathrm{TiO}_{2}$ for the photodegradation of $\mathrm{MB}$ and gaseous acetaldehyde under visible light $(\lambda<500 \mathrm{~nm})$. Afterwards, an always increasing number of papers have concerned the preparation of powders and films of $\mathrm{TiO}_{2}$ doped with nitrogen that are photoactive over the UV and much of the visible light region [77-154].

Recent papers report extensive information about properties and fundamental issues of these second generation $\mathrm{TiO}_{2}$ photocatalysts [77-80]. The mechanism of the visible light response in $\mathrm{N}$-doped $\mathrm{TiO}_{2}$ is still unknown and several hypotheses have been presented. Asahi et al. [76] proposed that the substitutional doping of nitrogen into the $\mathrm{TiO}_{2}$ lattice causes a significant shift of the absorption edge in the visible region because the $\mathrm{N} 2 \mathrm{p}$ states contribute to the band-gap narrowing by mixing with the $\mathrm{O} 2 \mathrm{p}$ states. Irie et al. [81] proposed that an isolated narrow band formed above the valence band in $\mathrm{TiO}_{2-x} \mathrm{~N}_{x}$ powders is responsible for the visible light response. In addition, the increase of the nitrogen concentration lowered the quantum yield under UV illumination, indicating that the doping sites could also work as recombination centers. Ihara et al. [82] synthesized nitrogen doped $\mathrm{TiO}_{2}$ with oxygen deficient stoichiometry and they concluded that the oxygen deficient sites formed in the grain boundaries were responsible for the visible light response, whilst the presence of nitrogen only improved the stabilization of these oxygen vacancies. Serpone [79] argued that the visible light activation of the anion doped $\mathrm{TiO}_{2}$ was the result of the formation of color centers associated with the oxygen vacancies created during the doping.

Matter of debate is the chemical nature and the location of the species that allow to extend the absorption to the visible light region: species such as $\mathrm{NO}_{x}, \mathrm{NH}_{x}$, and $\mathrm{N}^{2-}$ have been proposed, not to mention $\mathrm{NO}^{-}, \mathrm{NO}_{2}{ }^{-}$and $\mathrm{NO}_{3}{ }^{-}$species that have been confirmed experimentally [78]. On the other hand, contrary opinions exist about whether substitutional or interstitial N-doping is more effective for the visible light activity of the samples. 
$\mathrm{N}$-doped $\mathrm{TiO}_{2}$ samples have been obtained by various methods as sputtering of $\mathrm{TiO}_{2}$ in a $\mathrm{N}_{2}-\mathrm{Ar}$ atmosphere [76], high-temperature exposure of $\mathrm{TiO}_{2}$ to $\mathrm{NH}_{3}[83,137,138]$, hydrolysis of organic and inorganic titanium(IV) compounds such as titanium tetraisopropoxide [84-90], titanium butoxide [91-97], $\mathrm{Ti}\left(\mathrm{SO}_{4}\right)_{2}$ [82,98], $\mathrm{TiOSO}_{4}[99,100], \mathrm{TiCl}_{3}[100-107]$ and $\mathrm{TiCl}_{4}[85,99,108-113]$ with aqueous ammonia or ammonium salts. Sol-gel syntheses were usually followed by calcination of the resulting materials. It is worth noting that the direct comparison of the behaviour of the various samples is extremely difficult since the different methods of preparation employed lead to the production of powders, films or single crystals that are dramatically different in terms of N-doping concentration, crystalline type, and surface area [113]. Besides, the methods used to test the samples vary and no standard tests have been usually employed.

The nitrogen-doped $\mathrm{TiO}_{2}$ photocatalysts have been tested for the decomposition of aqueous solutions of dyes [134-136], organic compounds [137-147], volatile substances [148-150], pesticides [151,152], herbicides [153] and organic groundwater pollutants [137] under UV and visible light illumination.

Powders synthesized by high-temperature exposure of $\mathrm{TiO}_{2}$ to ammonia were active for the degradation of formic acid under visible light but the photoactivity under UV light was less than that of pure $\mathrm{TiO}_{2}$ [137]. Shang et al. [145] prepared $\mathrm{TiO}_{2-x} \mathrm{~N}_{x}$ powders with low $\mathrm{N}$-doping concentrations $(0.021<x<0.049)$ by annealing P25 under an $\mathrm{NH}_{3}$ flow at $550^{\circ} \mathrm{C}$. The photoactivity for the decomposition of 4-chlorophenol decreased as $x$ increased. The visible light response was ascribed to an $\mathrm{N}$-induced midgap level, formed above the valence band of $\mathrm{TiO}_{2}$.

$\mathrm{N}$-doped $\mathrm{TiO}_{2}$ powders obtained by calcination of the hydrolysis product of tetrabutyl titanate with $\mathrm{NH}_{3}$ were more efficient than P25 for phenol decomposition under visible light irradiation, whilst P25 showed higher photoactivity under sunlight irradiation [141].

D'Arienzo et al. [127] synthesized $\mathrm{N}$-doped $\mathrm{TiO}_{2}$ nanocrystals by hydrothermal treatment of a mixture of $\mathrm{TiO}_{2}$ and urea, followed by thermal annealing at different temperatures. The thermal treatment induces insertion of nitrogen into the $\mathrm{TiO}_{2}$ lattice in the form of nitride anions $\mathrm{N}^{-}$that behave as hole traps, reducing the recombination rate of the hole-electron couples. The samples showed high photoactivity for the degradation of phenol by $\mathrm{O}_{2}$, under visible illumination.

Cong et al. [95] prepared $\mathrm{N}$-doped $\mathrm{TiO}_{2}$ samples through a microemulsion-hydrothermal method by using triethylamine, urea, thiourea, or hydrazine hydrate. The photodegradation of RB under visible light irradiation $(\lambda>420 \mathrm{~nm})$ was greatly improved with respect to that of undoped $\mathrm{TiO}_{2}$ and P25. The most efficient catalyst was obtained by using triethylamine as the nitrogen source.

Nanocrystalline $\mathrm{N}$-doped $\mathrm{TiO}_{2}$ samples were synthesized by hydrolysis of $\mathrm{TiOSO}_{4}$ and $\mathrm{TiCl}_{4}$ with $\mathrm{NH}_{3}$ or $\mathrm{NH}_{4} \mathrm{Cl}$, respectively [99]. Some samples were more active than commercial Degussa P25 for the photodegradation of 4-nitrophenol under UV illumination. The visible light activity was attributed to mixing of $\mathrm{N} 2 \mathrm{p}$ and $\mathrm{O} 2 \mathrm{p}$ states for the samples obtained from $\mathrm{TiCl}_{4}$ and to the presence of a localised midgap band for those derived from $\mathrm{TiOSO}_{4}$.

$\mathrm{N}$-doped anatase and rutile were prepared by calcination of acidified $\mathrm{TiCl}_{3}$ in presence of urea and oxalic acid [101]. Whilst urea was used as a source of nitrogen, oxalic acid was found to be crucial in controlling the phase, porosity as well as the $\mathrm{N}$ content. Both the catalysts showed photocatalytic activity for the degradation of MB in sunlight. N-doped anatase obtained via solvothermal and ethylenediamine reflux treatment, followed by the sequential calcination in air and $\mathrm{NH}_{3} / \mathrm{N}_{2}$ atmosphere showed much higher photocatalytic activity than N-doped Degussa P25 for the degradation of phenol under both ultraviolet and visible light irradiation [142].
$\mathrm{N}$-doped $\mathrm{TiO}_{2}$ nanotubes were fabricated by hydrothermally treating $\mathrm{N}$-doped $\mathrm{TiO}_{2}$ nanorods in a $8 \mathrm{M} \mathrm{NaOH}$ solution at $110^{\circ} \mathrm{C}$ for $20 \mathrm{~h}$ [115]. The $\mathrm{N}$-doped $\mathrm{TiO}_{2}$ nanorods were synthesized by a solvothermal process with precursor solution containing titanium sulfate, urea, and dichloroethane. The nanotubes showed larger specific surface area and greater efficiency for the degradation of MO than the nanorods.

$\mathrm{N}$-doped $\mathrm{TiO}_{2}$ nanotube arrays were prepared by electrochemical anode oxidation of Ti foil followed by treatment with $\mathrm{N}_{2}$-plasma and subsequent annealing under Ar atmosphere [117] or by treating amorphous $\mathrm{TiO}_{2}$ nanotube arrays with hydrazine hydrate [116]. The doped samples exhibited excellent photocatalytic activity under visible light, with respect to the non-doped $\mathrm{TiO}_{2}$ nanotube arrays.

Microarrays of N-doped flower-like $\mathrm{TiO}_{2}$ composed of welldefined multilayer nanoflakes were synthesized by electrochemical anodization of $\mathrm{Ti}$ in $\mathrm{NH}_{4} \mathrm{~F}$ aqueous solution [133]. The effects of anodizing time, applied voltage and $\mathrm{NH}_{4} \mathrm{~F}$ concentration on the flower-like morphology were systematically examined. Under both UV and visible light irradiation, the $\mathrm{N}$-doped flower-like $\mathrm{TiO}_{2}$ microarrays showed remarkable photoactivity for the degradation of MO.

$\mathrm{N}$-doped $\mathrm{TiO}_{2} \mathrm{~S}$ display red-shifted absorption edges into the visible spectral region but their photoactivity under visible light is often significantly lower than under UV. Most specimens are less active than $\mathrm{TiO}_{2}$ under UV irradiation and their photostability or instability should also be addressed. Finally, only few papers have been concerned with the reusability of the photocatalysts $[95,144]$ and the incident light dependence of the photocatalytic process [146].

\section{Binary compounds}

\subsection{Binary oxides}

\subsection{1. $\mathrm{ZnO}$}

In addition to $\mathrm{TiO}_{2}$, other binary metal oxides have been studied to determine their photocatalytic oxidation properties. $\mathrm{ZnO}$ has been often considered a valid alternative to $\mathrm{TiO}_{2}$ because of its good optoelectronic, catalytic and photochemical properties along with its low cost. $\mathrm{ZnO}$ has a band gap of $3.0 \mathrm{eV}$ that is lower than that of anatase. Due to the position of the valence band of $\mathrm{ZnO}$, the photogenerated holes have strong enough oxidizing power to decompose most organic compounds [155]. ZnO has been tested to decompose aqueous solutions of several dyes [156-177], and many other environmental pollutants [178-189]. In many cases, $\mathrm{ZnO}$ has been reported to be more efficient than $\mathrm{TiO}_{2}$ [171-182] but the occurrence of photocorrosion [190] and the susceptibility of $\mathrm{ZnO}$ to facile dissolution at estreme $\mathrm{pH}$ values, have significantly limited its application in photocatalysis. Kislov et al. [191] showed that the photoactivity and the photostability of single crystal $\mathrm{ZnO}$ samples strongly depended on the crystallographic orientation.

Several studies have shown that $\mathrm{ZnO}$ was quite active under visible light illumination for the photodegradation of some organic compounds in aqueous solution [161-164,184]. Methyl green was successfully decolorized and degraded by $\mathrm{ZnO}$ under visible light irradiation at low watt irradiation [162] and the addition of an oxidant $\left(\mathrm{Na}_{2} \mathrm{~S}_{2} \mathrm{O}_{8}\right.$ or $\left.\mathrm{H}_{2} \mathrm{O}_{2}\right)$ enhanced the degradation rate of the pollutant. Lu et al. [164] used $\mathrm{ZnO}$ to degrade Basic Blue 11 under visible light irradiation and studied the effects of influential factors like initial dye concentration, catalyst dosage, and initial $\mathrm{pH}$. Pare et al. [163] found that the addition of an optimal amount of hydrogen peroxide and potassium persulphate increased the photocatalytic degradation of acridine orange whilst the efficiency was considerably decreased by addition of inert salts like $\mathrm{NaCl}$ and $\mathrm{Na}_{2} \mathrm{CO}_{3}$. 
Sakthivel et al. [174] studied the solar photodegradation of Acid Brown 14 as the model pollutant to evaluate the performance of both $\mathrm{ZnO}$ and $\mathrm{TiO}_{2}$. The photodegradation rate was determined for each experiment and the highest values were observed for $\mathrm{ZnO}$, suggesting that it absorbs large fraction of the solar spectrum and absorbs more light quanta than $\mathrm{TiO}_{2}$. Dindar and Içli [192] found that $\mathrm{TiO}_{2}$ was more efficient for the photodegradation of phenol under a sodium lamp and direct sunlight, but $\mathrm{ZnO}$ was as reactive as $\mathrm{TiO}_{2}$ under concentrated sunlight. This behaviour is quite logic and not unusual, as claimed by the authors, since different catalysts tend to perform similar under concentrated sunlight, as the rate-limiting factor is not the generation of photoactive species anymore, but rather the mass transfer limitations of the contaminant to the catalyst surface. Pardeshi and Patil [193] confirmed that phenol was degraded more effectively under solar light in comparison to artificial visible light irradiation. Besides, $\mathrm{ZnO}$ was reused for five times as it underwent photocorrosion only to a negligible extent. Therefore, $\mathrm{ZnO}$ is more suitable than $\mathrm{TiO}_{2}$ for photocatalytic degradation when sunlight is present.

Sobana and Swaminathan [166] increased the photocatalytic activity of $\mathrm{ZnO}$ for the solar assisted photocatalytic degradation of Direct Blue 53 by mixing $\mathrm{ZnO}$ and activated carbon at different proportions in an aqueous suspension. The synergistic effect increased the efficiency of the photocatalyst by a factor of 4.21 .

Comparelli et al. [158] reported that the presence of passivating molecules on the $\mathrm{ZnO}$ surface preserved the oxide from photocorrosion and $\mathrm{pH}$-dependent dissolution. Surface hybridization of $\mathrm{ZnO}$ with graphite-like carbon layers suppressed the photocorrosion of the $\mathrm{ZnO}$ nanoparticles and enhanced the photocatalytic activity of ZnO [194]. Photocorrosion inhibition and photoactivity enhancement was also obtained via hybridization of $\mathrm{ZnO}$ with monolayer polyaniline [195].

$\mathrm{ZnO}$ has been rarely tested as photocatalyst in gas-solid regimes although it was found that it was more active than commercial and home-prepared $\mathrm{TiO}_{2}$ for the photodecomposition of ethanoic acid [196]. High surface area hexagonal $\mathrm{ZnO}$ nanoparticles demonstrated an enhanced photocatalytic degradation of a tough pollutant such as gaseous $\left(\mathrm{CH}_{3}\right)_{2} \mathrm{~S}_{2}$ compared with a commercial ZnO powder [197].

El-Kemary et al. [198] synthesized ZnO nanoparticles by heating of a mixture of zinc acetate dehydrate and triethylamine in ethanol for $60 \mathrm{~min}$ at $50-60^{\circ} \mathrm{C}$. The photocatalytic activity for the degradation of ciprofloxacin was investigated under UV light irradiation. The degradation process was effective at $\mathrm{pH} 7$ and 10, but it was rather slow at $\mathrm{pH} 4$. ZnO nanoparticles [182] prepared from zinc acetate by triethylamine template assisted sol-gel precipitation and further hydrothermal treatment exhibited high conversion values for phenol photooxidation. Further calcination treatment led to conversions higher than that obtained with Degussa P25.

$\mathrm{ZnO}$ nanoparticles, prepared using zinc acetate and $\mathrm{NaOH}$ as precipitant, were tested for the photodegradation of Biebrich scarlet in aqueous phase [167]. The comparison with other commercial semiconductors $\left(\mathrm{TiO}_{2}, \mathrm{ZnO}, \mathrm{CdS}\right.$ and $\left.\mathrm{ZnS}\right)$ indicated that the nanosized $\mathrm{ZnO}$ was the best photocatalyst for the decolorization of the dye. The dissolution of $\mathrm{ZnO}$ was found to be negligible at alkaline $\mathrm{pH}$ ( $\mathrm{pH} 10)$ and the loss of activity after three cycles was very low.

Nanostructured ZnO obtained by thermal decomposition of zinc oxalate without using any additives or solvents was more efficient than commercial $\mathrm{ZnO}$ for the mineralization of Reactive Red 120 under solar irradiation [199]. Kitture et al. [200] prepared polydispersed $\mathrm{ZnO}$ nanoparticles with two different particle size distributions ( 120 and $30 \mathrm{~nm}$ ) that were tested for the degradation of MB and MO under sunlight irradiation. The larger sized nanoparticles exhibited inertness towards photocorrosion and were more efficient than their nanosized counterparts and $\mathrm{P} 25$. Shape- and size-selective $\mathrm{ZnO}$ nanorods with high alignment and uniformity were grown by using a microwave-assisted chemical bath deposition method on indium tin oxide substrates [201]. The nanorods were efficient for the degradation of MB under UV irradiation and exhibited a size-dependent activity.

Hierarchically assembled porous $\mathrm{ZnO}$ spherical nanoparticles showed a photoactivity for the degradation of phenol superior to that of $\mathrm{TiO}_{2}$ nanoparticles [202]. Li et al. [203] found that the photoreactivity of $\mathrm{ZnO}$ hollow spheres for the degradation of reactive brilliant red X-3B increased by a factor 4.66 compared with that of ZnO nanoparticles.

Mohajerani et al. [204] synthesized ZnO nanostructures in the shape of particle, rods, flower-like and microsphere that were tested for the decolorization of $\mathrm{CI}$ acid red 27 under direct sunlight irradiation. The photoactivity of the nanorods was slightly superior to that of the nanoparticles. The flower-like and microsphere 3D nanostructures showed much lower photoactivity.

$\mathrm{ZnO}$ nanoflowers were more efficient than $\mathrm{ZnO}$ nanorods for the degradation of 4-chlorophenol under UV light irradiation [205]. The superior performance of the nanoflowers resulted from the larger content of oxygen vacancy on the surface of the 1D nanomaterials. Likewise, 3D flower-like $\mathrm{ZnO}$ hierarchical microstructures prepared by a low-temperature aqueous solution route were more active than other nanostructured $\mathrm{ZnO}$ powders (nanoparticles, nanosheets, and nanorods) [206].

\subsection{2. $\mathrm{Cu}_{2} \mathrm{O}$}

$\mathrm{Cu}_{2} \mathrm{O}$ is a p-type semiconductor with a direct band gap of ca. 2.0-2.2 eV that has been studied for application in solar energy conversion [207]. The photocatalytic properties of $\mathrm{Cu}_{2} \mathrm{O}$ are strongly dependent on the shape of the crystals that determines the number of atoms located at the edges, corners, or surfaces [208]. $\mathrm{Cu}_{2} \mathrm{O}$ octahedra show better photocatalytic activity than cubes, because the $\left\{\begin{array}{lll}1 & 1 & 1\end{array}\right\}$ facets are more active than $\left\{\begin{array}{lll}0 & 0\end{array}\right\}$ facets due to the dangling bonds of $\left\{\begin{array}{lll}1 & 1 & 1\end{array}\right\}$ surfaces, whilst $\left\{\begin{array}{lll}1 & 0 & 0\end{array}\right\}$ facets have saturated chemical bonds and no dangling bands exist [209,210]. Zhang et al. [208] synthesized mixed 26-facet and 18-facet polyhedra of $\mathrm{Cu}_{2} \mathrm{O}$ microcrystals by a hydrothermal process with use of stearic acid as a structure-directing agent. Both 26 -facet and 18 -facet $\mathrm{Cu}_{2} \mathrm{O}$ polyhedra displayed higher activity for the photocatalytic decomposition of $\mathrm{MO}$ than $\mathrm{Cu}_{2} \mathrm{O}$ octahedra and cubes.

$\mathrm{Cu}_{2} \mathrm{O}$ microcrystals with well-formed facets were synthesized by a simple hydrothermal method and tested for the photodegradation of MO under visible light irradiation [211]. The $\mathrm{Cu}_{2} \mathrm{O}$ microcrystals exhibited a considerable photoactivity in the first runs, which was ascribed to the charge separation among crystal faces. During the photocatalytic bleaching of the dye, the $\mathrm{Cu}_{2} \mathrm{O}$ $\left\{\begin{array}{ll}0 & 0\end{array}\right\}$ and $\left\{\begin{array}{lll}1 & 10\end{array}\right\}$ facets gradually disappeared and transformed into nanosheets that presented stable photoactivity due to the mainly exposed $\left\{\begin{array}{lll}1 & 1 & 1\end{array}\right\}$ facets.

Huang et al. [212] prepared $\mathrm{Cu}_{2} \mathrm{O}$ nanoparticles and microparticles that were tested for the photodegradation of methyl orange. The nanoparticles were stable in ambient atmosphere, whilst the microparticles existed stably as a $\mathrm{Cu}_{2} \mathrm{O} / \mathrm{CuO}$ core/shell structure. The $\mathrm{Cu}_{2} \mathrm{O}$ microparticles, whose photocorrosion rate was very slow, had a higher photocatalytic activity than the nanoparticles that were easily deactivated during the photocatalytic reaction, $\mathrm{Cu}_{2} \mathrm{O} / \mathrm{Cu}$ nanocomposites synthesized using a two-step hydrothermal method [213] were used as photocatalysts for the degradation of Procion Red MX-5B, methylene blue and methyl orange. Different phase compositions were obtained by adjusting the reaction time. The $\mathrm{Cu}_{2} \mathrm{O} / \mathrm{Cu}$ nanocomposites exhibited a much higher photocatalytic activity than pure $\mathrm{Cu}_{2} \mathrm{O}$, due to the heterojunction effect. $\mathrm{Cu}_{2} \mathrm{O}$ acted as a sink for the electrons, promoting the interfacial charge-transfer kinetics between metal and semiconductor and improving the separation of the photogenerated electron-hole 
pairs. A high photoactivity was observed even at the end of four photocatalytic reaction cycles.

$\mathrm{Cu}_{2} \mathrm{O}$ flower-like architecture assembled by numerous petals of 2D nanosheet, composed of single-crystalline particles of several nanometers, was synthesized by a polyol process in the presence of acetamide [214]. The flower-like architecture possessed good photocatalytic activity for the degradation of Brilliant Red X-3B under simulated solar light and was more active and more stable than $\mathrm{Cu}_{2} \mathrm{O}$ nanocubes.

\subsection{3. $\mathrm{WO}_{3}$}

$\mathrm{WO}_{3}$ is a visible light-responsive photocatalyst that absorbs light up to ca. $480 \mathrm{~nm}$. Anyway, $\mathrm{WO}_{3}$ has generally showed a low photoactivity to degrade pollutants that has been attributed to the high recombination rate of the photoproduced electron/hole pairs and/or to the low rate of electron transfer to $\mathrm{O}_{2}$ [215]. A comparison among $\mathrm{WO}_{3}, \mathrm{TiO}_{2}, \mathrm{NiO}$, and $\mathrm{Fe}_{2} \mathrm{O}_{3}$ for phenol degradation in water using a $355 \mathrm{~nm}$ pulsed laser irradiation showed that the maximum degradation was obtained using $\mathrm{WO}_{3}$ [216]. The high photonic efficiency and higher degradation percentage of phenol in the presence of $\mathrm{WO}_{3}$ was ascribed to its band-gap suitability and higher activity under laser irradiation.

Sayama et al. [217] prepared a $\mathrm{WO}_{3}$ catalyst from amorphous peroxo-tungstic acid that was more active than $\mathrm{WO}_{3}$ samples obtained with various methods. The high activity for the degradation of various organic compounds was explained by the high surface area, good crystallinity, and efficient light absorption in the visible light region.

Nanoporous $\mathrm{WO}_{3}$ films anodically grown on tungsten foil substrates were photoactive for the oxidation of methylene blue and the reductive conversion of $\mathrm{Cr}(\mathrm{VI})$ under visible light illumination [218]. $\mathrm{WO}_{3}$ films deposited on a Pt substrate showed a higher photoelectrocatalytic activity for the photodegradation of naphthol blue black than $\mathrm{TiO}_{2}$ nanoparticulate film electrodes [219].

Gondal et al. [220] synthesized nano- $\mathrm{WO}_{3}$ powder by a sol-gel process using $\mathrm{H}_{2} \mathrm{WO}_{4}$ as precursor and methanol as solvent. The catalyst was tested in the presence of a $355 \mathrm{~nm}$ laser irradiation for the bacterial disinfection of water infected with Escherichia coli microorganism. The bacterial population decay with nano- $\mathrm{WO}_{3}$ was significantly higher than that obtained with a commercial micron sized $\mathrm{WO}_{3}$. The enhanced photoactivity was attributed to the reduced grain size and widened band-gap energy of the synthesized nano- $\mathrm{WO}_{3}$. A fast laser induced photocatalytic degradation of the dye Safranine-O was also obtained by using $\mathrm{WO}_{3}$ nanostructures synthesized by precipitation from aqueous solution of ammonium tungstate pentahydrate and nitric acid [221].

High density $\mathrm{WO}_{3}$ nanorods were prepared on $\mathrm{W}$ substrates by thermal evaporation of $\mathrm{WO}_{3}$ powder at high temperature without using any catalyst [222]. The nanorods showed a good photocatalytic activity for the photodegradation of MB that was attributed to their larger surface areas, higher light absorption capability and efficient charge separation of the photogenerated electron-hole pairs.

3D hierarchical $\mathrm{WO}_{3}$ hollow shells, including hollow dendrites, spheres and dumbbells self organized from tiny $\mathrm{WO}_{3}$ nanoplatelets, were synthesized by calcining acid-treated $\mathrm{PbWO}_{4}$ or $\mathrm{SrWO}_{4}$ precursors with similar morphologies [223]. Compared to commercial $\mathrm{WO}_{3}$ particles, the hollow structures showed enhanced photoactivity for the degradation of RhB and gaseous 2-propanol under visible light irradiation.

\subsection{4. $\mathrm{V}_{2} \mathrm{O}_{5}$}

Single-crystalline $\mathrm{V}_{2} \mathrm{O}_{5}$ nanowires were grown on sapphire and ITO coated glass substrates by thermal decomposition of a precursor film spin coated from an organic vanadium solution [224]. The nanowires, approximately $5 \mu \mathrm{m}$ long with an average diameter of
$100 \mathrm{~nm}$, were more efficient than bulk $\mathrm{V}_{2} \mathrm{O}_{5}$ for the degradation of toluidine blue $\mathrm{O}$ dye under ultraviolet irradiation. The thickness of the precursor film played a vital role to form uniform seed layers, essential for the growth of high quality nanowires.

Uniform $\mathrm{V}_{2} \mathrm{O}_{5} \cdot 0.9 \mathrm{H}_{2} \mathrm{O}$ nanobelts with high aspect ratios and ultra-long $\mathrm{V}_{2} \mathrm{O}_{5} \cdot 0.6 \mathrm{H}_{2} \mathrm{O}$ nanorolls with scroll-like structures were synthesized on a large scale by a simple hydrothermal growth method using $\mathrm{NH}_{4} \mathrm{VO}_{3}$ as the raw material in the presence of $\mathrm{H}_{2} \mathrm{SO}_{4}$ and $\mathrm{CH}_{3} \mathrm{COOH}$, respectively [225]. The nanobelts were tens of micrometres long, 100-150 nm wide and 20-30 nm thick. The nanorolls exhibited better photocatalytic activity than the nanobelts for the degradation of RhB. This result was ascribed to the larger surface area and lower water content of the nanorolls.

\subsubsection{Iron oxides}

Iron(III) (hydr)oxides absorb light up to $600 \mathrm{~nm}$. Most of them have semiconductor properties and have been studied as photocatalysts even though a very efficient electron/hole recombination generally takes place [226]. Mazellier and Bolte [227] synthesized goethite $(\alpha-\mathrm{FeOOH})$ that was tested for the photodegradation of 2,6-dimethylphenol. Goethite has a band gap of $2.2 \mathrm{eV}$ that corresponds to a wavelength of ca. $570 \mathrm{~nm}$. Under monochromatic illumination of 365, 436 and $546 \mathrm{~nm}$, the pollutant was efficiently degraded without any release of iron(II) or iron(III).

Bandara et al. [228] studied the photocatalytic degradation of various chlorophenols on aqueous suspensions of $\alpha-\mathrm{Fe}_{2} \mathrm{O}_{3}$ and $\alpha$-FeOOH illuminated by a lamp with a wavelength distribution simulating the solar radiation. $\alpha-\mathrm{Fe}_{2} \mathrm{O}_{3}$ was active for the degradation of the chlorophenols whilst $\alpha-\mathrm{FeOOH}$ was practically inactive. Anatase and rutile were more efficient than $\alpha-\mathrm{Fe}_{2} \mathrm{O}_{3}$.

Four iron oxides were investigated by Wang et al. [229] for the photodegradation of pyrene under UV irradiation. The rate of photodegradation followed the order: $\alpha$-FeOOH $>\alpha-\mathrm{Fe}_{2} \mathrm{O}_{3}>\gamma$ $\mathrm{Fe}_{2} \mathrm{O}_{3}>\gamma-\mathrm{FeOOH}$. The higher photocatalytic activity of $\alpha$-FeOOH was attributed to its basic morphology-acicular crystal structure. The iron oxides were also successfully used for the degradation of nine different types of polycyclic aromatic hydrocarbons in contaminated soils.

Anodic-biased $\alpha-\mathrm{Fe}_{2} \mathrm{O}_{3}$ films formed by metal organic deposition showed a high photocatalytic activity for the decomposition of 2-naphtol under visible light irradiation [230]. Anyway, $\alpha-\mathrm{Fe}_{2} \mathrm{O}_{3}$ was transformed to inactive hydroxide as the reaction proceeded whilst its activity was almost maintained in acetonitrile.

Hollow nanostructures are very interesting materials owing to their high specific surface area, low density and high permeation. Li et al. [231] synthesized $\mathrm{Fe}_{2} \mathrm{O}_{3}$ hollow spheres with mesopores on the surface by an efficient hydrothermal process, without templates in the system. The performance of the $\mathrm{Fe}_{2} \mathrm{O}_{3}$ hollow spheres for the photodegradation of salicylic acid was higher than that of ringlike $\alpha-\mathrm{Fe}_{2} \mathrm{O}_{3}$ nanoparticles. Hollow microspheres constructed with $\alpha-\mathrm{Fe}_{2} \mathrm{O}_{3}$ nanorods were effective photocatalysts for the direct degradation of methyl orange [232].

Submicrometer-sized hollow hematite particles were prepared through a surfactant-assisted solvothermal process [233]. Spheres, ellipsoids or peanuts were obtained by varying the amount of $\mathrm{FeCl}_{3} \cdot \mathrm{H}_{2} \mathrm{O}$ and cetyltrimethylammonium bromide, and the acidity of the solution. The $\mathrm{Fe}_{2} \mathrm{O}_{3}$ hollow particles were effective photocatalysts for the degradation of diethyl phthalate under UV irradiation.

\subsection{6. $\mathrm{Bi}_{2} \mathrm{O}_{3}$}

$\mathrm{Bi}_{2} \mathrm{O}_{3}$, with a direct band gap of $2.8 \mathrm{eV}$, can be excited by visible light. Bessekhouad et al. [234] found that $\mathrm{Bi}_{2} \mathrm{O}_{3}$ was able to degrade Orange II but the efficiency of the photocatalytic reaction was rather low. Monoclinic $\alpha-\mathrm{Bi}_{2} \mathrm{O}_{3}$, synthesized via calcination of hydrothermally prepared $(\mathrm{BiO})_{2} \mathrm{CO}_{3}$, was much more active than commercial $\mathrm{Bi}_{2} \mathrm{O}_{3}$ for the degradation of $\mathrm{NO}$ and formaldehyde at 
typical indoor air concentration [235]. No deactivation of the synthetic $\alpha-\mathrm{Bi}_{2} \mathrm{O}_{3}$ was observed during the prolonged photocatalytic reaction.

Eberl and Kisch [236] prepared $\alpha$-bismuth oxides of specific surface areas of $1-3 \mathrm{~m}^{2} / \mathrm{g}$ by three different methods. The samples were tested for the photodegradation of 4-chlorophenol under visible light. The photoactivity of the powders prepared by annealing $\mathrm{BiONO}_{3}, \mathrm{Bi}\left(\mathrm{NO}_{3}\right)_{3} \cdot 5 \mathrm{H}_{2} \mathrm{O},(\mathrm{BiO})_{2} \mathrm{CO}_{3}$, and $\mathrm{BiOCl}$ at $500^{\circ} \mathrm{C}$ without any pretreatment was poor to moderate. A very active powder was obtained if the salt $(\mathrm{BiO})_{2} \mathrm{CO}_{3}$ was washed with water and subsequently calcined at $450{ }^{\circ} \mathrm{C}$. High activity was exhibited by the powders prepared by annealing at $500^{\circ} \mathrm{C}$ the $\mathrm{Bi}(\mathrm{OH})_{3}$ precipitates resulting by the addition of $\mathrm{NaOH}$ to the solutions obtained by dissolution of $\mathrm{BiONO}_{3}$ and $\mathrm{Bi}\left(\mathrm{NO}_{3}\right)_{3} \cdot 5 \mathrm{H}_{2} \mathrm{O}$ in $\mathrm{HNO}_{3}$.

Nanocrystallite $\mathrm{Bi}_{2} \mathrm{O}_{3}$ were synthesized by a simple sonochemical route [237]. The presence of the surfactant polyvinylpyrrolidone had strong effects on the grain sizes and morphologies of the samples. The photoactivity of the nanocrystallite $\mathrm{Bi}_{2} \mathrm{O}_{3}$ was greatly superior to that of microsized $\mathrm{Bi}_{2} \mathrm{O}_{3}$ and P25. $\alpha-\mathrm{Bi}_{2} \mathrm{O}_{3}$ nanoparticles produced by laser ablation exhibited a good photocatalytic activity for the photodegradation of indigo carmine under $365 \mathrm{~nm}$ light emitting diode irradiation [238].

The use of nanoparticles is often limited because the suspended particulate catalysts are easily lost in the process of photocatalytic reaction and separation. Differently, the nanofibers can be more easily recovered by sedimentation. Wang et al. [239] prepared polymer/inorganic composite fibers from solutions containing polyacrylonitrile and $\mathrm{Bi}\left(\mathrm{NO}_{3}\right)_{3}$. The $\mathrm{Bi}_{2} \mathrm{O}_{3}$ nanofibers were obtained by successive calcination at $500{ }^{\circ} \mathrm{C}$. The photocatalytic test showed that the $\mathrm{Bi}_{2} \mathrm{O}_{3}$ nanofibers were active for the degradation of RhB under ultraviolet light and had a good sedimentation ability.

Uniform hierarchical nanostructures of $\mathrm{Bi}_{2} \mathrm{O}_{3}$ were synthesized by a template-free aqueous method [240]. The 3D hierarchitectures were composed of 2D nanosheets, which intercrossed with each other. Pore-size distribution analysis revealed that both mesopores and macropores existed in the product. The photodegradation rates of $\mathrm{RhB}$ under visible light exhibited by the $\mathrm{Bi}_{2} \mathrm{O}_{3}$ hierarchitectures were much higher (6-10 times) than that of the corresponding commercial $\mathrm{Bi}_{2} \mathrm{O}_{3}$.

\subsection{7. $\mathrm{NiO}, \mathrm{Nb}_{2} \mathrm{O}_{5}, \mathrm{Ta}_{2} \mathrm{O}_{5}$}

Cubic NiO nanoparticles with spherical shape, high purity, welldispersed and narrow size distribution ranging from 6 to $10 \mathrm{~nm}$ were synthesized by a sol-gel method [241]. The nano NiO samples demonstrated better photocatalytic efficiency than $\mathrm{TiO}_{2}$ for the degradation of phenol at $266 \mathrm{~nm}$. The degradation rate was increased significantly by increasing the initial $\mathrm{pH}$ of the solution.

Song and Gao [242] prepared NiO hierarchical architectures with controllable morphologies and sizes by a solvothermal method combined with a calcination process. The NiO hollow hierarchical structures showed significantly higher activities to decompose acid red 1 under UV irradiation than NiO hollow tubes, $\mathrm{NiO}$ solid spheres and $\mathrm{NiO}$ rods. An advantage of these catalysts was the possibility to be easily recycled under an external magnetic field.

$\mathrm{Nb}_{2} \mathrm{O}_{5}$, with a band-gap energy $(3.4 \mathrm{eV})$ similar to that of $\mathrm{TiO}_{2}$, would be expected to have a similar photocatalytic activity. Anyway, the application of $\mathrm{Nb}_{2} \mathrm{O}_{5}$ for the photodegradation of contaminants is rarely reported in the literature.

Kominami et al. [243] prepared $\mathrm{Nb}_{2} \mathrm{O}_{5}$ powders by solvothermal reaction of niobium $(\mathrm{V})$ pentabutoxide in toluene at $300^{\circ} \mathrm{C}$ in the absence or presence of water. The phase, amorphous or crystalline, was controlled by the amount of water in the feed and through post calcination. The amorphous powders, due to their large surface area, were more efficient than the crystalline samples for the oxidative decomposition of acetic acid.
Prado et al. [244] found that $\mathrm{TiO}_{2}$ and $\mathrm{ZnO}$ were more efficient than $\mathrm{Nb}_{2} \mathrm{O}_{5}$ for the degradation of the indigo carmine dye but the recovery of $\mathrm{TiO}_{2}$ and $\mathrm{ZnO}$ was difficult so that their re-use was not effective. Whilst $\mathrm{TiO}_{2}$ and $\mathrm{ZnO}$ had an abrupt loss of their catalytic activity, $\mathrm{Nb}_{2} \mathrm{O}_{5}$ maintained $85 \%$ of the dye degradation after 10 cycles of reaction.

$\mathrm{Ta}_{2} \mathrm{O}_{5}$, with a band gap of $3.0 \mathrm{eV}$, has been seldom used as photocatalyst. A good photocatalytic performance for the degradation of gaseous formaldehyde under UV light radiation was obtained with nanosized $\mathrm{Ta}_{2} \mathrm{O}_{5}$ powders synthesized by using $\mathrm{TaCl}_{5}$ as precursor [245].

\subsection{8. $\mathrm{ZrO}_{2}, \mathrm{CeO}_{2}, \mathrm{Ga}_{2} \mathrm{O}_{3}$}

The photocatalytic performances of $\mathrm{ZrO}_{2}$ have been successfully tested for the oxidation of various organic compounds such as 2-propanol [246] and aniline [247], the photodegradation of 4-chlorophenol [248] and 4-nitrophenol [249] and for the transformation of environmentally important substrates, such as nitrite, EDTA and $\mathrm{Cr}(\mathrm{VI})$ [250]. The efficiency of the $\mathrm{ZrO}_{2}$ powders was significantly lower than that of $\mathrm{TiO}_{2} \cdot \mathrm{ZrO}_{2}$ nanoparticles prepared through a high current electrical arc discharge of $\mathrm{Zr}$ electrodes in water showed a photocatalytic activity for the degradation of $\mathrm{RhB}$ near two times higher than that of P25 [251].

$\mathrm{CeO}_{2}$ is an n-type semiconductor with a band gap of $2.94 \mathrm{eV}$, that can be photoactivated by irradiation with light in the near UV-vis range. $\mathrm{CeO}_{2}$ thin films were found to be inactive for the photocatalytic degradation of methylene blue [156], but commercial $\mathrm{CeO}_{2}$ powders were able to photodegrade toluene in gas phase [252]. Although the rate of photooxidation of toluene was an order of magnitude lower than that observed in presence of $\mathrm{TiO}_{2}$, toluene was completely mineralized without significant catalyst deactivation. This behaviour was confirmed also employing $\mathrm{CeO}_{2}$ nanoparticles prepared from reverse microemulsions [253] and was attributed to a different mechanism of photooxidation on $\mathrm{CeO}_{2}$.

Anpo et al. prepared $\mathrm{CeO}_{2}$ powder from $\mathrm{Ce}\left(\mathrm{NO}_{3}\right)_{3} \cdot 6 \mathrm{H}_{2} \mathrm{O}$ and $\mathrm{NH}_{4} \mathrm{OH}$ that was tested for the degradation of the azo dye acid orange 7 under visible light irradiation [254]. The performance of $\mathrm{CeO}_{2}$ was better than that of Degussa P25 due to the superior adsorption capacity of $\mathrm{CeO}_{2}$.

Ordered nanocrystalline mesoporous $\mathrm{CeO}_{2}$ was synthesized by using MCM-48 molecular sieves as hard template [255]. The obtained sample exhibited high similarity to the cubic Ia3d symmetry of the silica template. The activity of the mesoporous catalyst tested for the decolorization of acid orange 7 under visible light illumination was substantially higher than those of a nonporous $\mathrm{CeO}_{2}$ and Degussa P25. Nanocrystalline $\mathrm{CeO}_{2}$ obtained from $\mathrm{Ce}_{2}\left(\mathrm{CO}_{3}\right)_{3} \cdot n \mathrm{H}_{2} \mathrm{O}$ by using $\left(\mathrm{NH}_{4}\right) \mathrm{HCO}_{3}$ as precipitant degraded about $97 \%$ of the dye Acidic Black $10 \mathrm{~B}$ after $2 \mathrm{~h}$ of sunshine illumination [256].

$\mathrm{Ga}_{2} \mathrm{O}_{3}$ is a wide band-gap semiconductor $(4.8 \mathrm{eV})$ that can be photoexcited only by UV irradiation $(\lambda<260 \mathrm{~nm})$. Anyway, the position of its conduction band is much higher than that of $\mathrm{TiO}_{2}$ so that $\mathrm{Ga}_{2} \mathrm{O}_{3}$ has been reported to act as a photocatalyst for some reductive reactions.

Three polymorphs of $\mathrm{Ga}_{2} \mathrm{O}_{3}$ were evaluated for the decomposition of benzene, toluene and ethylbenzene in dry air stream under UV illumination [257]. The $\mathrm{Ga}_{2} \mathrm{O}_{3}$ catalysts showed much higher photocatalytic activity than commercial $\mathrm{TiO}_{2}$. The efficiency of the polymorphs followed the sequence $\beta-\mathrm{Ga}_{2} \mathrm{O}_{3}>\gamma-\mathrm{Ga}_{2} \mathrm{O}_{3}>\alpha-\mathrm{Ga}_{2} \mathrm{O}_{3}$. The superior performance of $\beta-\mathrm{Ga}_{2} \mathrm{O}_{3}$ was attributed to its good crystallinity and distorted geometric structure.

Zhao and Zhang [258] prepared $\beta-\mathrm{Ga}_{2} \mathrm{O}_{3}$ powder using $\mathrm{Ga}\left(\mathrm{NO}_{3}\right)_{3}$ as precursor. Perfluorooctanoic acid, that is a new environmental persistent organic pollutant, was significantly decomposed by $\beta-\mathrm{Ga}_{2} \mathrm{O}_{3}$, whilst little decomposition was observed in the presence of P25. 


\subsection{Binary sulfides}

Some transition metal sulfides have been considered as photocatalysts for the removal of organic pollutants because they have narrow band gap and proper band potentials, which match well with the visible light photon energy and the thermodynamic conditions for the degradation of many compounds, respectively.

$\mathrm{CdS}$, with a direct band-gap energy of $2.42 \mathrm{eV}$, has been extensively studied for the photocatalytic production of hydrogen from water with visible light and for photovoltaic devices. However, CdS is not suitable for the photocatalytic removal of organic pollutants because it is unstable under irradiation and suffers photocorrosion [259] that not only destroys the photocatalyst but, more importantly, releases toxic cadmium ions in solution.

Recently, Yang et al. [260] prepared a stable and regenerable CdS photocatalyst by coating CdS nanoparticles incorporated in hexagonal mesoporous silica spheres with a polyelectrolyte layer. In contrast to the catalyst without polyelectrolyte coating which lost its activity after three runs, the coated catalyst completely degraded some dyes and phenolic compounds for over 22 runs without leakage of cadmium species into the solution.

Other heavy metal sulfides as $\mathrm{Bi}_{2} \mathrm{~S}_{3}$, $\mathrm{ZnS}$ and $\mathrm{MoS}_{2}$ have been tested for the photocatalytic degradation of organic pollutants. ZnS nanoporous nanoparticles composed of building blocks comprising hexagonal wurtzite $\mathrm{ZnS}$ nanocrystals of several nanometers in diameter were prepared by a solution-phase thermal decomposition route in the presence of poly( $\mathrm{N}$-vinyl-2-pyrrolidone) [261]. The $\mathrm{ZnS}$ nanoporous nanoparticles showed much greater activity for the photodegradation of eosin B than that of P25 or ZnS nanocrystallites.

Crystalline $\mathrm{Sb}_{2} \mathrm{~S}_{3}$ synthesized by solid-state reaction had a very narrow band gap of about $1.55 \mathrm{eV}$, corresponding to the absorption edge of about $800 \mathrm{~nm}$ [262]. The photocatalytic activity of $\mathrm{Sb}_{2} \mathrm{~S}_{3}$ for the degradation of MO under visible light was much higher than that of $\mathrm{Bi}_{2} \mathrm{~S}_{3}, \mathrm{P} 25$ and CdS. The high efficiency of $\mathrm{Sb}_{2} \mathrm{~S}_{3}$ was ascribed to the broad spectrum response and the suitable valence band position.

Sun et al. [263] synthesized $\mathrm{Sb}_{2} \mathrm{~S}_{3}$ nanorods with a simple wet chemical method under refluxing condition. The results of $\mathrm{MO}$ degradation showed that the photocatalytic activity of $\mathrm{Sb}_{2} \mathrm{~S}_{3}$ was higher than that of $\mathrm{TiO}_{2-x} \mathrm{~N}_{x}$ and $\mathrm{CdS}$, and the conversion ratio of pollutant was up to $97 \%$ after 50 min of irradiation. It is worth noting that the photoactivity of $\mathrm{Sb}_{2} \mathrm{~S}_{3}$ under visible light was even better than that of P25 under UV irradiation. The as-prepared $\mathrm{Sb}_{2} \mathrm{~S}_{3}$ sample was stable and was recycled and reused five times exhibiting only a slight loss of activity.

\section{Ternary compounds}

\subsection{Ternary oxides}

The research on ternary and quaternary oxides is an efficient strategy to overcome the intrinsic limitations of the binary metal oxides and new materials have been obtained which are suitable to exploit the visible component of sunlight. Efforts have been initially addressed to produce $\mathrm{H}_{2}$ and $\mathrm{O}_{2}$ by water splitting but, subsequently, these materials have been also tested as photocatalysts for the visible light degradation of various types of pollutants.

\subsubsection{Vanadates}

The layered vanadate $\mathrm{BiVO}_{4}$ has attracted considerable attention as photocatalyst for $\mathrm{O}_{2}$ evolution under visible light irradiation $[264,265] . \mathrm{BiVO}_{4}$ exists in three crystalline phases: monoclinic sheelite-type, tetragonal sheelite-type and tetragonal zircon-type, but only the monoclinic phase exhibits appreciable visible light photocatalytic properties [264-268].

Kohtani et al. [269-271] reported that $\mathrm{BiVO}_{4}$ can efficiently decompose long-chain alkylphenols and polycyclic aromatic hydrocarbons under visible light irradiation. However, only traces of $\mathrm{CO}_{2}$ were observed for all 4 - $n$-alkylphenol solutions after $5 \mathrm{~h}$ of irradiation [269]. Only a little increase of mineralization was obtained by loading $\mathrm{BiVO}_{4}$ with silver fine particles [271].

Many methods have been employed for the synthesis of $\mathrm{BiVO}_{4}$. Generally, monoclinic $\mathrm{BiVO}_{4}$ is obtained by high-temperature processes, whereas tetragonal $\mathrm{BiVO}_{4}$ is prepared in aqueous media at low temperatures. Zhang et al. [272] prepared tetragonal and monoclinic $\mathrm{BiVO}_{4}$ powders by simple aqueous processes. The photocatalytic activities of the different $\mathrm{BiVO}_{4}$ samples were determined by degradation of MB under visible light irradiation and compared with that of Degussa P25. The photoactivity of monoclinic $\mathrm{BiVO}_{4}$ was significantly higher than that of P25 whilst the activity of tetragonal $\mathrm{BiVO}_{4}$ was negligible.

A highly efficient monoclinic $\mathrm{BiVO}_{4}$ photocatalyst was synthesized by an aqueous method with the assistance of cetyltrimethylammonium bromide [273]. The photocatalytic activity was evaluated by the degradation of $\mathrm{RhB}$ under visible light irradiation. The degradation rate over the as-prepared $\mathrm{BiVO}_{4}$ was superior to that of a reference $\mathrm{BiVO}_{4}$ prepared by an aqueous method and much higher than that of a $\mathrm{BiVO}_{4}$ sample prepared by solid-state reaction. The high efficiency was attributed to the existence of an impurity level in the band gap.

Zhang et al. [274] prepared monoclinic $\mathrm{BiVO}_{4}$ nanosheets via mild hydrothermal treatment in the presence of sodium dodecyl benzene sulfonate as a morphology-directing template. The nanosheets showed a much higher photocatalytic activity than the bulk material for the degradation of RhB under solar irradiation.

Single-crystalline $\mathrm{BiVO}_{4}$ microtubes, with square cross-sections and flower-like morphology constructed by several tubes radiating from the center (see Fig. 8), were synthesized by a facile reflux method without involving surfactants or templates in the shaping process [275]. The microtubes had a monoclinic structure with a $\{010\}$ growth direction with a side length of ca. $800 \mathrm{~nm}$ and a wall thickness of ca. $100 \mathrm{~nm}$. The presence of $\mathrm{NaHCO}_{3}$ was crucial to form the tubular structure by controlling the $\mathrm{BiVO}_{4}$ concentration within the bulk solution to mediate the nucleation and growth of monoclinic $\mathrm{BiVO}_{4}$. The photodegradation rate of $\mathrm{RhB}$ under visible

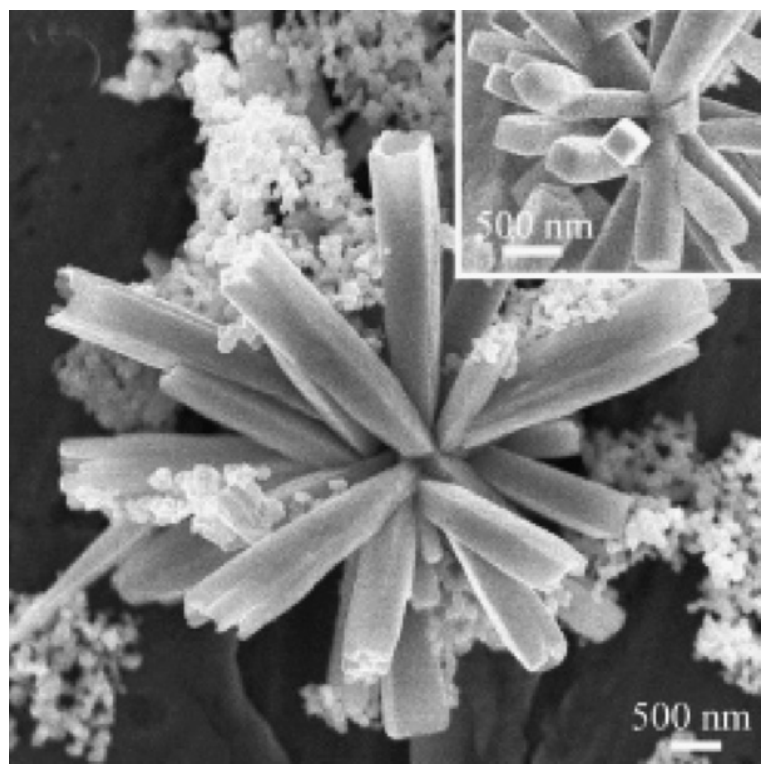

Fig. 8. SEM images of the $\mathrm{BiVO}_{4}$ microtubes. Reproduced with permission from ref. [194]. 
light was much higher than that of the corresponding sample prepared by solid-state reaction. The superior photocatalytic activity of the microtubes was ascribed to the novel square tubular structure and/or the flower-like morphology.

Nanocrystalline monoclinic $\mathrm{BiVO}_{4}$ synthesized via a sonochemical method degraded up to $90 \%$ of MO under visible light in $30 \mathrm{~min}$, whilst only ca. $8 \%$ and $6 \%$ of dye were degraded by monoclinic $\mathrm{BiVO}_{4}$ prepared by solid-state reaction and Degussa P25, respectively [276].

$\mathrm{Ag}_{3} \mathrm{VO}_{4}$ powders synthesized by precipitation [277] were evaluated for the decolorization of acid red $\mathrm{B}$ under visible light irradiation. All $\mathrm{Ag}_{3} \mathrm{VO}_{4}$ samples were remarkably more efficient than $\mathrm{TiO}_{2}$. The powders prepared with an excess of vanadium or silver exhibited higher photoactivity than the sample prepared with a stoichiometric ratio. The activity was increased by 3.8 times when a $\mathrm{NiO}$ catalyst was loaded on the surface of $\mathrm{Ag}_{3} \mathrm{VO}_{4}$.

Zhang et al. [278] prepared $\mathrm{Ag}_{3} \mathrm{VO}_{4}$ samples with crystalline particles from $100 \mathrm{~nm}$ to $5 \mu \mathrm{m}$ by a simple coprecipitation process at temperatures of $0-80^{\circ} \mathrm{C}$. The addition of polyethyleneglycol resulted in the formation of particles with sizes of $50-100 \mathrm{~nm}$. The $\mathrm{Ag}_{3} \mathrm{VO}_{4}$ samples, particularly the nanosized $\mathrm{Ag}_{3} \mathrm{VO}_{4}$ sample, were much more active than P25 for the photocatalytic degradation of $\mathrm{RhB}$ under visible light irradiation. In addition, after four recycles, there was no significant decrease in the photocatalytic activity of the $\mathrm{Ag}_{3} \mathrm{VO}_{4}$ samples.

Various silver vanadates were synthesized using a lowtemperature hydrothermal method [279]. The structures of the samples were tuned by changing the hydrothermal time and with the assistance of a surfactant. The powders consisted of $\mathrm{Ag}_{3} \mathrm{VO}_{4}$ or $\mathrm{Ag}_{4} \mathrm{~V}_{2} \mathrm{O}_{7}$ or mixed phases of $\mathrm{Ag}_{3} \mathrm{VO}_{4}$ and $\mathrm{Ag}_{4} \mathrm{~V}_{2} \mathrm{O}_{7}$. The mixed samples showed the highest photocatalytic activity for the degradation of 2-propanol and benzene vapours. The reactivity of the most efficient sample under visible light irradiation was 16.6 and 16.2 times higher than that of P25 for 2-propanol and benzene, respectively.

$\mathrm{InVO}_{4}$, with a band gap of about $2.0 \mathrm{eV}$, is an interesting visible light responding photocatalyst [280]. $\mathrm{InVO}_{4}$ is usually prepared by solid-state or melting reactions so that it is not homogeneous and has low surface area. Zhang et al. [281] prepared $\mathrm{InVO}_{4}$ nanoparticles by calcining an amorphous complex precursor at the relatively low temperature of $600^{\circ} \mathrm{C}$. The samples were tested for the decomposition of gaseous formaldehyde under UV and visible light irradiation. The $\mathrm{InVO}_{4}$ nanoparticles showed higher photocatalytic activities than that of a sample obtained by traditional solid-state reaction.

Aerosol flow-synthesized nanocrystalline $\mathrm{InVO}_{4}$ hollow microspheres were used to oxidize gaseous NO at indoor air level under visible light [282]. The $\mathrm{InVO}_{4}$ hollow spheres were more active than a sample obtained by a hydrothermal method. The photocatalytic activity enhancement was attributed to the large surface area and special hollow structures, which were favorable for the diffusion of intermediates and inhibited the deactivation of the photocatalyst.

Recently, some lanthanide ( $\mathrm{Ce}, \mathrm{Pr}$ and $\mathrm{Nd}$ ) orthovanadates obtained by solution-based techniques have been investigated as prospective photocatalysts [283]. The kinetic rate constants of these compounds for the degradation of MB were found to be comparable to that of $\mathrm{P} 25$.

Nanosized $\mathrm{CeVO}_{4}, \mathrm{PrVO}_{4}$, and $\mathrm{NdVO}_{4}$ were synthesized under microwave exposure, and their photocatalytic activity was investigated by degrading various dyes and some phenols [284]. The degradation rates measured in presence of the microwavesynthesized vanadates were higher than that observed with the samples prepared by solid-state technique and P25.

\subsection{2. $\mathrm{Bi}_{2} \mathrm{WO}_{6}, \mathrm{BiMoO}_{6}$}

$\mathrm{Bi}_{2} \mathrm{WO}_{6}$ is one of the simplest Aurivillius oxides, which possess layered structure with the perovskite-like slab of $\mathrm{WO}_{6}$. Tang et al. [285] were the first to demonstrate that $\mathrm{Bi}_{2} \mathrm{WO}_{6}$, a semiconductor with a band gap of $2.7-2.8 \mathrm{eV}$, was active not only for the photocatalytic evolution of $\mathrm{O}_{2}$ but also to mineralize both $\mathrm{CHCl}_{3}$ and $\mathrm{CH}_{3} \mathrm{CHO}$ contaminants. $\mathrm{Bi}_{2} \mathrm{WO}_{6}$ was prepared by a solid-state reaction between $\mathrm{Bi}_{2} \mathrm{O}_{3}$ and $\mathrm{WO}_{3}$ and its surface area was only $0.64 \mathrm{~m}^{2} / \mathrm{g}$. Yu et al. [286] prepared $\mathrm{Bi}_{2} \mathrm{WO}_{6}$ powders with a much higher specific surface area $\left(21.1 \mathrm{~m}^{2} / \mathrm{g}\right)$ by a simple hydrothermal method using $\mathrm{Bi}\left(\mathrm{NO}_{3}\right)_{3}$ and $\mathrm{Na}_{2} \mathrm{WO}_{4}$ as raw materials. The samples were active for the visible light oxidation of formaldehyde in air and the best results were obtained with the powder calcined at $500^{\circ} \mathrm{C}$.

Zhang et al. [287] prepared ultrafine $\mathrm{Bi}_{2} \mathrm{WO}_{6}$ powders with large specific surface areas by a low-temperature combustion synthesis among $\mathrm{Bi}\left(\mathrm{NO}_{3}\right)_{3} \cdot 5 \mathrm{H}_{2} \mathrm{O}, \mathrm{Na}_{2} \mathrm{WO}_{4} \cdot 2 \mathrm{H}_{2} \mathrm{O}$ and appropriate amounts of glycine as fuel. When the molar ratio of fuel to oxidizer was 1 , the photocatalyst exhibited the highest degradation efficiency for the photodegradation of $\mathrm{RhB}$ and phenol under visible light irradiation. Amano et al. [288] found that $\mathrm{Bi}_{2} \mathrm{WO}_{6}$ crystallites obtained by hydrothermal reaction induced the complete oxidative decomposition of gaseous acetaldehyde even under visible irradiation whilst amorphous $\mathrm{Bi}_{2} \mathrm{WO}_{6}$ showed negligible photoactivity due to the fast recombination of the electron-hole pairs.

$\mathrm{Bi}_{2} \mathrm{WO}_{6}$ was also effective for the photocatalytic inactivation of E. coli [289] and to eliminate marine microalgae as Amphidium carterae and Tetraselmis suecica [290].

The photoactivity of a catalyst is closely related with the diameter size and surface area so that the synthesis of nanostructured $\mathrm{Bi}_{2} \mathrm{WO}_{6}$ samples has been the subject of considerable research interest. Zhu et al. [291-294] prepared $\mathrm{Bi}_{2} \mathrm{WO}_{6}$ nanoplates and nanoparticles by typical hydrothermal processes. The samples showed a high efficiency for the visible light degradation of RhB and were not photocorroded during the photocatalytic oxidation of the pollutant molecule. Nanosized $\mathrm{Bi}_{2} \mathrm{WO}_{6}$ was much more active for the photodegradation of 4-chlorophenol than a sample prepared by the solid-state reaction and a $\mathrm{TiO}_{2-x} \mathrm{~N}_{x}$ sample $(x=0.0488)$ [295]. The photoactivity was sensitive to the $\mathrm{pH}$ of the solution, and the best results were obtained at $\mathrm{pH}$ 7.2.

The photoactivity of $\mathrm{Bi}_{2} \mathrm{WO}_{6}$ nanoparticles prepared by calcining an amorphous complex precursor at a relatively low temperature above $450^{\circ} \mathrm{C}$ was about 8.8 times higher than that of the sample prepared by traditional solid-state reaction [293]. Analogous results were obtained with $\mathrm{Bi}_{2} \mathrm{WO}_{6}$ nanoplates synthesized via a template-free hydrothermal method using $\mathrm{Bi}\left(\mathrm{NH}_{3}\right)_{2} \mathrm{C}_{6} \mathrm{H}_{7} \mathrm{O}_{7} \cdot \mathrm{H}_{2} \mathrm{O}$ as precursor [296]. Nanocrystalline $\mathrm{Bi}_{2} \mathrm{WO}_{6}$ with nanosheet morphology obtained by a microwave solvothermal process showed higher photocatalytic activity than that of the sample obtained by a conventional hydrothermal process $[297,298]$.

Zhang et al. [299] synthesized new types of $\mathrm{Bi}_{2} \mathrm{WO}_{6}$ with complex morphologies, namely, flower-like, tyre- and helixlike, and platelike shapes. Amano et al. [300-302] prepared $\mathrm{Bi}_{2} \mathrm{WO}_{6}$ flakeball particles and other $\mathrm{Bi}_{2} \mathrm{WO}_{6}$ morphologies by slightly different hydrothermal conditions without organic agents. The samples were tested for the oxidative decomposition of acetic acid in an aqueous suspension and gaseous acetaldehyde in air. The photocatalytic activity of the flake-ball particles under ultraviolet light irradiation was comparable to that of a commercial anatase sample and much higher than that of other $\mathrm{Bi}_{2} \mathrm{WO}_{6}$ samples prepared by conventional solid-state and hydrothermal reactions. The activitiy of the $\mathrm{Bi}_{2} \mathrm{WO}_{6}$ flake-ball particles increased 1.6-3.3 times by calcination at $600^{\circ} \mathrm{C}$ and the calcined samples were highly active for the photodecomposition of acetic acid even under visible irradiation [302].

Monodispersed 3D hierarchical $\mathrm{Bi}_{2} \mathrm{WO}_{6}$ microspheres synthesized by a microwave-assisted hydrothermal method were very efficient to remove NO under visible light irradiation and 


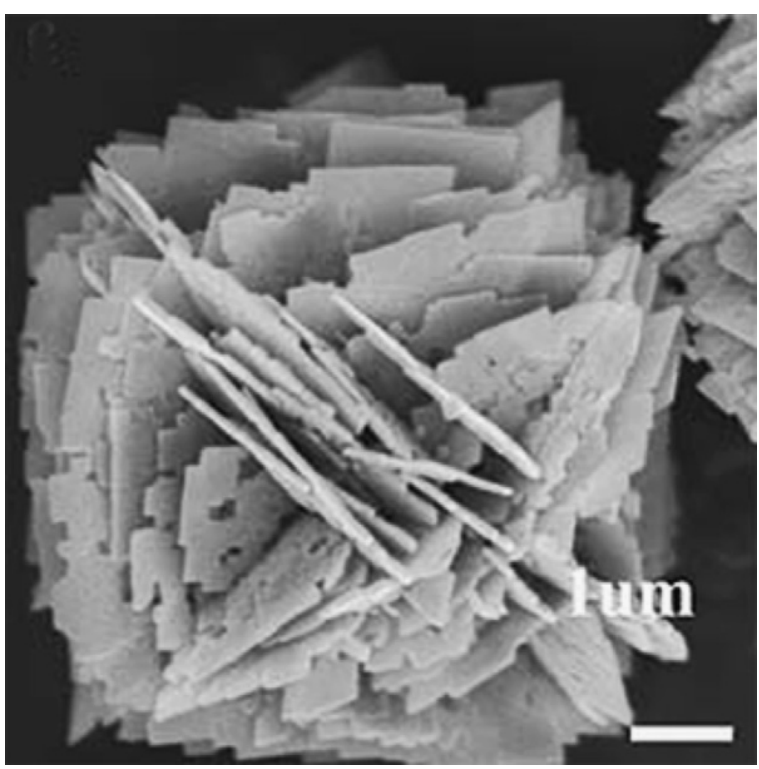

Fig. 9. SEM image of a hierarchical $\mathrm{Bi}_{2} \mathrm{WO}_{6}$ octahedron. Reproduced with permission from ref. [222].

maintained a high level of photocatalytic activity after multiple reaction cycles [303].

Zhang et al. [304] realized a novel flower-like $\mathrm{Bi}_{2} \mathrm{WO}_{6}$ spherical superstructure by a hydrothermal process without any surfactant or template. The flower-like superstructure was retained after calcination at $550^{\circ} \mathrm{C}$ for $4 \mathrm{~h}$. The photocatalytic efficiencies of both uncalcined and calcined $\mathrm{Bi}_{2} \mathrm{WO}_{6}$ for the visible light degradation of RhB were much higher than those of Degussa P25 and of a $\mathrm{Bi}_{2} \mathrm{WO}_{6}$ sample prepared by traditional solid-state reaction. Excellent performances were also obtained with octahedron-like $\mathrm{Bi}_{2} \mathrm{WO}_{6}$ hierarchical structures consisting of many quasi-square nanosheets [305] or $\mathrm{Bi}_{2} \mathrm{WO}_{6}$ hierarchical nest-like structures [306]. The superior photoactivity of the hierarchical configurations (see Fig. 9) was attributed to their large specific surface area and the great number of pores in the structure allowing the reactant molecules to reach easily the reactive sites on the framework walls of the photocatalysts. Unfortunately, the mechanical stability of these types of photocatalysts was not investigated.

The high visible photocatalytic activity of $\mathrm{Bi}_{2} \mathrm{WO}_{6}$ was enhanced by chemically adsorbing fullerene on the surface of nanosized $\mathrm{Bi}_{2} \mathrm{WO}_{6}$ [307]. The optimal loading amount of $\mathrm{C}_{60}$ on $\mathrm{Bi}_{2} \mathrm{WO}_{6}$ was $1.25 \%$. An outer layer of $\mathrm{C}_{60}$ covered the surface of the $\mathrm{Bi}_{2} \mathrm{WO}_{6}$ nanosheet whose lattice structure was not modified. The photoactivity of the $\mathrm{C}_{60}$-modified $\mathrm{Bi}_{2} \mathrm{WO}_{6}$ increased about 5.0 and 1.5 times for the degradation of $\mathrm{MB}$ and $\mathrm{RhB}$ under visible light irradiation, and 4.6 and 2.1 times under xenon lamp irradiation, respectively. The enhanced photoactivity was ascribed to the higher separation efficiency of the electron-hole pairs produced by the interaction of $\mathrm{Bi}_{2} \mathrm{WO}_{6}$ with the delocalized conjugated $\pi$-structure of fullerene.

The molybdates have generally the same crystalline patterns as the tungstates and, like $\mathrm{Bi}_{2} \mathrm{WO}_{6}$, also $\mathrm{Bi}_{2} \mathrm{MoO}_{6}$ exhibited visible light photocatalytic activitiy [308,309]. Bi et al. [310] synthesized nanocrystalline $\mathrm{Bi}_{2} \mathrm{MoO}_{6}$ samples that were more efficient than Degussa P25 for the decomposition of RhB. Nanosheets were obtained by conventional solvothermal route whilst nanorods developed under microwave irradiation. The best performances of the samples prepared by the microwave treatment were attributed to the presence of a higher number of surface defects acting as traps for the photogenerated electrons.

The hydrothermal method was used to synthesize $\mathrm{Bi}_{2} \mathrm{MoO}_{6}$ nanoplates that efficiently degraded RhB [311,312] and MB [311] and were used for five consecutive runs without significant loss of photoactivity. $\mathrm{Bi}_{2} \mathrm{MoO}_{6}$ nanocrystals prepared by an ultrasonicassisted method showed much higher (4-6 times) photocatalytic activity than the corresponding sample prepared by solid-state reaction [313].

Zhang et al. [314] prepared $\mathrm{Bi}_{2} \mathrm{MoO}_{6}$ nanocrystals with tunable morphology by a simple hydrothermal method without adding any surfactant. Nanosheets and microrods were selectively obtained by adjusting the $\mathrm{pH}$ value of the solution. With increasing the $\mathrm{pH}$ from 1 to 13 , the shape of the nanostructures evolved from nanosheets to nanoplates and finally to nanorods. The sample prepared at $\mathrm{pH}$ 1 exhibited a photocatalytic activity 12 times higher than that prepared at $\mathrm{pH} 13$.

$\gamma-\mathrm{Bi}_{2} \mathrm{MoO}_{6}$ samples with different morphologies and surface structures were investigated for the degradation of RhB under visible light irradiation [315]. The $\gamma-\mathrm{Bi}_{2} \mathrm{MoO}_{6}$ sheets with the preferentially exposed $\left\{\begin{array}{lll}0 & 1 & 0\end{array}\right\}$ surface exhibited a greatly enhanced photocatalytic activity, due to the particular reactive surface with much more oxygen defects and in-plane vacancies.

$\mathrm{Bi}_{2} \mathrm{MoO}_{6}$ nanoparticles were synthesized using an amorphous complex precursor [316] or by a simple low-temperature molten salt method [317]. Yin et al. [318] prepared cage-like $\mathrm{Bi}_{2} \mathrm{MoO}_{6}$ hollow spheres by a hard-template method. The spheres, with a diameter of about $1.5 \mu \mathrm{m}$, showed much higher efficiency in the degradation of phenol under visible light irradiation than the $\mathrm{Bi}_{2} \mathrm{MoO}_{6}$ synthesized by solid-state reaction due to their larger specific surface area.

The comparison between $\mathrm{Bi}_{2} \mathrm{WO}_{6}$ and $\mathrm{Bi}_{2} \mathrm{MoO}_{6}$ samples synthesized using the citrate complex method [319] showed that $\mathrm{Bi}_{2} \mathrm{WO}_{6}$ was more active for the visible light degradation of $\mathrm{RhB}$, due to its electronic and textural properties. Similar results were obtained with $\mathrm{Bi}_{2} \mathrm{MO}_{6}(\mathrm{M}=\mathrm{W}, \mathrm{Mo})$ nanocrystals prepared via an ultrasonicassisted method [313].

\subsection{3. $\mathrm{ZnWO}_{4}, \mathrm{CdWO}_{4}, \mathrm{PbWO}_{4}$}

$\mathrm{ZnWO}_{4}$ was studied by Zhu and coworkers [320-328] as a potential photocatalyst for environmental applications. A comparison between the activities of $\mathrm{ZnWO}_{4}$ and $\mathrm{Bi}_{2} \mathrm{WO}_{6}$ for the degradation of RhB under UV illumination showed that both catalysts exhibited high photocatalytic activity [326]. Anyway, the photocatalytic performances of $\mathrm{Bi}_{2} \mathrm{WO}_{6}$ were excellent in the wide light region whilst $\mathrm{ZnWO}_{4}$ was active only in the UV region. $\mathrm{ZnWO}_{4}$ samples obtained by hydrothermal crystallization processes $[321,325]$ or by calcining a co-precipitated precursor [324] were more active than P25 for the degradation of gaseous formaldehyde.

The hydrothermal process is an easy method to control morphology and crystal growth orientation that ultimately influence the photocatalytic properties of the samples. $\mathrm{ZnWO}_{4}$ powders with various morphologies were synthesized in different hydrothermal conditions in the presence of cetyltrimethyl ammonium bromide as surfactant [322] or by a template-free hydrothermal process [328]. The nanorods with a highly $\left\{\begin{array}{lll}1 & 0 & 0\end{array}\right\}$ preferred orientation exhibited the highest photocatalytic activity for the degradation of MB and RhB.

Porous $\mathrm{ZnWO}_{4}$ films, prepared on ITO glasses from an amorphous heteronuclear complex with the addition of polyethylene glycol, exhibited excellent photocurrent response and high photocatalytic activity [327]. The synergetic effect of electro-oxidation and photocatalysis increased the mineralization degree of RhB [320].

$\mathrm{CdWO}_{4}$ is another tungstate that has been investigated for the photodegradation of organic compounds under UV light irradiation $[329,330]$. Monoclinic $\mathrm{CdWO}_{4}$ short rods synthesized via a hydrothermal process exhibited a high photocatalytic activity for the degradation of MO and RhB [329]. The photactivities of $\mathrm{CdWO}_{4}$ and $\mathrm{ZnWO}_{4}$ were practically the same but $\mathrm{TiO}_{2}$ revealed a higher 
velocity to degrade MO. Yan et al. [330] selectively prepared monoclinic and tetragonal $\mathrm{CdWO}_{4}$ by an aqueous solvothermal process and found that the monoclinic polymorph was much more active than the tetragonal $\mathrm{CdWO}_{4}$.

$\mathrm{PbWO}_{4}$ prepared by mild hydrothermal crystallization showed a poor activity to photodegrade RhB either under UV and visible light illumination [326]. Recently, solid and hollow $\mathrm{PbWO}_{4}$ spheres were obtained by ultrasonic spray pyrolysis [331]. Photocatalytic tests showed that the hollow spheres degraded NO in air under UV illumination and were significantly more active than the solid spheres. The enhanced photoactivity was ascribed to the synergistic consequence of small crystal size, high surface area, large pore volume, and the special cage-like hollow structure favorable to multiple reflections of UV light within the sphere interior voids, allowing a more efficient light harvesting.

Shan et al. [332] synthesized $\mathrm{MWO}_{4}(\mathrm{M}=\mathrm{Ca}, \mathrm{Sr}, \mathrm{Ba})$ powders by a solid-state reaction using $\mathrm{MCO}_{3}$ and $\mathrm{WO}_{3}$ as raw materials. The samples were efficient for the degradation of MO under UV irradiation and the photocatalytic activity was in the order $\mathrm{BaWO}_{4}>\mathrm{SrWO}_{4}>\mathrm{CaWO}_{4}$ under both neutral and acidic conditions.

\subsection{4. $\mathrm{Zn}_{2} \mathrm{SnO}_{4}, \mathrm{~Pb}_{2} \mathrm{Sn}_{2} \mathrm{O}_{6}, \mathrm{PbSnO}_{3}$}

Nanosized $\mathrm{Zn}_{2} \mathrm{SnO}_{4}$ materials, with a typical inverse spinel structure and a band gap of $3.6 \mathrm{eV}$, were active for the decomposition of benzene in water solution under UV irradiation [333] and for the degradation of various dyes [334,335]. Zeng et al. [336] synthesized $\mathrm{Zn}_{2} \mathrm{SnO}_{4}$ nanocrystals that exhibited better performance than P25 for the photodegradation of $\mathrm{MB} . \mathrm{Zn}_{2} \mathrm{SnO}_{4}$ nanoparticles synthesized by a hydrothermal process in water/ethylene glycol solutions using various amines as alkaline mineralizer showed high activity and durability for the photodegradation of MO [337]. The photoactivity was affected by the crystallinity of the samples and was comparable or superior to that of P25.

Nanocrystalline $\mathrm{Zn}_{2} \mathrm{SnO}_{4}$ microcubes synthesized via a hydrothermal route were tested for the degradation of NO and formaldehyde at typical concentrations for indoor air quality [338]. The photocatalytic activity of the microcubes under UV-vis light irradiation was higher than that of $\mathrm{ZnO}, \mathrm{SnO}_{2}$, Degussa P25 as well as $\mathrm{C}$-doped $\mathrm{TiO}_{2}$. Only a slight deactivation was observed after eight cycles of NO degradation. The excellent catalytic activity and the stability of the $\mathrm{Zn}_{2} \mathrm{SnO}_{4}$ microcubes were attributed to their special microporous structure favorable for the diffusion of intermediates and final products of the $\mathrm{NO} / \mathrm{HCHO}$ oxidation.

Among the stannates, a novel nanocrystalline $\mathrm{Pb}_{2} \mathrm{Sn}_{2} \mathrm{O}_{6}$ photocatalyst exhibited almost the same photoactivity as Degussa P25 for the decomposition of MO under $365 \mathrm{~nm}$ UV light irradiation [339]. Nanostructured $\mathrm{PbSnO}_{3}$ photocatalysts with particulate and tubular morphologies showed much higher activity than bulk $\mathrm{PbSnO}_{3}$ for the degradation of 2-propanol under visible light irradiation [340].

\subsubsection{Indates, gallates, antimonates}

Ye and coworkers [341-343] demonstrated that $\mathrm{MIn}_{2} \mathrm{O}_{4}(\mathrm{M}=\mathrm{Ca}$, $\mathrm{Sr}, \mathrm{Ba}$ ) samples efficiently degraded $\mathrm{MB}$ under visible light irradiation. The activity order was $\mathrm{CaIn}_{2} \mathrm{O}_{4}>\operatorname{SrIn}_{2} \mathrm{O}_{4}>\mathrm{BaIn}_{2} \mathrm{O}_{4}$ in agreement with band structure calculations indicating that the oxidizing power of the $\mathrm{MIn}_{2} \mathrm{O}_{4}$ catalysts decreased with increasing the radius of the $\mathrm{M}$ ion [341]. The photocatalytic activity of $\mathrm{CaIn}_{2} \mathrm{O}_{4}$ was high in a wide light region up to $580 \mathrm{~nm}$ whilst the performance of P25 was very limited [344].

The large band gap of some ternary oxides such as $\mathrm{ZnGa}_{2} \mathrm{O}_{4}$, $\mathrm{ZnGe}_{2} \mathrm{O}_{4}$ and $\mathrm{Sr}_{2} \mathrm{Sb}_{2} \mathrm{O}_{7}$ endows these materials with high oxidizing power for the photocatalytic degradation of stable aromatic pollutants. Nanocrystalline $\mathrm{ZnGa}_{2} \mathrm{O}_{4}$ prepared via a coprecipitation method showed a photocatalytic activity and stability for benzene degradation superior to that of P25 but lower than that of another wide band semiconductor as $\mathrm{Sr}_{2} \mathrm{Sb}_{2} \mathrm{O}_{7}$ [345]. The different photoactivities of $\mathrm{ZnGa}_{2} \mathrm{O}_{4}$ and $\mathrm{Sr}_{2} \mathrm{Sb}_{2} \mathrm{O}_{7}$ were attributed to the difference in their geometric structures.

Porous nanocrystalline $\mathrm{ZnGa}_{2} \mathrm{O}_{4}$ samples with high surface areas were synthesized by a soft-chemical method at low temperature [346]. The best sample, obtained at $80^{\circ} \mathrm{C}$, was more efficient than $\mathrm{TiO}_{2}$ and $\mathrm{Pt} / \mathrm{TiO}_{2}$ for the photooxidation of benzene, toluene and ethylbenzene to $\mathrm{CO}_{2}$. No remarkable deactivation of $\mathrm{ZnGa}_{2} \mathrm{O}_{4}$ was observed in $80 \mathrm{~h}$ of benzene degradation, whereas $\mathrm{TiO}_{2}$ deactivated in $24 \mathrm{~h}$. Similar results were obtained with $\mathrm{Zn}_{2} \mathrm{GeO}_{4}$ nanorods [347] and nanocrystalline $\mathrm{Cd}_{2} \mathrm{Ge}_{2} \mathrm{O}_{6}$ [348], prepared by a surfactant-assisted hydrothermal method. The photoactivity of $\mathrm{Cd}_{2} \mathrm{Ge}_{2} \mathrm{O}_{6}$ was superior to that of $\mathrm{Zn}_{2} \mathrm{GeO}_{4}$ and $\mathrm{Sr}_{2} \mathrm{Sb}_{2} \mathrm{O}_{7}$.

$\mathrm{ZnGa}_{2} \mathrm{O}_{4}$ thin films exhibited excellent photocatalytic performance for degrading MB [349]. The photocatalytic efficiency of $\mathrm{ZnGa}_{2} \mathrm{O}_{4}$ was improved by substituting zinc with cadmium to form $\mathrm{Zn}_{1-x} \mathrm{Cd}_{x} \mathrm{Ga}_{2} \mathrm{O}_{4}(0 \leq x \leq 1)$ solid solutions [350]. The best results were obtained with the $\mathrm{Zn}_{0.6} \mathrm{Cd}_{0.4} \mathrm{Ga}_{2} \mathrm{O}_{4}$ sample.

Alkali earth antimonates have been also examined for the photodecomposition of organic pollutants. $\mathrm{M}_{2} \mathrm{Sb}_{2} \mathrm{O}_{7}(\mathrm{M}=\mathrm{Ca}, \mathrm{Sr})$ powders synthesized by a solid-state reaction method were tested for the degradation of MO under UV illumination [351]. The results showed that the photocatalytic efficiency of $\mathrm{Sr}_{2} \mathrm{Sb}_{2} \mathrm{O}_{7}$ was much higher than that of $\mathrm{Ca}_{2} \mathrm{Sb}_{2} \mathrm{O}_{7}$. The two compounds have the same orthorhombic crystal structure and quite similar band-gap values (4.02 eV for $\mathrm{Ca}_{2} \mathrm{Sb}_{2} \mathrm{O}_{7}$ and $3.86 \mathrm{eV}$ for $\mathrm{Sr}_{2} \mathrm{Sb}_{2} \mathrm{O}_{7}$ ) so that the more open structure of $\mathrm{Sr}_{2} \mathrm{Sb}_{2} \mathrm{O}_{7}$ was suggested to be responsible for its higher photoactivity.

Nanocrystalline $\mathrm{Sr}_{2} \mathrm{Sb}_{2} \mathrm{O}_{7}$ prepared via a hydrothermal method from $\mathrm{Sr}\left(\mathrm{CH}_{3} \mathrm{COO}\right)_{2} \cdot 0.5 \mathrm{H}_{2} \mathrm{O}$ and $\mathrm{Sb}_{2} \mathrm{O}_{5}$ showed a high photocatalytic activity for the degradation of gaseous benzene under $254 \mathrm{~nm}$ UV irradiation [352]. The performance of the nanocrystalline $\mathrm{Sr}_{2} \mathrm{Sb}_{2} \mathrm{O}_{7}$ was superior to both $\mathrm{P} 25$ and $\mathrm{Sr}_{2} \mathrm{Sb}_{2} \mathrm{O}_{7}$ prepared by the conventional solid-state reaction and no deactivation was observed during the prolonged photocatalytic reaction. Three-dimensional (3D) hierarchical flower-like architectures were obtained if the hydrothermal process occurred in the presence of cetyltrimethyl ammonium bromide or polyvinyl pyrrolidone as surfactants [353]. All the $\mathrm{Sr}_{2} \mathrm{Sb}_{2} \mathrm{O}_{7}$ samples were active for the photodegradation of salicylic acid and the best performance was exhibited by the sample prepared with the assistance of polyvinyl pyrrolidone.

$\mathrm{ZnIn}_{2} \mathrm{~S}_{4}$ is a ternary semiconductor chalcogenide that belongs to the $\mathrm{AB}_{2} \mathrm{X}_{4}$ family of the ternary compounds. $\mathrm{ZnIn}_{2} \mathrm{~S}_{4}$, with a band gap of $2.2 \mathrm{eV}$, is an interesting potential photocatalyst for solar-driven applications. Hu et al. [354] synthesized hierarchically porous $\mathrm{ZnIn}_{2} \mathrm{~S}_{4}$ submicrospheres that showed an enhanced photocatalytic activity for the degradation of $\mathrm{MB}$ under visible light illumination. The samples were three times more active than nonporous $\mathrm{ZnIn}_{2} \mathrm{~S}_{4}$ due to the 3D accessible structural configuration of the submicrospheres that allowed an efficient light harvesting and provided efficient transport channels to the reactive sites of the $\mathrm{ZnIn}_{2} \mathrm{~S}_{4}$ framework.

Marigold-like $\mathrm{ZnIn}_{2} \mathrm{~S}_{4}$ microspheres prepared by a hydrothermal synthesis at $80-200^{\circ} \mathrm{C}$ were tested for the visible light photodegradation of three azo dyes [355]. As expected, the photoactivity of the $\mathrm{ZnIn}_{2} \mathrm{~S}_{4}$ microspheres was noticeably higher than that of a $\mathrm{TiO}_{2-x} \mathrm{~N}_{x}$ sample and the $\mathrm{ZnIn}_{2} \mathrm{~S}_{4}$ synthesized at $80^{\circ} \mathrm{C}$ for $6 \mathrm{~h}$ showed the highest activity. A remarkable photocatalytic bactericidal ability under visible light was exhibited by a $\mathrm{ZnIn}_{2} \mathrm{~S}_{4}$ film electrodeposited on a Ti substrate [356]. The photocatalytic inactivation of $E$. coli was enhanced if the process was assisted by a $0.6 \mathrm{~V}$ positive potential.

$\mathrm{SnIn}_{4} \mathrm{~S}_{8}$ is another ternary sulfide that has been recently studied for the visible light-induced decomposition of organic pollutants. In particular, porous $\mathrm{SnIn}_{4} \mathrm{~S}_{8}$ microspheres were highly efficient and stable towards the photodegradation of MO, RhB and MB [357]. 
The photocatalytic activity of the $\mathrm{SnIn}_{4} \mathrm{~S}_{8}$ microspheres was much higher than that of the binary constituent $\operatorname{In}_{2} \mathrm{~S}_{3}$ and $\mathrm{SnS}_{2}$ and the ternary chalcogenide $\mathrm{ZnIn}_{2} \mathrm{~S}_{4}$.

\subsubsection{Bismutates, titanates, ferrites, niobates}

In view of an efficient utilization of the visible light, many ternary oxides with narrow band gaps have been synthesized and tested for the decomposition of organic contaminants. Tang and al. [358] prepared a $\mathrm{CaBi}_{2} \mathrm{O}_{4}$ photocatalyst that efficiently degraded gaseous acetaldehyde and $\mathrm{MB}$ under visible light irradiation. The high activity was attributed to the hybridization of the Bi $6 \mathrm{~s}$ and 02 p orbitals that makes the valence band largely dispersed favoring the mobility of the photoholes and consequently the oxidation reaction.

$\mathrm{ZnBi}_{12} \mathrm{O}_{20}$, with a hybridized valence band including $\mathrm{O} 2 \mathrm{p}, \mathrm{Zn}$ $3 \mathrm{~d}$ and $\mathrm{Bi} 6 \mathrm{~s}$ orbitals easily decomposed acetaldehyde under visible light illumination $(\lambda>440 \mathrm{~nm})$ [359]. The intrinsic band gap of $\mathrm{ZnBi}_{12} \mathrm{O}_{20}$ was determined as $2.69 \mathrm{eV}$ from the onset of the steep edge of the absorption spectrum.

$\mathrm{BaBiO}_{3}$, that has a band gap of only $2.05 \mathrm{eV}$, efficiently degraded acetaldehyde and $\mathrm{MB}$ either under UV light or visible light irradiation [360]. Compared with $\mathrm{CaBi}_{2} \mathrm{O}_{4}$ and $\mathrm{ZnBi}_{12} \mathrm{O}_{20}, \mathrm{BaBiO}_{3}$ showed the highest photocatalytic activity, due to the large portion of $\mathrm{s}$ orbital components in the valence and conduction bands resulting in the narrowest band gap, higher mobility of the photogenerated charge carriers, and lower barrier to the electron transitions.

Kako et al. [361] demonstrated that $\mathrm{NaBiO}_{3}\left(E_{\mathrm{g}}=2.6 \mathrm{eV}\right)$ was a very efficient visible light sensitive photocatalyst. The photoactivity of $\mathrm{NaBiO}_{3}$ for the degradation of MB was significantly higher than that exhibited by $\mathrm{BiVO}_{4}$ and $\mathrm{N}$-doped $\mathrm{TiO}_{2} \cdot \mathrm{NaBiO}_{3}$ also showed high activity for the decomposition of various dangerous organic pollutants (polycyclic aromatic hydrocarbons [362], 4-t-octylphenol [363], sodium pentachlorophenate [364]). Anyway, $\mathrm{NaBiO}_{3}$ was not stable under acidic conditions, and could be converted into $\mathrm{BiOCl}$ or other $\mathrm{Bi}^{3+}$ containing compounds in the presence of $\mathrm{HCl}$ [363].

$\mathrm{SrTiO}_{3}$ is a typical ternary perovskite-type oxide with a band gap of $\sim 3.2 \mathrm{eV}$ that has been largely studied for the photocatalytic water splitting because of its superior physical and chemical properties, such as excellent thermal stability and photocorrosion resistance. $\mathrm{SrTiO}_{3}$ powders prepared using a sol-gel process were able to degrade NO under either UV light and sunshine [365] or to decompose MO under sunlight irradiation [366].

$\mathrm{SrTiO}_{3}$ is usually synthesized by solid-state reaction between $\mathrm{SrCO}_{3}$ and $\mathrm{TiO}_{2}$ at temperatures higher than $900{ }^{\circ} \mathrm{C}$ but this technique normally does not allow to obtain an appropriate reproducibility of the properties required for photocatalytic applications. Puangpetch et al. [367] prepared mesoporous-assembled $\mathrm{SrTiO}_{3}$ nanocrystals by a sol-gel method with the aid of structure-directing surfactants. The photocatalytic activity for the degradation of MO exhibited by the sample obtained at a calcination temperature of $700^{\circ} \mathrm{C}$ was much higher than that of a non mesoporous commercial $\mathrm{SrTiO}_{3}$. Likewise, $\mathrm{SrTiO}_{3}$ nanocrystallines synthesized by a solvothermal method using $\mathrm{H}_{2} \mathrm{TiO}_{3}$ as starting material were more active for the photodegradation of $\mathrm{MB}$ than commercial $\mathrm{SrTiO}_{3}$ nanoparticles [368].

Zheng et al. [369] synthesized $\mathrm{SrTiO}_{3}$ hollow microspheres built by regular nanocubes (see Fig. 10) that were tested for the reduction of $\mathrm{Cr}(\mathrm{VI})$ under UV light irradiation. The conduction band edge of $\mathrm{SrTiO}_{3}(-1.4 \mathrm{~V}$ vs. SCE) is more negative than that of anatase $\mathrm{TiO}_{2}\left(-1.2 \mathrm{~V}\right.$ vs. SCE) so that the photogenerated electrons of $\mathrm{SrTiO}_{3}$ have a stronger reducing ability. The $\mathrm{SrTiO}_{3}$ microspheres exhibited a high photocatalytic activity but if the hollow structure was destroyed by crushing the as-synthesized $\mathrm{SrTiO}_{3}$ samples, the photoactivity obviously decreased but it was always superior to that of Degussa P25.
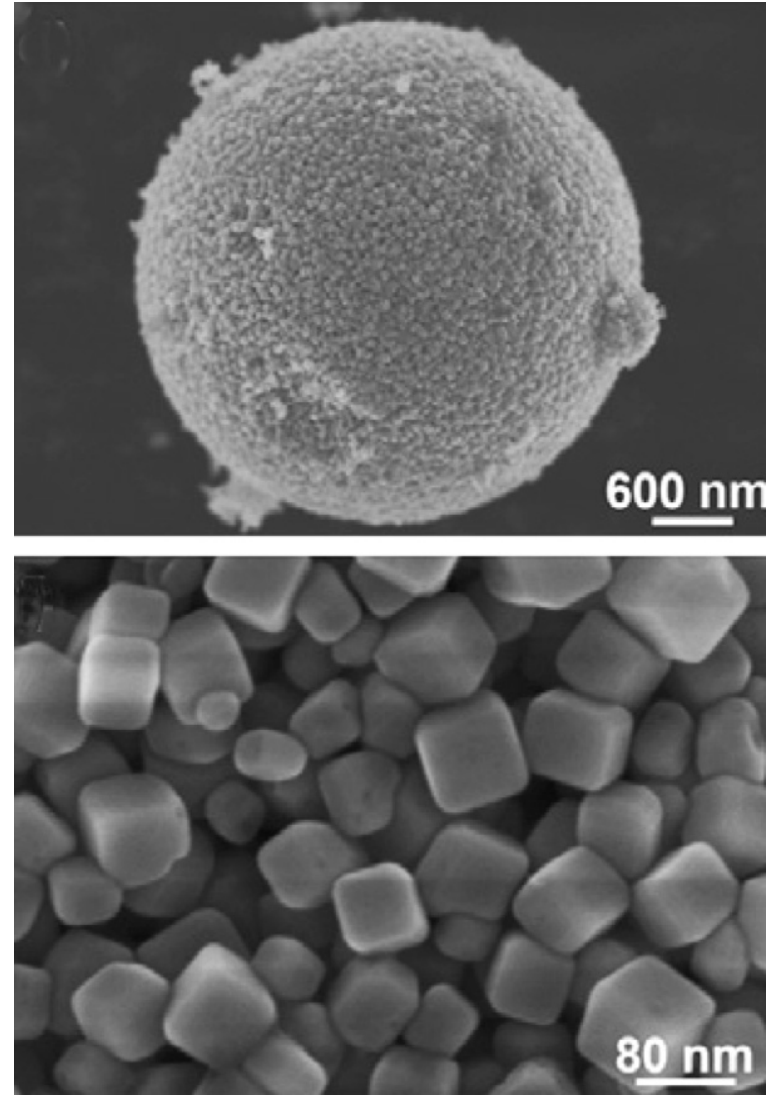

Fig. 10. SEM images of the $\mathrm{SrTiO}_{3}$ hollow microspheres. Reproduced with permission from ref. [285].

Recently, some layered oxides have received increasing attention since they are much more active than $\mathrm{TiO}_{2}$ or $\mathrm{SrTiO}_{3}$ for the photocatalytic water splitting. The high efficiency of these materials has been attributed to the effective utilization of the interlayer spaces as reaction sites. Layered perovskite $\mathrm{Bi}_{4} \mathrm{Ti}_{3} \mathrm{O}_{12}$ or $\mathrm{Bi}_{2} \mathrm{Ti}_{2} \mathrm{O}_{7}$ crystals with pyrochlore structure were synthesized by a chemical solution decomposition method [370,371]. Both catalysts showed high photocatalytic activity for the photodegradation of MO under UV irradiation and, in particular, the photoactivity of $\mathrm{Bi}_{2} \mathrm{Ti}_{2} \mathrm{O}_{7}$ was much higher than that of P25 [371]. Layered perovskite $\mathrm{La}_{2} \mathrm{Ti}_{2} \mathrm{O}_{7}$ prepared by a solid-state reaction was efficiently employed for the decomposition of an aqueous solution of 2-propanol [372].

$\mathrm{ZnFe}_{2} \mathrm{O}_{4}$ was synthesized by coprecipitation of the parent nitrates with an aqueous solution of $\mathrm{NH}_{4} \mathrm{OH}$ [373]. The photocatalytic activity of $\mathrm{ZnFe}_{2} \mathrm{O}_{4}$ for the degradation of phenol was higher than that of $\mathrm{ZnO}$ or $\mathrm{Fe}_{2} \mathrm{O}_{3}$ but lower than that of P25, due to the adsorption of intermediate oxidation products which competed with the phenol adsorption. The active lifetime of the catalyst was extended by using a $\mathrm{ZnFe}_{2} \mathrm{O}_{4}$ prepared by calcination at $500^{\circ} \mathrm{C}$ of a zinc-iron(III)-sulfate layered double hydroxide precursor followed by extraction of the $\mathrm{ZnO}$ with aqueous $\mathrm{NaOH}$ [374]. The increased photoactivity was ascribed to the higher porosity of the sample, which allowed an easier diffusion of the oxidation subproducts away from the initial adsorption sites.

Nanometer $\mathrm{REFeO}_{3}(\mathrm{RE}=\mathrm{Sm}, \mathrm{Eu}, \mathrm{Gd})$ perovskite-type samples prepared by a sol-gel method were investigated for the photocatalytic degradation of four water-soluble dyes under UV illumination [375]. Reactive brilliant red X-3B and reactive brilliant orange K3N nearly completely disappeared after $2 \mathrm{~h}$ of irradiation. The photocatalytic activities of the three samples increased in the sequence: $\mathrm{SmFeO}_{3}<\mathrm{EuFeO}_{3}<\mathrm{GdFeO}_{3}$. 
The perovskite-type $\mathrm{BiFeO}_{3}$ has attracted considerable attention owing to its magnetic properties, narrow band-gap energy $(2.1-2.5 \mathrm{eV})$ and high chemical stability. Gao et al. [376] reported that sol-gel synthesized $\mathrm{BiFeO}_{3}$ nanoparticles ranging from 80 to $120 \mathrm{~nm}$ showed a significant photocatalytic activity for the decomposition of MO under UV and visible light irradiation. Unexpectedly, single-crystalline $\mathrm{BiFeO}_{3}$ nanoparticles with diameters of about $150-200 \mathrm{~nm}$ synthesized through a chemical coprecipitation process from bismuth and iron nitrates [377] did not show any efficient visible light photoactivity, although the nanoparticles absorbed visible light in the wavelength range of $400-580 \mathrm{~nm}$.

Huo et al. [378] prepared perovskite-type $\mathrm{BiFeO}_{3}$ uniform microspheres with high surface area that were much more efficient for the visible light degradation of $\mathrm{MB}$ than $\mathrm{BiFeO}_{3}$ obtained via solid-state reaction and Degussa P25. The higher photoactivity of the $\mathrm{BiFeO}_{3}$ microspheres was attributed to their high crystallization, narrow band-gap energy and hollow structure.

Polycrystalline samples of $\mathrm{BiNbO}_{4}$ and $\mathrm{BiTaO}_{4}$ synthesized by a ceramic route at high temperatures were tested for the photocatalytic degradation of orange $G$, methyl violet and alizarin green, under UV illumination [379]. The results revealed a selectivity of $\mathrm{BiNbO}_{4}$ towards the aromatics containing quinonic and azo functional groups.

Zhang et al. [380] prepared nanocrystalline $\mathrm{InNbO}_{4}$ by reaction of indium acetylacetonate and niobium chloride in anhydrous benzyl alcohol at $200^{\circ} \mathrm{C}$. Although the reaction temperature was low and the reaction duration was only $24 \mathrm{~h}$, the as-prepared $\mathrm{InNbO}_{4}$ was characterized by high crystallinity and high surface area. Furthermore, the photocatalytic activity for the degradation of RhB under visible light irradiation was much higher than that of Degussa $\mathrm{P} 25$, carbon-doped mesoporous $\mathrm{TiO}_{2}$ and bulk $\mathrm{InNbO}_{4}$ prepared by a high-temperature ceramic method.

Nanosized $\mathrm{Bi}_{3} \mathrm{NbO}_{7}$ powders [381] synthesized by a sol-gel method showed a photocatalytic activity for the decomposition of acid red $\mathrm{G}$ in water under visible light irradiation much larger than that of a sample synthesized by the solid-state reaction and Degussa P25. The as-prepared $\mathrm{Bi}_{3} \mathrm{NbO}_{7}$ nanopowders were also very efficient for the visible light degradation of acetone in air.

Two lead niobates with a pyrochlore crystal structure, viz. $\mathrm{Pb}_{3} \mathrm{Nb}_{2} \mathrm{O}_{8}$ and $\mathrm{Pb}_{3} \mathrm{Nb}_{4} \mathrm{O}_{13}$, were prepared by a solid-state reaction between $\mathrm{PbO}$ and $\mathrm{Nb}_{2} \mathrm{O}_{5}$ [382]. The energy band gaps were 2.95 and $2.72 \mathrm{eV}$, for $\mathrm{Pb}_{3} \mathrm{Nb}_{4} \mathrm{O}_{13}$ and $\mathrm{Pb}_{3} \mathrm{Nb}_{2} \mathrm{O}_{8}$, respectively. $\mathrm{Pb}_{3} \mathrm{Nb}_{4} \mathrm{O}_{13}$ performed much better than $\mathrm{Pb}_{3} \mathrm{Nb}_{2} \mathrm{O}_{8}$ for the degradation of gaseous 2-propanol under visible light illumination due to the more positive position of the valence band top of $\mathrm{Pb}_{3} \mathrm{Nb}_{4} \mathrm{O}_{13}$ and the corresponding stronger oxidation ability of the photogenerated holes. $\mathrm{Pb}_{3} \mathrm{Nb}_{4} \mathrm{O}_{13}$ obtained by a coprecipitation method possessed much greater surface area, smaller particle size, and exhibited a notably improved photocatalytic activity.

$\mathrm{Pb}_{3} \mathrm{Nb}_{4} \mathrm{O}_{13}$ was successfully supported on fumed $\mathrm{SiO}_{2}$ and tested for the degradation of RhB [383]. The rate of degradation was ca. 3.5 times faster than that determined with the unsupported $\mathrm{Pb}_{3} \mathrm{Nb}_{4} \mathrm{O}_{13}$ sample. The enhanced photoactivity was ascribed to the interaction between $\mathrm{SiO}_{2}$ and $\mathrm{Pb}_{3} \mathrm{Nb}_{4} \mathrm{O}_{13}$.

\subsubsection{Ag-based oxides}

$\alpha-\mathrm{AgGaO}_{2}$ and $\beta-\mathrm{AgGaO}_{2}$ powders synthesized through a cation exchange reaction were tested for the degradation of 2-propanol [384]. The band-gap values of the two polymorphs were $2.4 \mathrm{eV}$ for $\alpha-\mathrm{AgGaO}_{2}$ and $2.1 \mathrm{eV}$ for $\beta-\mathrm{AgGaO}_{2}$, respectively. $\alpha-\mathrm{AgGaO}_{2}$ effectively produced propanone and $\mathrm{CO}_{2}$ by irradiating with either UV light or visible light whereas $\beta-\mathrm{AgGaO}_{2}$ showed a negligible activity. These results were attributed to the larger band gap of $\alpha-\mathrm{AgGaO}_{2}$ and consequently to its higher oxidation power due to the more positive position of the valence band edge. In addition, the larger dispersed valence band of the delafossite structure of
$\alpha-\mathrm{AgGaO}_{2}$ allowed a high hole mobility. A comparison among the performances of $\alpha-\mathrm{AgGaO}_{2}, \alpha-\mathrm{AgInO}_{2}, \beta-\mathrm{AgAlO}_{2}$, and $\beta-\mathrm{AgGaO}_{2}$ [385] showed that the order of photoactivity was $\alpha-\mathrm{AgGaO}_{2}>\beta$ $\mathrm{AgAlO}_{2}>\beta-\mathrm{AgGaO}_{2}>\alpha-\mathrm{AgInO}_{2}$.

Dong et al. [386] prepared delafossite-structured oxides $\mathrm{AgMO}_{2}$ ( $\mathrm{M}=\mathrm{Al}, \mathrm{Ga}, \mathrm{In}$ ) via a low-temperature hydrothermal technique. The band-gap values estimated were 3.2, 2.4 and $2.0 \mathrm{eV}$ for $\mathrm{AgAlO}_{2}$, $\mathrm{AgGaO}_{2}$ and $\mathrm{AgInO}_{2}$ respectively, showing a decrease in the band gap with the increase of the $\mathrm{M}^{3+}$ radius ( $\mathrm{M}=\mathrm{Al}$, $\mathrm{Ga}$ and In). All three samples were active for the degradation of RhB and MO under visible light irradiation and their photocatalytic activity followed the order: $\mathrm{AgInO}_{2}>\mathrm{AgGaO}_{2}>\mathrm{AgAlO}_{2}$ opposite to that observed in gas-solid regime [385]. The relative high photocatalytic activity of $\mathrm{AgInO}_{2}$ was attributed to the high quantity of surface hydroxyl groups.

$\mathrm{AgAlO}_{2}$ with a layered orthorhombic structure and a band gap of $\sim 2.8 \mathrm{eV}$ was prepared by cation exchange reaction and characterized by the photocatalytic degradation of alizarin red [387]. The sample was quite efficient and about $70 \%$ of the dye was decomposed after $2 \mathrm{~h}$ of visible light irradiation.

Due to the relatively high band gap, the light absorption of $\mathrm{AgAlO}_{2}$ in the visible region is limited, so that its photoactivity for the degradation of organic dyes is quite low. In order to enhance the photoactivity, Ouyang et al. [388] prepared Agbased oxides where $\mathrm{Al}$ was substituted by $\mathrm{Cr}$. $\mathrm{AgAlO}_{2}$ and $\mathrm{Ag}_{2} \mathrm{CrO}_{4}$ had orthorhombic structures whereas $\mathrm{AgCrO}_{2}$ had a hexagonal structure. The band gaps of $\mathrm{AgAlO}_{2}, \mathrm{AgCrO}_{2}$, and $\mathrm{Ag}_{2} \mathrm{CrO}_{4}$ were estimated to be $2.95,1.68$, and $1.75 \mathrm{eV}$, respectively. The three materials were tested for the degradation of MO and gaseous benzene under visible light illumination. The order of activity was $\mathrm{Ag}_{2} \mathrm{CrO}_{4}>\mathrm{AgAlO}_{2}>\mathrm{P} 25>\mathrm{AgCrO}_{2} \approx 0$, indicating that the hexavalent $\mathrm{Cr}$ ion was better than the trivalent $\mathrm{Cr}$ ion for increasing the visible light response. The photoactivity of $\mathrm{Ag}_{2} \mathrm{CrO}_{4}$ for the decomposition of benzene was higher than that of P25 also under UV light irradiation.

Other Ag-based oxides were recently tested for environmental remediation. $\mathrm{AgSbO}_{3}$ prepared by a conventional solid-state reaction method was active for the mineralization of 2-propanol [389]. $\mathrm{Ag}_{2} \mathrm{GeO}_{3}$, with a band gap of $1.8 \mathrm{ev}$, efficiently degraded four typical organic dyes that were mineralized also under irradiation of a commercial white fluorescent lamp [390].

\subsection{Bismuth oxyhalides}

Bismuth oxyhalides ( $\mathrm{BiOX}(\mathrm{X}=\mathrm{Cl}, \mathrm{Br}, \mathrm{I})$ ) are other ternary semiconductors that have been studied as potential candidates for photocatalytic applications. All BiOX compounds crystallize in the tetragonal matlockite structure, a layer structure characterized by $\left[\mathrm{Bi}_{2} \mathrm{O}_{2}\right]$ slabs interleaved by double slabs of halogen atoms.

Many solution routes have been applied to synthesize these compounds. Single-crystalline BiOX samples prepared using $\mathrm{NaBiO}_{3}$ and $\mathrm{HX}$ aqueous solutions as raw materials were tested for the photodecomposition of four kinds of typical phenolic endocrine disrupting chemicals [391]. The band-gap values of the oxyhalides were $1.76,2.75$ and $3.19 \mathrm{eV}$, for $\mathrm{BiOI}, \mathrm{BiOBr}$ and $\mathrm{BiOCl}$, respectively. $\mathrm{BiOI}$, with the narrow band gap, was the most efficient to remove the four pollutants under Xenon-light irradiation whilst BiOCl was the worst. Meanwhile, the photoactivity of $\mathrm{BiOCl}$ was higher than that of P25 although their band-gap values were similar.

Zhang et al. [392] synthesized BiOX microspheres with hierarchical superstructures by a one-pot solvothermal process by employing ethylene glycol as solvent. The resulting BiOX samples were well crystallized and the microspheres consisted of nanoplates of several nanometers in thickness. The photocatalytic activities of the various samples were evaluated by the degradation of methyl orange. All the BiOX powders were more active than 
P25 under UV-vis light irradiation and C-doped $\mathrm{TiO}_{2}$ under visible light illumination, respectively. BiOI exhibited the best photoactivity among all the BiOX samples.

An et al. [393] synthesized sheet-shaped $\mathrm{BiOX}(\mathrm{X}=\mathrm{Cl}, \mathrm{Br}$, and I) samples by reaction between $\mathrm{Bi}_{2} \mathrm{O}_{3}$ and concentrated halogen acid. $\mathrm{BiOBr}$ showed the highest photocatalytic activity in decomposing $\mathrm{RhB}$ under visible light irradiation whilst $\mathrm{BiOCl}$ was the most efficient for the photooxidation of gaseous isopropanol.

$\mathrm{BiOCl}$ has shown high photocatalytic activity for the degradation of various organic pollutants as RhB [394-397], MO [396,398] and phenol [398] under UV illumination. The photoactivity of BiOCl nanofibers obtained by electrospinning was three times greater than that of $\mathrm{Bi}_{2} \mathrm{O}_{3}$ [394] and $\mathrm{BiOCl}$ powders synthesized by a hydrolysis method were more stable and more active than P25 [398]. Another Bi-based oxychloride as $\mathrm{Bi}_{3} \mathrm{O}_{4} \mathrm{Cl}$ was more efficient than anatase $\mathrm{TiO}_{2}$ for degrading methyl orange under UV light illumination [399].

$\mathrm{BiOBr}$ has been recently studied for its excellent performances as visible light-induced photocatalyst. In particular, $\mathrm{BiOBr}$ nanostructures with various morphologies have been employed to obtain large light-harvesting capacities and easy solid/liquid separation. $\mathrm{BiOBr}$ crystalline flakes synthesized using a hydrothermal synthesis process in acidic conditions exhibited noticeable activity under visible light [400]. The diameter and the thickness of the flakes were easily tailored by controlling time and temperature of the hydrothermal treatment.

Zhang et al. [401] synthesized 3D flower-like $\mathrm{BiOBr}$ architectures by an ethylene glycol mediated self-assembly process. These $\mathrm{BiOBr}$ materials, composed of many radially grown nanosheets as petals, showed a much greater activity than BiOBr bulk plates. Hierarchical $\mathrm{BiOBr}$ nanoplate microspheres prepared by a non aqueous sol-gel method were used to remove NO in indoor air under visible light irradiation [402]. The NO removal efficiency of the microspheres was superior to that of BiOBr powders and Degussa P25 as well as $\mathrm{C}$-doped $\mathrm{TiO}_{2}$. The $\mathrm{BiOBr}$ microspheres were stable and kept long-term activity after multiple photocatalytic removal runs.

Shang et al. [403] synthesized a lamellar BiOBr by a hydrothermal route using cetyl trimethyl ammonium bromide (CTAB) which acted not only as the template but also as the $\mathrm{Br}$ source. The activity of the lamellar $\mathrm{BiOBr}$ for the photodegradation of MO was nearly four times higher than that obtained with a $\mathrm{BiOBr}$ sample prepared using $\mathrm{KBr}$ instead of CTAB.

Among the bismuth oxyhalides, BiOI has the smallest band gap $(\sim 1.8 \mathrm{eV})$ whilst BiOF has the largest value $(\sim 3.4 \mathrm{eV})[404]$. BiOI nanosheets exhibited a high photocatalytic performance to remove sodium pentachlorophenate from an aqueous solution under simulated solar light irradiation [405]. BiOF was found to be an effective photocatalyst for the degradation of many organic pollutants as phenol, MO, salicylic acid and RhB in aqueous media and benzene in air by using a $254 \mathrm{~nm}$ illumination [406].

Solid solutions between $\mathrm{BiOCl}$ and $\mathrm{BiOI}, x \mathrm{BiOI}-(1-x) \mathrm{BiOCl}$, with $x=0.2,0.4,0.6,0.8$ showed high efficiency for the degradation of MO under visible light irradiation [407]. The optical band gaps of the samples were in the range $1.92-2.31 \mathrm{eV}$. The photodegradation ability rose monotonically as the value of $x$ increased but the photoactivity of $\mathrm{BiOI}(x=1)$ was lower than that of the four $x \mathrm{BiOI}-(1-x) \mathrm{BiOCl}$ samples. Similar results were obtained with solid solutions between $\mathrm{BiOBr}$ and $\mathrm{BiOI}$ [408]. BiOBr was less active than the $x \mathrm{BiOBr}-(1-x) \mathrm{BiOI}$ samples under visible light illumination but was more active under UV illumination.

\subsection{Indium hydroxides}

$\operatorname{In}(\mathrm{OH})_{3}$ is a wide band gap $\left(E_{\mathrm{g}}=5.15 \mathrm{eV}\right)$ ternary semiconductor that has been tested successfully for the photoinduced oxidation of benzene. Nanometer $\operatorname{In}(\mathrm{OH})_{3}$ synthesized by peptization of a colloidal precipitate under ultrasound radiation [409] and single-crystalline $\operatorname{In}(\mathrm{OH})_{3}$ nanocubes synthesized by a two-step hydrothermal process [410] were highly photoactive and stable for the gas phase removal of benzene under $254 \mathrm{~nm}$ UV light irradiation, even in dry $\mathrm{O}_{2}$ atmosphere. The comparison with the results obtained with Degussa P25 showed that both the conversion of benzene and the mineralization yield were notably accelerated in the presence of $\operatorname{In}(\mathrm{OH})_{3}$. The superior photooxidation power of $\operatorname{In}(\mathrm{OH})_{3}$ was attributed to the more positive potential of the photogenerated holes. Nanosized porous $\operatorname{In}(\mathrm{OH})_{3}$ samples with high surface areas were active for the decomposition of acetone, benzene, and toluene [411].

Also InOOH, an oxyhydroxide with a band gap of $3.7 \mathrm{eV}$, showed photocatalytic activity for the degradation of benzene [412]. The conversion of the pollutant under $300 \mathrm{~nm}$ UV light irradiation was comparable to that obtained with P25 but the mineralization was higher and no obvious deactivation of InOOH was observed after $30 \mathrm{~h}$ of illumination.

The substitution of $\mathrm{OH}^{-}$with $\mathrm{S}^{2-}$ allows to extend the response of $\operatorname{In}(\mathrm{OH})_{3}$ in the visible light region [413]. Li et al. [414] demonstrated that $\operatorname{In}(\mathrm{OH})_{x} S_{y}$ solid solutions were active for the decomposition of gaseous propanone under visible light irradiation. Hollow $\operatorname{In}(\mathrm{OH})_{x} S_{y}$ nanocubes synthesized by a solution route at $80^{\circ} \mathrm{C}$ exhibited a photocatalytic oxidation activity for RhB in water and NO in air much higher than that of P25 and the most active $\mathrm{In}(\mathrm{OH})_{x} \mathrm{~S}_{y}$ sample prepared hydrothermally at $180^{\circ} \mathrm{C}$ [415].

\section{Quaternary compounds}

\subsection{Quaternary oxides}

Single-phase quaternary oxide materials have been recently studied with the aim to develop novel photocatalysts showing high activity in the visible light region. Luan and coworkers [416-425] synthesized various series of these compounds utilizing binary oxides as the starting materials. In particular, these series contained $\mathrm{Ta}\left(\mathrm{Bi}_{2} \mathrm{MTaO}_{7}\left(\mathrm{M}=\mathrm{Ga}\right.\right.$, In, La, Y)) [416-418], Nb $\left(\mathrm{M}_{2} \mathrm{BiNbO}_{7}(\mathrm{M}=\mathrm{In}\right.$ and $\mathrm{Ga})$ ) [419], $\mathrm{V}\left(\mathrm{Bi}_{2} \mathrm{MVO}_{7}(\mathrm{M}=\mathrm{Ga}, \mathrm{Fe}, \mathrm{Al}, \mathrm{Sb})\right.$ ) [420-423] or $\mathrm{Sb}$ $\left(\mathrm{Y}_{2} \mathrm{MSbO}_{7}(\mathrm{M}=\mathrm{Fe}, \mathrm{In})\right)[424,425]$. The materials were tested for the degradation of $\mathrm{MB}$ or RhB under visible irradiation. The solid-state reaction among single-metal oxide counterparts allowed to tune the band gap of the final multiple-metal oxides. The comparison among the performances of compounds of the same series showed that the photoactivity of the various samples generally increased as the $E_{\mathrm{g}}$ value diminished. Other quaternary oxides as $\mathrm{Ga}_{2} \mathrm{BiTaO}_{7}$ [426], $\mathrm{Gd}_{2} \mathrm{YSbO}_{7}$ [427], $\mathrm{Gd}_{2} \mathrm{BiSbO}_{7}$ [427] and $\mathrm{Bi}_{2} \mathrm{YVO}_{8}$ [428] were active under visible light illumination.

$\mathrm{Nb}$-containing oxides as $\mathrm{CsBiNb}_{2} \mathrm{O}_{7}, \mathrm{CsBi}_{2} \mathrm{Nb}_{5} \mathrm{O}_{16}$, and $\mathrm{PbBi}_{2} \mathrm{Nb}_{2} \mathrm{O}_{9}$ were examined for the visible light decomposition of gaseous 2-propanol. The photocatalytic activity of $\mathrm{CsBi}_{2} \mathrm{Nb}_{5} \mathrm{O}_{16}$ was higher than that of $\mathrm{CsBiNb}_{2} \mathrm{O}_{7}$ [429] and $\mathrm{PbBi}_{2} \mathrm{Nb}_{2} \mathrm{O}_{9}\left(E_{\mathrm{g}}=2.88 \mathrm{eV}\right)$ was much more active than $\mathrm{TiO}_{2-x} \mathrm{~N}_{x}$ $\left(E_{\mathrm{g}}=2.73 \mathrm{eV}\right)$ [430]. $\mathrm{RbBi}_{2} \mathrm{Nb}_{5} \mathrm{O}_{16}$ and $\mathrm{RbBiNb}_{2} \mathrm{O}_{7}$ decomposed gaseous acetaldehyde and $\mathrm{RbBi}_{2} \mathrm{Nb}_{5} \mathrm{O}_{16}$ showed a higher photoactivity than $\mathrm{RbBiNb}_{2} \mathrm{O}_{7}$ in accordance with their different absorption properties [431].

$\mathrm{LiBi}_{4} \mathrm{M}_{3} \mathrm{O}_{14}(\mathrm{M}=\mathrm{Nb}$, Ta $)$ samples were tested for the degradation of various dyes and phenolic compounds under UV irradiation [432]. The measured band-gap values of $\mathrm{LiBi}_{4} \mathrm{Ta}_{3} \mathrm{O}_{14}$ and $\mathrm{LiBi}_{4} \mathrm{Nb}_{3} \mathrm{O}_{14}$ were 3.5 and $3.0 \mathrm{eV}$, respectively. Both materials exhibited reasonable photocatalytic activity in degrading some of the dyes despite their low surface area. $\mathrm{LiBi}_{4} \mathrm{Nb}_{3} \mathrm{O}_{14}$ was more efficient for the degradation of the phenolic compounds, due to its lower band gap and preferential affinity of niobium for the phenolic functional groups. 
$\mathrm{Ba}_{2} \mathrm{RBiO}_{6}(\mathrm{R}=\mathrm{La}, \mathrm{Ce}, \mathrm{Nd}, \mathrm{Sm}, \mathrm{Eu}, \mathrm{Gd}$, Dy) samples with a double-perovskite structure showed very high activities for the degradation of MB and gaseous 2-propanol under visible light illumination [433].

The photocatalytic activities of the materials prepared by solidstate reactions at high temperatures are limited by their low specific surface area. Garza-Tovar et al. [434] reported an alternative sol-gel route for the preparation of $\mathrm{Bi}_{2} \mathrm{MNbO}_{7}(\mathrm{M}=\mathrm{Al}$, In, $\mathrm{Fe}$, $\mathrm{Sm}$ ) samples by using metalorganic precursors. The sol-gel materials annealed at $400^{\circ} \mathrm{C}$ exhibited better performance for the MB degradation under UV illumination than that of samples prepared by solid-state reaction or $\mathrm{P} 25 . \mathrm{Bi}_{2} \mathrm{InTaO}_{7}$ obtained by the sol-gel method showed a high efficiency for the UV-induced degradation of Alizarin Red S [435].

Li et al. [436] synthesized polycrystalline $\mathrm{Ag}_{2} \mathrm{ZnGeO}_{4}$ at $220^{\circ} \mathrm{C}$ by the cation exchange method with $\mathrm{Na}_{2} \mathrm{ZnGeO}_{4}$ as the parent compound. The $\mathrm{Ag}_{2} \mathrm{ZnGeO}_{4}$ sample showed good activity for the photodegradation of RhB and Orange II. After $360 \mathrm{~min}$ of visible light $(\lambda>420 \mathrm{~nm})$ irradiation, RhB was completely degraded and $69.2 \%$ of Orange II was converted.

\subsection{Quaternary oxyhalides}

Recently, Lin et al. [437-439] tested layered Bi-based oxyhalides for the degradation of MO under UV and visible illumination. $\mathrm{Bi}_{4} \mathrm{NbO}_{8} \mathrm{Cl}\left(E_{\mathrm{g}}=2.38 \mathrm{eV}\right)$ showed an excellent visible light efficiency and was more active than the ternary oxychloride $\mathrm{Bi}_{3} \mathrm{O}_{4} \mathrm{Cl}\left(E_{\mathrm{g}}=2.80 \mathrm{eV}\right)$ [437]. The photoactivity followed the order: $\mathrm{Bi}_{4} \mathrm{NbO}_{8} \mathrm{Cl}>\mathrm{Bi}_{3} \mathrm{O}_{4} \mathrm{Cl}>$ anatase $\mathrm{TiO}_{2}$, different from the order found under UV light illumination $\left(\mathrm{Bi}_{3} \mathrm{O}_{4} \mathrm{Cl}>\right.$ anatase $\left.\mathrm{TiO}_{2}>\mathrm{Bi}_{4} \mathrm{NbO}_{8} \mathrm{Cl}\right)$. Analogous results were obtained with $\mathrm{Na}_{0.5} \mathrm{Bi}_{1.5} \mathrm{O}_{2} \mathrm{Cl}\left(E_{\mathrm{g}}=3.04 \mathrm{eV}\right)$ that was more efficient than $\mathrm{BiOCl}\left(E_{\mathrm{g}}=3.44 \mathrm{eV}\right)$ under visible light illumination $\left(\mathrm{Na}_{0.5} \mathrm{Bi}_{1.5} \mathrm{O}_{2} \mathrm{Cl}>\mathrm{TiO}_{2}>\mathrm{BiOCl}\right)$ but less active under $\mathrm{UV}$ light $\left(\mathrm{BiOCl}>\mathrm{Na}_{0.5} \mathrm{Bi}_{1.5} \mathrm{O}_{2} \mathrm{Cl}>\mathrm{TiO}_{2}\right)$ [438].

$\mathrm{PbBiO}_{2} \mathrm{Br}$, tested for the degradation of $\mathrm{MB}$ and $\mathrm{MO}$, was more photocatalytically active than $\mathrm{PbBi}_{2} \mathrm{Nb}_{2} \mathrm{O}_{9}, \mathrm{TiO}_{2-x} \mathrm{~N}_{x}$ and $\mathrm{BiOBr}$ under visible light [439].

\section{Conclusions}

This review summarizes most of the papers concerning the efforts to obtain valid alternative materials to $\mathrm{TiO}_{2}$ that, until a few years ago, has been used as an almost unique photocatalyst for environmental remediation by using both artificial and natural UV-vis irradiation.

Due to the drawbacks of bare $\mathrm{TiO}_{2}$, in particular the small fraction of photons absorbed in the visible region and the high electron-hole recombination rate, work has been undertaken to obtain visible light-active $\mathrm{TiO}_{2}$ by using several strategies as for instance surface modification by sensitizers, coupling with other semiconductors, doping with metal or not metal species. These efforts have afforded only modest improvements in the photoreactivity because the increased absorption of visible light cannot be straightforwardly related to the reaction rate and the foreign species often work as recombination centers for the photogenerated electron/hole pairs. Consequently, an increasing amount of works has been addressed in searching alternative materials to $\mathrm{TiO}_{2}$. Anyway, the information gathered in this review indicates that a valid alternative to the use of $\mathrm{TiO}_{2}$ for photocatalytic detoxification has not been up to now found, although the intrinsic electronic and physico-chemical properties of some compounds reported in the literature suggest their possible use in particular niche environmental applications, in addition to their employment in photocells for water splitting.
Notably, many papers are focused on the preparation aspects of the catalysts giving limited effort to the thorough testing of the materials. It is rarely reported whether the reactivity of the photocatalysts was determined in the presence or absence of oxygen which can strongly affect the photoactivity and stability of the materials to be used for environmental remediation. Moreover, the incident light dependence of the photocatalytic process has been seldom examined.

Generally, the reacting photocatalytic systems here described were not capable to give rise to a total degradation of the pollutants both in liquid-and gas-solid regimes and only decolorization was often observed when dyes were used as probe molecules. Moreover, the preparation of some materials is expensive and sometimes the specific surface areas and the extent of adsorption of the starting pollutant species are too small to ensure an acceptable photocatalytic activity. The main advantages of a photodegradative process as a clean degradative route should be the absence of foreign chemical reagents, organic solvents, photocorrosion and deactivation of the photocatalyst under illumination. Finally, concerning the process economy, especially in scaled up processes, not only employment of sunlight, but also concentration of the solar photons and assembling of pilot photoreactors should be considered. The achievement of these goals when materials different from $\mathrm{TiO}_{2}$ are used seems still far.

\section{Acknowledgments}

Authors wish to thank University of Palermo for financial support.

\section{References}

[1] M.R. Hoffmann, S.T. Martin, W.Y. Choi, D.W. Bahnemann, Environmental applications of semiconductor photocatalysis, Chem. Rev. 95 (1995) 69-96.

[2] K. Rajeshwar, M.E. Osugi, W. Chanmanee, C.R. Chenthamarakshan, M.V.B. Zanoni, P. Kajitvichyanukul, R. Krishnan-Ayer, Heterogeneous photocatalytic treatment of organic dyes in air and aqueous media, J. Photochem. Photobiol. C: Photochem. Rev. 9 (2008) 171-192.

[3] H.Zhang, G. Chen, D.W. Bahnemann, Photoelectrocatalytic materials for environmental applications, J. Mat. Chem. 19 (2009) 5089-5121.

[4] M.D. Hernández-Alonso, F. Fresno, S. Suárez, J.M. Coronado, Development of alternative photocatalysts to $\mathrm{TiO}_{2}$ : challenges and opportunities, Energy Environ. Sci. 2 (2009) 1231-1257.

[5] R. Vinu, G. Madras, Environmental remediation by photocatalysis, J. Indian Inst. Sci. 90 (2010) 189-230.

[6] T.K. Tseng, Y.S. Lin, Y.J. Chen, H. Chu, A review of photocatalysts prepared by sol-gel method for VOCs removal, Int. J. Mol. Sci. 11 (2010) 2336-2361.

[7] J.H. Kou, J. Gao, Z.S. Li, Z.G. Zou, Research on photocatalytic degradation properties of organics with different new photocatalysts, Curr. Org. Chem. 14 (2010) 728-744.

[8] D. Zhang, G. Li, J.C. Yu, Inorganic materials for photocatalytic water disinfection, J. Mater. Chem. 20 (2010) 4529-4536.

[9] J. Matos, J. Laine, J.-M. Herrmann, Synergy effect in the photocatalytic degradation of phenol on a suspended mixture of titania and activated carbon, Appl. Catal. B: Environ. 18 (1998) 281-291.

[10] J. Matos, J. Laine, J.-M. Herrmann, Effect of the type of activated carbons on the photocatalytic degradation of aqueous organic pollutants by UV-irradiated titania, J. Catal. 200 (2001) 10-20.

[11] J. Araña, J.M. Doña-Rodríguez, E. Tello Rendón, C. Garriga i Cabo, O. GonzálezDíaz, J.A. Herrera-Melián, J. Pérez-Peña, G. Colón, J.A. Navío, $\mathrm{TiO}_{2}$ activation by using activated carbon as a support. Part II. Photoreactivity and FTIR study, Appl. Catal. B: Environ. 44 (2003) 153-160.

[12] J. Matos, J. Laine, J.-M. Herrmann, D. Uzcategui, J.L. Brito, Influence of activated carbon upon titania on aqueous photocatalytic consecutive runs of phenol photodegradation, Appl. Catal. B: Environ. 70 (2007) 461-469.

[13] J. Matos, E. García-López, L. Palmisano, A. García, G. Marcì, Influence of activated carbon in $\mathrm{TiO}_{2}$ and $\mathrm{ZnO}$ mediated photo-assisted degradation of 2-propanol in gas-solid regime, Appl. Catal. B: Environ. 99 (2010) 170-180.

[14] M. Inagaki, F. Kojin, B. Tryba, M. Toyoda, Carbon-coated anatase: the role of the carbon layer for photocatalytic performance, Carbon 43 (2005) 1652-1659.

[15] T. Tsumura, N. Kojitani, I. Izumi, N. Iwashita, M. Toyoda, M. Inagaki, Carbon coating of anatase type $\mathrm{TiO}_{2}$ and photoactivity, J. Mater. Chem. 12 (2002) 1391-1396.

[16] B. Tryba, A.W. Morawski, T. Tsumura, M. Toyoda, M. Inagaki, Hybridization of adsorptivity with photocatalytic activity - carbon-coated anatase, J. Photochem. Photobiol. A: Chem. 167 (2004) 127-135. 
[17] T. Tsumura, N. Kojitani, H. Umemura, M. Toyoda, M. Inagaki, Composites between photoactive anatase-type $\mathrm{TiO}_{2}$ and adsorptive carbon, Appl. Surf. Sci. 196 (2002) 429-436.

[18] J. Zhong, F. Chen, J. Zhang, Carbon-deposited $\mathrm{TiO}_{2}$ : synthesis, characterization and visible photocatalytic performance, J. Phys. Chem. C 111 (2010) 933-939.

[19] B. Tryba, T. Tsumura, M. Janus, A.W. Morawski, M. Inagaki, Carbon-coated anatase: adsorption and decomposition of phenol in water, Appl. Catal. B: Environ. 50 (2004) 177-183.

[20] N. Takeda, T. Torimoto, S. Sampath, S. Kuwabata, H. Yoneyama, Effect of inert supports for titanium dioxide loading on enhancement of photodecomposition rate of gaseous propionaldehyde, J. Phys. Chem. 99 (1995) 9986-9991.

[21] T. Torimoto, S. Ito, S. Kuwabata, H. Yoneyama, Effects of adsorbents used as supports for titanium dioxide loading on photocatalytic degradation of propyzamide, Environ. Sci. Technol. 30 (1996) 1275-1281.

[22] T. Torimoto, Y. Okawa, N. Takeda, H. Yoneyama, Effect of activated carbon content in $\mathrm{TiO}_{2}$-loaded activated carbon on photodegradation behaviors of dichloromethane, J. Photochem. Photobiol. A: Chem. 103 (1997) 153-157.

[23] B. Tryba, A.W. Morawski, M. Inagaki, Application of $\mathrm{TiO}_{2}$-mounted activated carbon to the removal of phenol from water, Appl. Catal. B: Environ. 41 (2003) 427-433.

[24] S. Nagaoka, Y. Hamasaki, S. Ishihara, M. Nagata, K. Iio, C. Nagasawa, H. Ihara, Preparation of carbon/TiO $\mathrm{T}_{2}$ microsphere composites from cellulose $/ \mathrm{TiO}_{2}$ microsphere composites and their evaluation, J. Mol. Catal. A: Chem. 177 (2002) 255-263.

[25] C.H. Ao, S.C. Lee, Enhancement effect of $\mathrm{TiO}_{2}$ immobilized on activated carbon filter for the photodegradation of pollutants at typical indoor air level, Appl. Catal. B: Environ. 44 (2003) 191-205.

[26] S.X. Liu, X.Y. Chen, X. Chen, $\mathrm{A} \mathrm{TiO}_{2} / \mathrm{AC}$ composite photocatalyst with high activity and easy separation prepared by a hydrothermal method, J. Hazard. Mater. 143 (2007) 257-263.

[27] Y. Li, S. Zhang, Q. Yu, W. Yin, The effects of activated carbon supports on the structure and properties of $\mathrm{TiO}_{2}$ nanoparticles prepared by a sol-gel method, Appl. Surf. Sci. 253 (2007) 9254-9258.

[28] Y. Li, X. Li, J. Li, J. Yin, $\mathrm{TiO}_{2}$-coated active carbon composites with increased photocatalytic activity prepared by a properly controlled sol-gel method, Mater. Lett. 59 (2005) 2659-2663.

[29] X. Wang, Z. Hu, Y. Chen, G. Zhao, Y. Liu, Z. Wen, A novel approach towards high-performance composite photocatalyst of $\mathrm{TiO}_{2}$ deposited on activated carbon, Appl. Surf. Sci. 255 (2009) 3953-3958.

[30] J.A. Toledo, M.A. Cortes-Jacome, S.L. Orozco-Cerros, E. Montiel-Palacios, R. Suarez-Parra, C. Angeles-Chavez, J. Navarrete, E. López-Salinas, Assessing optimal photoactivity on titania nanotubes using different annealing temperatures, Appl. Catal. B: Environ. 100 (2011) 47-54

[31] Z. Liu, X. Zhang, S. Nishimoto, M. Jin, D.A. Tryk, T. Murakami, A. Fujishima, Highly ordered $\mathrm{TiO}_{2}$ nanotube arrays with controllable length for photoelectrocatalytic degradation of phenol, J. Phys. Chem. C 112 (2008) 253-259.

[32] H. Zhuang, C. Lin, Y. Lai, L. Sun, J. Li, Some critical structure factors of titanium oxide nanotube array in its photocatalytic activity, Environ. Sci. Technol. 41 (2007) 4735-4740.

[33] H. Xu, G. Vanamu, Z. Nie, H. Konishi, R. Yeredla, J. Phillips, Y. Wang, Photocatalytic oxidation of a volatile organic component of acetaldehyde using titanium oxide nanotubes, J. Nanomater. 2006 (2006) 1-8, Article ID 78902.

[34] J.M. Macak, M. Zlamal, J. Krysa, P. Schmuki, Self-organized $\mathrm{TiO}_{2}$ nanotube layers as highly efficient photocatalysts, Small 3 (2007) 300-304.

[35] Y.Lai, L. Sun, Y.Chen, H.Zhuang, C. Lin, J.W. Chin, Effects of the structure of $\mathrm{TiO}_{2}$ nanotube array on Ti substrate on its photocatalytic activity, J. Electrochem. Soc. 153 (2006) D123-D128.

[36] L.K. Tan, M.K. Kumar, W.W. An, H. Gao, Transparent, well-aligned $\mathrm{TiO}_{2}$ nanotube arrays with controllable dimensions on glass substrates for photocatalytic applications, ACS Appl. Mater. Interfaces 2 (2010) 498-503.

[37] Z. Liu, X. Zhang, S. Nishimoto, T. Murakami, A. Fujishima, Efficient photocatalytic degradation of gaseous acetaldehyde by highly ordered $\mathrm{TiO}_{2}$ nanotube arrays, Environ. Sci. Technol. 42 (2008) 8547-8551.

[38] K.L. Schulte, P.A. DeSario, K.A. Gray, Effect of crystal phase composition on the reductive and oxidative abilities of $\mathrm{TiO}_{2}$ nanotubes under UV and visible, Appl. Catal. B: Environ. 97 (2010) 354-360.

[39] N. Bouazza, M. Ouzine, M.A. Lillo-Rodenas, D. Eder, A. Linares-Solano, $\mathrm{TiO}_{2}$ nanotubes and $\mathrm{CNT}-\mathrm{TiO}_{2}$ hybrid materials for the photocatalytic oxidation of propene at low concentration, Appl. Catal. B: Environ. 92 (2009) 377-383.

[40] D. Eder, Carbon nanotube-inorganic hybrids, Chem. Rev. 110 (2010) 1348-1385.

[41] Y. Yu, J.C. Yu, J.-G. Yu, Y.-C. Kwok, Y.-K. Che, J.-C. Zhao, L. Ding, W.-K. Ge, P.-K. Wong, Enhancement of photocatalytic activity of mesoporous $\mathrm{TiO}_{2}$ by using carbon nanotubes, Appl. Catal. A: Gen. 289 (2005) 186-196.

[42] W. Wang, P. Serp, P. Kalck, J.L. Faria, Photocatalytic degradation of phenol on MWNT and titania composite catalysts prepared by a modified sol-gel method, Appl. Catal. B: Environ. 56 (2005) 305-312.

[43] W. Wang, P. Serp, P. Kalck, J.L. Faria, Visible light photodegradation of phenol on $\mathrm{MWNT}^{-\mathrm{TiO}_{2}}$ composite catalysts prepared by a modified sol-gel method, J. Mol. Catal. A: Chem. 235 (2005) 194-199.

[44] W. Wang P. Serp, P. Kalck, C.G. Silva, J.L. Faria, Preparation and characterization of nanostructured MWCNT- $\mathrm{TiO}_{2}$ composite materials for photocatalytic water treatment applications, Mater. Res. Bull. 43 (2008) 958-967.

[45] Y. Yao, G. Li, S. Ciston, R.M. Lueptow, K.A. Gray, Photoreactive $\mathrm{TiO}_{2} /$ carbon nanotube composites: synthesis and reactivity, Environ. Sci. Technol. 42 (2008) 4952-4957.
[46] C.-Y. Yen, Y.-F. Lin, C.-H. Hung, Y.-H. Tseng, C.-C.M. Ma, M.-C. Chang, H. Shao The effects of synthesis procedures on the morphology and photocatalytic activity of multi-walled carbon nanotubes $/ \mathrm{TiO}_{2}$ nanocomposites, Nanotechnology 19 (2008) 045604-045611.

[47] H. Yu, X. Quan, S. Chen, H. Zhao, Y. Zhang, $\mathrm{TiO}_{2}$-carbon nanotube heterojunction arrays with a controllable thickness of $\mathrm{TiO}_{2}$ layer and their first application in photocatalysis, J. Photochem. Photobiol. A: Chem. 200 (2008) 301-306.

[48] Q. Wang, D. Yang, D. Chen, Y. Wang, Z. Jiang, Synthesis of anatase titaniacarbon nanotubes nanocomposites with enhanced photocatalytic activity through a nanocoating-hydrothermal process, J. Nanopart. Res. 9 (2007) 1087-1096.

[49] W.-C. Oh, M.-L. Chen, Synthesis and characterization of $\mathrm{CNT} / \mathrm{TiO}_{2}$ composites thermally derived from MWCNT and titanium(IV) $n$-butoxide, Bull. Korean Chem. Soc. 29 (2008) 159-164.

[50] M.-L. Chen, F.-J. Zhang, W.-C. Oh, Photocatalytic degradation of methylene blue by $\mathrm{CNT} / \mathrm{TiO}_{2}$ composites prepared from MWCNT and titanium(IV) nbutoxide with benzene, J. Korean Ceram. Soc. 45 (2008) 651-657.

[51] Y. Yu, J.C. Yu, C.-Y. Chan, Y.-K. Che, J.-C. Zhao, L. Ding, W.-K. Ge, P.-K. Wong, Enhancement of adsorption and photocatalytic activity of $\mathrm{TiO}_{2}$ by using carbon nanotubes for the treatment of azo dye, Appl. Catal. B: Environ. 61 (2005) $1-11$.

[52] A. Di Paola, M. Bellardita, R. Ceccato, L. Palmisano, F. Parrino, Highly active photocatalytic $\mathrm{TiO}_{2}$ powders obtained by thermohydrolysis of $\mathrm{TiCl}_{4}$ in water, J. Phys. Chem. C 113 (2009) 15166-15174.

[53] S. Suzuki, C. Bower, Y. Watanabe, O. Zhou, Work functions and valence band states of pristine and Cs-intercalated single-walled carbon nanotube bundles, Appl. Phys. Lett. 76 (2000) 4007-4009.

[54] Y. Luo, J. Liu, X. Xia, X. Li, T. Fang, S. Li, Q. Ren, J. Li, Z. Jia, Fabrication and characterization of $\mathrm{TiO}_{2}$ /short MWNTs with enhanced photocatalytic activity, Mater. Lett. 61 (2007) 2467-2472.

[55] B. Gao, C. Peng, G.Z. Chen, G. Li Puma, Photo-electro-catalysis enhancement on carbon nanotubes/titanium dioxide $\left(\mathrm{CNTs} / \mathrm{TiO}_{2}\right)$ composite prepared by a novel surfactant wrapping sol-gel method, Appl. Catal. B: Environ. 85 (2008) $17-23$.

[56] B. Gao, G.Z. Chen, G. Li Puma, Carbon nanotubes/titanium dioxide (CNTs/ $\left./ \mathrm{TiO}_{2}\right)$ nanocomposites prepared by conventional and novel surfactant wrapping sol-gel methods exhibiting enhanced photocatalytic activity, Appl. Catal. B Environ. 89 (2009) 503-509.

[57] G. Yu, J. Gao, J.C. Hummelen, F. Wudl, A.J. Heeger, Polymer photovoltaic cells: enhanced efficiencies via a network of internal donor-acceptor heterojunctions, Science 270 (1995) 1789-1791.

[58] S. Shanmugam, A. Gabashvili, D.S. Jacob, J.C. Yu, A. Gedanken, Synthesis and characterization of $\mathrm{TiO}_{2} @ \mathrm{C}$ core-shell composite nanoparticles and evaluation of their photocatalytic activities, Chem. Mater. 18 (2006) 2275-2282.

[59] L.-W. Zhang, H.-B. Fu, Y.-F. Zhu, Efficient $\mathrm{TiO}_{2}$ photocatalysts from surface hybridization of $\mathrm{TiO}_{2}$ particles with graphite-like carbon, Adv. Funct. Mater. 18 (2008) 2180-2189.

[60] Z. Lei, Y. Xiao, L. Dang, W. You, G. Hu, J. Zhang, Nickel-catalyzed fabrication of $\mathrm{SiO}_{2}, \mathrm{TiO}_{2} /$ graphitized carbon, and the resultant graphitized carbon with periodically macroporous structure, Chem. Mater. 19 (2007) 477-484.

[61] L. Yang, S. Luo, S. Liu, Q. Cai, Graphitized carbon nanotubes formed in $\mathrm{TiO}_{2}$ nanotube arrays: a novel functional material with tube-in-tube nanostructure, J. Phys. Chem. C 112 (2008) 8939-8943.

[62] G.D. Panagiotou, M.D. Tzirakis, J. Vakros, L. Loukatzikou, M. Orfanopoulos, C. Kordulis, A. Lycourghiotis, Development of [60]fullerene supported on silica catalysts for the photo-oxidation of alkenes, Appl. Catal. A 372 (2010) 16-25.

[63] M.D. Tizirakis, J. Vakros, L. Loukatzikou, V. Amargianitakis, M. Orfanopoulos, C. Kordulis, A. Lycourghiotis, $\gamma$-alumina-supported [60]fullerene catalysts: synthesis, properties and applications in the photoosidation of alkenes, J. Mol Catal. A: Chem. 316 (2010) 65-74.

[64] V. Apostolopoulou, J. Vakros, C. Kordulis, A. Lycourghiotis, Preparation and characterization of [60]fullerene nanoparticles supported on titania used as photocatalyst, Colloids Surf. A. 349 (2009) 189-194.

[65] P.V. Kamat, I. Bedja, S. Hotchandani, Photoinduced charge transfer between carbon and semiconductor clusters. One-electron reduction of $C_{60}$ in colloidal $\mathrm{TiO}_{2}$ semiconductor suspensions, J. Phys. Chem. 98 (1994) 9137-9142.

[66] V. Krishna, N. Noguchi, B. Koopman, B. Moudgil, Enhancement of titanium dioxide photocatalysis by water-soluble fullerenes, J. Colloid Interf. Sci. 304 (2006) 166-171.

[67] W.-C. Oh, A.-R. Jung, W.-B. Ko, Preparation of fullerene $/ \mathrm{TiO}_{2}$ composite and its photocatalytic effect, J. Ind. Eng. Chem. 13 (2007) 1208-1214.

[68] S. Mu, Y. Long, S. Kang, J. Mu, Surface modification of $\mathrm{TiO}_{2}$ nanoparticles with a $\mathrm{C}_{60}$ derivative and enhanced photocatalytic activity for the reduction of acqueous $\mathrm{Cr}(\mathrm{VI})$ ions, Catal. Commun. 11 (2010) 741-744.

[69] Y. Park, N.J. Singh, K.S. Kim, T. Tachikawa, T. Majima, W. Choi, Fullerol-titania charge transfer mediated photocatalysis working under visible light, Chem. Eur. J. 15 (2009) 10843-10850.

[70] Y. Wang, R. Shi, J. Lin, Y. Zhu, Significant photocatalytic enhancement in methylene blue degradation of $\mathrm{TiO}_{2}$ photocatalysts via graphene-like carbon in situ hybridization, Appl. Catal. B: Environ. 100 (2011) 179-183.

[71] M. Ishigami, J.H. Chen, W.G. Cullen, M.S. Fuhrer, E.D. Williams, Atomic struc ture of graphene on $\mathrm{SiO}_{2}$, Nano Lett. 7 (2007) 1643-1648.

[72] H. Zhang, X. Lv, Y. Li, Y. Wang, J. Li, P25-graphene composite as a high performance photocatalyst, ACS Nano 4 (2010) 380-386. 
[73] M.A. Lillo-Ródenas, N. Bouazza, A. Berenguer-Murcia, J.J. Linares-Salinas, P. Soto, A. Linares-Solano, Photocatalytic oxidation of propene at low concentration, Appl. Catal. B: Environ. 71 (2007) 298-309.

[74] N. Bouazza, M.A. Lillo-Ródenas, A. Linares-Solano, Enhancement of the photocatalytic activity of pelletized $\mathrm{TiO}_{2}$ for the oxidation of propene at low concentration, Appl. Catal. B: Environ. 77 (2008) 284-293.

[75] S. Sato, Photocatalytic activity of $\mathrm{NO}_{x}$-doped $\mathrm{TiO}_{2}$ in the visible light region, Chem. Phys. Lett. 123 (1986) 126-128.

[76] R. Asahi, T. Morikawa, T. Ohwaki, K. Aoki, Y. Taga, Visible-light photocatalysis in nitrogen-doped titanium oxides, Science 293 (2001) 269-271.

[77] Y. Xin, H. Liu, L. Han, Study on mechanism of enhanced photocatalytic performance of $\mathrm{N}$-doped $\mathrm{TiO}_{2} / \mathrm{Ti}$ photoelectrodes by theoretical and experimental methods, J. Mater. Sci. 46 (2011) 7822-7829.

[78] A.V. Emeline, V.N. Kuznetsov, V.K. Rybchuk, N. Serpone, Visible-light-active titania photocatalysts: the case of $\mathrm{N}$-doped $\mathrm{TiO}_{2} \mathrm{~S}-$ properties and some fundamental issues, Int. J. Photoenergy 2008 (2008) 1-19, Article ID 258394.

[79] N. Serpone, Is the band gap of pristine $\mathrm{TiO}_{2}$ narrowed by anion- and cationdoping of titanium dioxide in second-generation photocatalysts? J. Phys. Chem. B 110 (2006) 24287-24293.

[80] C. Di Valentin, E. Finazzi, G. Pacchioni, A. Selloni, S. Livraghi, M.C. Paganini, E. Giamello, N-doped $\mathrm{TiO}_{2}$ : theory and experiment, Chem. Phys. 339 (2007) 44-56.

[81] H. Irie, Y. Watanabe, K. Hashimoto, Nitrogen-concentration dependence on photocatalytic activity of $\mathrm{TiO}_{2-x} \mathrm{~N}_{x}$ powders, J. Phys. Chem. B 107 (2003) 5483-5486.

[82] T. Ihara, M. Miyoshi, Y. Iriyama, O. Matsumoto, S. Sugihara, Visible-light-active titanium oxide photocatalyst realized by an oxygen-deficient structure and by nitrogen doping, Appl. Catal. B 42 (2003) 403-409.

[83] B. Kosowska, S. Mozia, A.W. Morawski, B. Grzmil, M. Janus, K. Kałucki, The preparation of $\mathrm{TiO}_{2}$-nitrogen doped by calcination of $\mathrm{TiO}_{2} \cdot x \mathrm{H}_{2} \mathrm{O}$ under ammonia atmosphere for visible light photocatalysis, Sol. Energy Mater. Sol. Cells 88 (2005) 269-280.

[84] F. Spadavecchia, G. Cappelletti, S. Ardizzone, C.L. Bianchi, S. Cappelli, C. Oliva, P. Scardi, M. Leoni, P. Fermo, Solar photoactivity of nano-N-TiO 2 from tertiary amine: role of defects and paramagnetic species, Appl. Catal. B: Environ. 96 (2010) 314-322

[85] S. Sato, R. Nakamura, S. Abe, Visible-light sensitization of $\mathrm{TiO}_{2}$ photocatalysts by wet-method N doping, Appl. Catal. A: Gen. 284 (2005) 131-137.

[86] J. Ananpattarachai, P. Kajitvichyanukul, S. Seraphin, Visible light absorption ability and photocatalytic oxidation activity of various interstitial N-doped $\mathrm{TiO}_{2}$ prepared from different nitrogen dopants, J. Hazard. Mater. 168 (2009) 253-261.

[87] X. Wang, C. Wang, W. Guo, J. Wang, A novel single-step synthesis of N-doped $\mathrm{TiO}_{2}$ via a sonochemical method, Mater. Res. Bull. 46 (2011) 2041-2044.

[88] R. Kun, S. Tarjan, A. Oszko, T. Seemann, V. Zollmer, M. Busse, I. Dekany, Preparation and characterization of mesoporous $\mathrm{N}$-doped and sulfuric acid treated anatase $\mathrm{TiO}_{2}$ catalysts and their photocatalytic activity under UV and Vis illumination, J. Solid State Chem. 182 (2009) 3076-3084.

[89] S. Livraghi, M.C. Paganini, E. Giamello, A. Selloni, C. Di Valentin, G. Pacchioni, Origin of photoactivity of nitrogen-doped titanium dioxide under visible light, J. Am. Chem. Soc. 128 (2006) 15666-15671.

[90] C. Burda, Y. Lou, X. Chen, A.C.S. Samia, J. Stout, J.L. Gole, Enhanced nitrogen doping in $\mathrm{TiO}_{2}$ nanoparticles, Nano Lett. 3 (2003) 1049-1051.

[91] D. Wu, M. Long, W. Cai, C. Chen, Y. Wu, Low temperature hydrothermal synthesis of $\mathrm{N}$-doped $\mathrm{TiO}_{2}$ photocatalyst with high visible-light activity, J. Alloys Compd. 502 (2010) 289-294.

[92] Y. Zhao, X. Qiu, C. Burda, The effects of sintering on the photocatalytic activity of N-doped $\mathrm{TiO}_{2}$ nanoparticles, Chem. Mater. 20 (2008) 2629-2636.

[93] M. Xing, J. Zhang, F. Chen, New approaches to prepare nitrogen-doped $\mathrm{TiO}_{2}$ photocatalysts and study on their photocatalytic activities in visible light, Appl. Catal. B: Environ. 89 (2009) 563-569.

[94] Y.Q. Wang, X.J. Yu, D.Z. Sun, Synthesis, characterization, and photocatalytic activity of $\mathrm{TiO}_{2-x} \mathrm{~N}_{x}$ nanocatalyst, J. Hazard. Mater. 144 (2007) 328-333.

[95] Y. Cong, J. Zhang, F. Chen, M. Anpo, Synthesis and characterization of nitrogen doped $\mathrm{TiO}_{2}$ nanophotocatalyst with high visible light activity, J. Phys. Chem. C 111 (2007) 6976-6982.

[96] B. Chi, L. Zhao, T. Jin, One-step template-free route for synthesis of mesoporous N-doped titania spheres, J. Phys. Chem. C 111 (2007) 6189-6193.

[97] Y. Huo, Z. Bian, X. Zhang, Y. Jin, J. Zhu, H. Li, Highly active $\mathrm{TiO}_{2-x} \mathrm{~N}_{x}$ visible photocatalyst prepared by N-doping in $\mathrm{Et}_{3} \mathrm{~N} / \mathrm{EtOH}$ fluid under supercritical conditions, J. Phys. Chem. C 112 (2008) 6546-6550.

[98] T. Ihara, N. Miyoshi, Y. Iriyama, O. Matsumoto, S. Sugihara, Visible-light-active titanium oxide photocatalyst realized by an oxygen-deficient structure and by nitrogen doping, Appl. Catal. B 42 (2003) 403-409.

[99] M. Bellardita, M. Addamo, A. Di Paola, L. Palmisano, A.M. Venezia, Preparation of $\mathrm{N}$-doped $\mathrm{TiO}_{2}$ : characterization and photocatalytic performance under UV and visibile light, Phys. Chem. Chem. Phys. 11 (2009) 4084-4093.

[100] A.R. Gandhe, J.B. Fernandes, A simple method to synthesize N-doped rutile titania with enhanced photocatalytic activity in sunlight, J. Solid State Chem. 178 (2005) 2953-2957.

[101] A.R. Gandhe, S.P. Naik, J.B. Fernandes, Selective synthesis of N-doped mesoporous $\mathrm{TiO}_{2}$ phases having enhanced photocatalytic activity, Micropor. Mesopor. Mat. 87 (2005) 103-109.

[102] S. Yin, K. Ihara, Y. Aita, M. Komatsu, T. Sato, Visible-light induced photocatalytic activity of $\mathrm{TiO}_{2-x} \mathrm{~A}_{y}(\mathrm{~A}=\mathrm{N}, \mathrm{S})$ prepared by precipitation route, $\mathrm{J}$. Photochem. Photobiol. A 179 (2006) 105-114.
[103] Z. Wang, F. Zhang, Y. Yiang, J. Cui, Q. Sun, N. Guan, One-pot synthesis of visiblelight-responsive $\mathrm{TiO}_{2}$ in the presence of various amines, Chin. J. Catal. 27 (2006) 1091-1095.

[104] S. Sakthivel, M. Janczarek, H. Kisch, Visible light activity and photoelectrochemical properties of nitrogen-doped $\mathrm{TiO}_{2}$, J. Phys. Chem. B 108 (2004) 19384-19387.

[105] Z.Y. Wang, F.X. Zhang, Y.L. Yang, B. Xue, J. Cui, N.J. Guan, Facile postsynthesis of visible-light-sensitive titanium dioxide/mesoporous SBA-15, Chem. Mater. 19 (2007) 3286-3293.

[106] Y. Aita, M. Komatsu, S. Yin, T. Sato, Phase-compositional control and visible light photocatalytic activity of nitrogen-doped titania via solvothermal process, J. Solid State Chem. 177 (2004) 3235-3238.

[107] J.S. Jang, H.G. Kim, S.M. Ji, S.W. Bae, J.H. Jung, B.H. Shon, J.S. Lee, Formation of crystalline $\mathrm{TiO}_{2-x} \mathrm{~N}_{x}$ and its photocatalytic activity, J. Solid State Chem. 179 (2006) 1067-1075.

[108] M. Chekini, M.R. Mohammadizadeh, S.M.V. Allaei, Photocatalytic and superhydrophilicity properties of $\mathrm{N}$-doped $\mathrm{TiO}_{2}$ nanothin films, Appl. Surf. Sci. 257 (2011) 7179-7183.

[109] J. Xu, W. Dai, J. Li, Y. Cao, H. Li, H. He, K. Fan, Simple fabrication of thermally stable apertured $\mathrm{N}$-doped $\mathrm{TiO}_{2}$ microtubes as a highly efficient photocatalyst under visible light irradiation, Catal. Commun. 9 (2008) 146-152.

[110] S. Hu, A. Wang, X. Li, H. Löwe, Hydrothermal synthesis of well-dispersed ultrafine $\mathrm{N}$-doped $\mathrm{TiO}_{2}$ nanoparticles with enhanced photocatalytic activity under visible light, J. Phys. Chem. Solids 71 (2010) 156-162.

[111] S. Liu, X. Chen, X. Chen, Preparation of N-doped visible-light response nanosize $\mathrm{TiO}_{2}$ photocatalyst using the acid-catalyzed hydrolysis method, Chin. J. Catal. 27 (2006) 697-702.

[112] S. Sakthivel, H. Kisch, Photocatalytic and photoelectrochemical properties of nitrogen-doped titanium dioxide, Chemphyschem 4 (2003) 487-490.

[113] H.M. Yates, M.G. Nolan, D.W. Sheel, M.E. Pemble, The role of nitrogen doping on the development of visible light-induced photocatalytic activity in thin $\mathrm{TiO}_{2}$ films grown on glass by chemical vapour deposition, J. Photochem. Photobiol. A: Chem. 179 (2006) 213-223.

[114] M. Sathish, B. Viswanathan, R.P. Viswanath, Characterization and photocatalytic activity of $\mathrm{N}$-doped $\mathrm{TiO}_{2}$ prepared by thermal decomposition of Ti-melamine complex, Appl. Catal. B: Environ. 74 (2007) 307-312.

[115] Z. He, H.Y. He, Synthesis and photocatalytic property of N-doped $\mathrm{TiO}_{2}$ nanorods and nanotubes with high nitrogen content, Appl. Surf. Sci. 258 (2011) 972-976

[116] J. Xu, Y. Ao, M. Chen, D. Fu, Photoelectrochemical property and photocatalytic activity of $\mathrm{N}$-doped $\mathrm{TiO}_{2}$ nanotube arrays, Appl. Surf. Sci. 256 (2010) 4397-4401.

[117] X. Liu, Z. Liu, J. Zheng, X. Yan, D. Li, S. Chen, W. Chu, Characteristics of N-doped $\mathrm{TiO}_{2}$ nanotube arrays by $\mathrm{N}_{2}$-plasma for visible light-driven photocatalysis, $\mathrm{J}$ Alloys Compd. 509 (2011) 9970-9976.

[118] L. Han, Y. Xin, H. Liu, X. Ma, G. Tang, Photoelectrocatalytic properties of nitrogen doped $\mathrm{TiO}_{2} / \mathrm{Ti}$ photoelectrode prepared by plasma based ion implantation under visible light, J. Hazard. Mater. 175 (2010) 524-531.

[119] M. Qiao, Q. Chen, S. Wu, J. Shen, Novel sol-gel synthesis of N-doped TiO hollow spheres with high photocatalytic activity under visible light, J. Sol-Gel Sci. Thecnol. 55 (2010) 377-384.

[120] X. Zhou, F. Peng, H. Wang, H. Yu, J. Yang, Preparation of nitrogen doped $\mathrm{TiO}_{2}$ photocatalyst by oxidation of titanium nitride with $\mathrm{H}_{2} \mathrm{O}_{2}$, Mater. Res. Bull. 46 (2011) 840-844.

[121] Y. Suda, H. Kawasaki, T. Ueda, T. Ohshima, Preparation of high quality nitrogen doped $\mathrm{TiO}_{2}$ thin film as a photocatalyst using a pulsed laser deposition method, Thin Solid Films 453-454 (2004) 162

[122] T. Matsumoto, N. Iyi, Y. Kaneko, K. Kitamura, S. Ishihara, Y. Takasu, Y. Murakami, High visible-light photocatalytic activity of nitrogen-doped titania prepared from layered titania/isostearate nano composite, Catal. Today 120 (2007) 226-232.

[123] K.A. Michalow, D. Logvinovich, A. Weidenkaff, M. Amberg, G. Fortunato, A. Heel, T. Graule, M. Rekas, Synthesis, characterization and electronic structure of nitrogen-doped $\mathrm{TiO}_{2}$ nanopowder, Catal. Today 144 (2009) 7-12.

[124] J.L. Gole, J.D. Stout, C. Burda, Y. Lou, X. Chen, Highly efficient formation of visible light tunable $\mathrm{TiO}_{2-x} \mathrm{~N}_{x}$ photocatalysts and their transformation at the nanoscale, J. Phys. Chem. B 108 (2004) 1230-1240.

[125] J. Fang, F. Wang, K. Qian, H.Z. Bao, Z.Q. Jiang, W.X. Huang, Bifunctional $\mathrm{N}$-doped mesoporous $\mathrm{TiO}_{2}$ photocatalysts, J. Phys. Chem. C 112 (2008) $18150-18156$.

[126] P.A. Mangrulkar, S.P. Kamble, M.M. Joshi, J.S. Meshram, N.K. Labhsetwar, S.S Rayalu, Photocatalytic degradation of phenolics by N-doped mesoporous titania under solar radiation, Int. J. Photoenergy 2012 (2012) 1-10, Article ID 780562.

[127] M. D’Arienzo, R. Scotti, L. Wahba, C. Battocchio, E. Bemporad, A. Nale, F. Morazzoni, Hydrothermal $\mathrm{N}$-doped $\mathrm{TiO}_{2}$ : explaining photocatalytic properties by electronic and magnetic identification of $\mathrm{N}$ active sites, Appl. Catal. B: Environ. 93 (2009) 149-155.

[128] R. Silveyra, L. De La Torre Sáenz, W. Antúnez Flores, V. Collins Martínez, A. Aguilar Elguézabal, Doping of $\mathrm{TiO}_{2}$ with nitrogen to modify the interval of photocatalytic activation towards visible radiation, Catal. Today 107-108 (2005) 602-605.

[129] X. Zhang, K. Udagawa, Z. Liu, S. Nishimoto, C. Xu, Y. Liu, H. Sakai, M. Abe, T. Murakami, A. Fujishma, Photocatalytic and photoelectrochemical studies on $\mathrm{N}$-doped $\mathrm{TiO}_{2}$ photocatalyst, J. Photochem. Photobiol. A: Chem. 202 (2009) 39-47. 
[130] M. Kitano, K. Funatsu, M. Matsuoka, M. Ueshima, M. Anpo, Preparation of nitrogen-substituted $\mathrm{TiO}_{2}$ thin film photocatalysts by the radio frequency magnetron sputtering deposition method and their photocatalytic reactivity under visible light irradiation. J. Phys. Chem. B 110 (2006) 25266-25272.

[131] I.-C. Kang, Q. Zhang, S. Yin, T. Sato, F. Saito, Novel method for preparation of high visible active $\mathrm{N}$-doped $\mathrm{TiO}_{2}$ photocatalyst with its grinding in solvent, Appl. Catal. B: Environ. 84 (2008) 570-576.

[132] C. Belver, R. Bellod, A. Fuerte, M. Fernández-García, Nitrogen-containing $\mathrm{TiO}_{2}$ photocatalysts. Part 2. Photocatalytic behavior under sunlight excitation, Appl. Catal. B: Environ. 65 (2006) 309-314.

[133] C. Wang, M. Wang, K. Xie, Q. Wu, L. Sun, Z. Lin, C. Lin, Room temperature onestep synthesis of microarrays of $\mathrm{N}$-doped flower-like anatase $\mathrm{TiO}_{2}$ composed of well-defined multilayer nanoflakes by Ti anodization, Nanotechnology 22 (2011) 305607 (9pp).

[134] J. Wang, W. Zhu, Y. Zhang, S. Liu, An efficient two-step technique for nitrogen-doped titanium dioxide synthesizing: visible-light-induced photodecomposition of methylene blue, J. Phys. Chem. C 111 (2007) 1010-1014.

[135] B. Wawrzyniak, A.W. Morawski, Solar-light-induced photocatalytic decomposition of two azo dyes on new $\mathrm{TiO}_{2}$ photocatalyst containing nitrogen, Appl. Catal. B: Environ. 62 (2006) 150-158.

[136] S.M. Marques, C.J. Tavares, L.F. Oliveira, A.M.F. Oliveira-Campos, Photocatalytic degradation of C.I. reactive blue 19 with nitrogen-doped $\mathrm{TiO}_{2}$ catalysts thin films under UV/visible light, J. Mol. Struct. 983 (2010) 147-152.

[137] W. Balcerski, S.Y. Ryu, M.R. Hoffmann, Visible-light photoactivity of nitrogendoped $\mathrm{TiO}_{2}$ : photo-oxidation of $\mathrm{HCO}_{2} \mathrm{H}$ to $\mathrm{CO}_{2}$ and $\mathrm{H}_{2} \mathrm{O}$, J. Phys. Chem. $\mathrm{C} 111$ (2007) 15357-15362.

[138] T. Tachikawa, Y. Takai, S. Tojo, M. Fujitsuka, H. Irie, K. Hashimoto, T. Majima, Visible light-induced degradation of ethylene glycol on nitrogen-doped $\mathrm{TiO}_{2}$ powders, J. Phys. Chem. B 110 (2006) 13158-13165.

[139] D. Meroni, S. Ardizzone, G. Cappelletti, C. Oliva, M. Ceotto, D. Poelman, H. Poelman, Photocatalytic removal of ethanol and acetaldehyde by $\mathrm{N}$-promoted $\mathrm{TiO}_{2}$ films: the role of the different nitrogen sources, Catal. Today 161 (2011) 169-174.

[140] Y. Yokosuka, K. Oki, H. Nishikiori, Y. Tatsumi, N. Tanaka, T. Fujii, Photocatalytic degradation of trichloroethylene using $\mathrm{N}$-doped $\mathrm{TiO}_{2}$ prepared by a simple sol-gel process, Res. Chem. Intermed. 35 (2009) 43-53.

[141] Z. Wang, W. Cai, X. Hong, X. Zhao, F. Xu, C. Cai, Photocatalytic degradation of phenol in aqueous nitrogen-doped $\mathrm{TiO}_{2}$ suspensions with various light sources, Appl. Catal. B: Environ. 57 (2005) 223-231.

[142] G. Tian, Y. Chen, K. Pan, D. Wang, W. Zhou, Z. Ren, H. Fu, Efficient visible lightinduced degradation of phenol on $\mathrm{N}$-doped anatase $\mathrm{TiO}_{2}$ with large surface area and high crystallinity, Appl. Surf. Sci. 256 (2010) 3740-3745.

[143] H. Sun, Y. Bai, H. Liu, W. Jin, N. Xu, Photocatalytic decomposition of 4chlorophenol over an efficient $\mathrm{N}$-doped $\mathrm{TiO}_{2}$ under sunlight irradiation, J. Photochem. Photobiol. A: Chem. 201 (2009) 15-22.

[144] H. Sun, Y. Bai, W. Jin, N. Xu, Photocatalytic decomposition of 4-chlorophenol over an efficient $\mathrm{N}$-doped $\mathrm{TiO}_{2}$ under sunlight irradiation, Solar Energy Mater. Solar Cells 92 (2008) 76-83.

[145] G. Shang, H. Fu, S. Yang, T. Xu, Mechanistic study of visible-light-induced photodegradation of 4-chlorophenol by $\mathrm{TiO}_{2-x} \mathrm{~N}_{x}$ with low nitrogen concentration, Int. J. Photoenergy 2012 (2012) 1-9, art. no. 759306.

[146] K. Nishijima, B. Ohtani, X. Yan, T. Kamai, T. Chiyoya, T. Tsubota, N. Murakami, T. Ohno, Incident light dependence for photocatalytic degradation of acetaldehyde and acetic acid on S-doped and $\mathrm{N}$-doped $\mathrm{TiO}_{2}$ photocatalysts, Chem. Phys. 339 (2007) 64-72.

[147] A.V. Emeline, X. Zhang, M. Jin, T. Murakami, A. Fujishima, Spectral dependences of the activity and selectivity of $\mathrm{N}$-doped $\mathrm{TiO}_{2}$ in photodegradation of phenols, J. Photochem. Photobiol. A: Chem. 207 (2009) 13-19.

[148] C.L. Bianchi, G. Cappelletti, S. Ardizzone, S. Gialanella, A. Naldoni, C. Oliva, C. Pirola, N-doped $\mathrm{TiO}_{2}$ from $\mathrm{TiCl}_{3}$ for photodegradation of air pollutants, Catal. Today 144 (2009) 31-36.

[149] D. Li, H. Haneda, S. Hishita, N. Ohashi, Visible-light-driven nitrogen-doped $\mathrm{TiO}_{2}$ photocatalysts: effect of nitrogen precursors on their photocatalysis for decomposition of gas-phase organic pollutants, Mater. Sci. Eng. B 117 (2005) 67-75.

[150] L. Zhou, X. Tan, L. Zhao, M. Sun, Photocatalytic oxidation of $\mathrm{NO}_{x}$ over visible-light-responsive nitrogen-doped $\mathrm{TiO}_{2}$, Korean J. Chem. Eng. 24 (2007) 1017-1021.

[151] J. Senthilnathan, L. Philip, Photocatalytic degradation of lindane under UV and visible light using $\mathrm{N}$-doped $\mathrm{TiO}_{2}$, Chem. Eng. J. 161 (2010) 83-92.

[152] S. Bangkedphol, H.E. Keenan, C.M. Davidson, A. Sakultantimetha, W. Sirisaksoontorn, A. Songsasen, Enhancement of tributyltin degradation under natural light by N-doped $\mathrm{TiO}_{2}$ photocatalyst, J. Hazard. Mater. 184 (2010) 533-537.

[153] D. Šojić, V. Despotović, B. Abramović, N. Todorova, T. Giannakopoulou, C. Trapalis, Photocatalytic degradation of mecoprop and clopyralid in aqueous suspensions of nanostructured $\mathrm{N}$-doped $\mathrm{TiO}_{2}$, Molecules 15 (2010) 2994-3009.

[154] D. Klauson, E. Portjanskaja, S. Preis, Visible light-assisted photocatalytic oxidation of organic pollutants using nitrogen-doped titania, Environ. Chem. Lett. 6 (2008) 35-39.

[155] M. Miyauchi, A. Nakajima, T. Watanabe, K. Hashimoto, Photocatalysis and photoinduced hydrophilicity of various metal oxide thin films, Chem. Mater. 14 (2002) 2812-2816

[156] A. Akyol, M. Bayramoglu, Photocatalytic degradation of Remazol Red F3B using ZnO catalyst, J. Hazard. Mater. B 124 (2005) 241-246.
[157] N. Daneshvar, D. Salari, A.R. Khataee, Photocatalytic degradation of azo dye acid red 14 in water on $\mathrm{ZnO}$ as an alternative catalyst to $\mathrm{TiO}_{2}$, J. Photochem. Photobiol. A: Chem. 162 (2004) 317-322.

[158] R. Comparelli, E. Fanizza, M.L. Curri, P.D. Cozzi, G. Mascolo, G. Agostiano, UV-induced photocatalytic degradation of azo dyes by organic-capped $\mathrm{ZnO}$ nanocrystals immobilized onto substrates, Appl. Catal. B: Environ. 60 (2005) $1-11$.

[159] H.C. Yatmaz, A. Akyol, M. Bayramoglu, Kinetics of the photocatalytic decolorization of an azo reactive dye in aqueous $\mathrm{ZnO}$ suspensions, Ind. Eng. Chem. Res. 43 (2004) 6035-6039.

[160] S. Su, S.X. Lu, W.G. Xu, Photocatalytic degradation of reactive brilliant blue XBR in aqueous solution using quantum-sized ZnO, Mater. Res. Bull. 43 (2008) 2172-2178.

[161] A. Sharma, P. Rao, R.P. Mathur, S.C. Ameta, Photocatalytic reactions of xylidine ponceau on semiconducting zinc oxide powder, J. Photochem. Photobiol. A 86 (1995) 197-200

[162] F.D. Mai, C.C. Chen, J.L. Chen, S.C. Liu, Photodegradation of methyl green using visible irradiation in $\mathrm{ZnO}$ suspensions. Determination of the reaction pathway and identification of intermediates by a high-performance liquid chromatography-photodiode array-electrospray ionization-mass spectrometry method, J. Chromatogr. A 1189 (2008) 355-365.

[163] B. Pare, S.B. Jonnalagadda, H. Tomar, P. Singh, V.W. Bhagwat, ZnO assisted photocatalytic degradation of acridine orange in aqueous solution using visible irradiation, Desalination 232 (2008) 80-90.

[164] C. Lu, Y. Wu, F. Mai, W. Chung, C. Wu, W. Lin, C. Chen, Degradation efficiencies and mechanisms of the $\mathrm{ZnO}$-mediated photocatalytic degradation of Basic Blue 11 under visible light irradiation, J. Mol. Catal. A: Chem. 310 (2009) $159-165$.

[165] G. Torres Delgado, C.I. Zúñiga Romero, S.A. Mayén Hernández, R. Castanedo Pérez, O. Zelaya Angel, Optical and structural properties of the sol-gelprepared $\mathrm{ZnO}$ thin films and their effect on the photocatalytic activity, Sol. Energy Mater. Sol. Cells 93 (2009) 55-59.

[166] N. Sobana, M. Swaminathan, Combination effect of $\mathrm{ZnO}$ and activated carbon for solar assisted photocatalytic degradation of Direct Blue 53, Sol. Energy Mater. Sol. Cells 91 (2007) 727-734.

[167] S.K. Kansal, A.H. Ali, S. Kapoor, Photocatalytic decolorization of biebrich scarlet dye in aqueous phase using different nanophotocatalysts, Desalination 259 (2010) 147-155.

[168] YJ. Jang, C. Simer, T. Ohm, Comparison of zinc oxide nanoparticles and its nano-crystalline particles on the photocatalytic degradation of methylene blue, Mater. Res. Bull. 41 (2006) 67-77.

[169] E. Yassitepe, H.C. Yatmaz, C. Öztürk, K. Öztürk, C. Duran, Photocatalytic efficiency of $\mathrm{ZnO}$ plates in degradation of azo dye solutions, J. Photochem. Photobiol. A: Chem. 198 (2008) 1-6.

[170] S. Navarro, J. Fenoll, N. Vela, E. Ruiz, G. Navarro, Photocatalytic degradation of eight pesticides in leaching water by use of $\mathrm{ZnO}$ under natural sunlight, J. Hazard. Mater. 172 (2009) 1303-1310.

[171] C.C. Chen, Degradation pathways of ethyl violet by photocatalytic reaction with ZnO dispersions, J. Mol. Catal. A: Chem. 264 (2006) 82-92.

[172] C.A.K. Gouvêa, F. Wypych, S.G. Moraes, N. Durán, N. Nagata, P. Peralta-Zamora, Semiconductor-assisted photocatalytic degradation of reactive dyes in aqueous solution, Chemosphere 40 (2000) 433-440.

[173] A. Akyol, H.C. Yatmaz, M. Bayramoglu, Photocatalytic decolorization of Remazol Red RR in aqueous ZnO suspensions, Appl. Catal. B: Environ. 54 (2004) $19-24$.

[174] S. Sakthivel, B. Neppolian, M.V. Shankar, B. Arabindoo, M. Palanichamy, V. Murugesan, Solar photocatalytic degradation of azo dye: comparison of photocatalytic efficiency of $\mathrm{ZnO}$ and $\mathrm{TiO}_{2}$, Sol. Energy Mater. Sol. Cells 77 (2003) 65-82.

[175] C. Lizama, J. Ferrer, J. Baeza, H.D. Mansilla, Optimized photodegradation of reactive blue 19 on $\mathrm{TiO}_{2}$ and $\mathrm{ZnO}$ suspensions, Catal. Today 76 (2002) 235-246.

[176] I. Poulios, I. Tsachpinis, Photodegradation of the textile dye Reactive Black 5 in the presence of semiconducting oxides, J. Chem. Technol. Biotechnol. 74 (1999) 349-357.

[177] B. Neppolian, S. Sakthivel, B. Arabindoo, M. Palanichamy, V. Murugesan, Degradation of textile dye by solar light using $\mathrm{TiO}_{2}$ and $\mathrm{ZnO}$ photocatalysts, J. Environ. Sci. Health A Tox. Hazard. Subst. Environ. Eng. 34 (1999) 1829-1838.

[178] V. Kandavelu, H. Kastien, K.R. Thampi, Photocatalytic degradation of isothiazolin-3-ones in water and emulsion paints containing nanocrystalline $\mathrm{TiO}_{2}$ and $\mathrm{ZnO}$ catalysts, Appl. Catal. B: Environ. 48 (2004) 101-111.

[179] P. Percherancier, R. Chapelon, B. Pouyet, Semiconductor-sensitized photodegradation of pesticides in water: the case of carbetamide, J. Photochem. Photobiol. A: Chem. 87 (1995) 261-266.

[180] A.A. Khodja, T. Sehili, J.F. Pihichowski, P. Boule, Photocatalytic degradation of 2-phenylphenol on $\mathrm{TiO}_{2}$ and $\mathrm{ZnO}$ in aqueous suspensions, J. Photochem. Photobiol. A: Chem. 141 (2001) 231-239.

[181] I. Poulios, M. Kositzi, A. Kouras, Photocatalytic decomposition of triclopyr over aqueous semiconductor suspensions, J. Photochem. Photobiol. A: Chem. 115 (1998) 175-183.

[182] G. Colón, M.C. Hidalgo J.A. Navío, E. Pulido Melián, O. González Díaz, J.M. Doña Rodríguez, Highly photoactive $\mathrm{ZnO}$ by amine capping-assisted hydrotherma treatment, Appl. Catal. B 83 (2008) 30-38.

[183] M.C. Yeber, J. Rodríguez, J. Freer, J. Baeza, N. Durán, H.D. Mansilla, Advanced oxidation of a pulp mill bleaching wastewater, Chemosphere 39 (1999) 1679-1688. 
[184] L.B. Khalil, W.E. Mourad, M.W. Rophael, Photocatalytic reduction of environmental pollutant $\mathrm{Cr}(\mathrm{VI})$ over some semiconductors under UV/visible light illumination, Appl. Catal. B 17 (1998) 267-273.

[185] E. Evgenidou, I. Konstantinou, K. Fytianos, I. Poulios, T. Albanis, Photocatalytic oxidation of methyl parathion over $\mathrm{TiO}_{2}$ and $\mathrm{ZnO}$ suspensions, Catal. Today 124 (2007) 156-162.

[186] A. Akyol, M. Bayramoglu, Performance comparison of $\mathrm{ZnO}$ photocatalyst in various reactor systems, J. Chem. Technol. Biotechnol. 85 (2010) 1455-1462.

[187] E. García-López, G. Marcì, N. Serpone, H. Hidaka, Photoassisted oxidation of the recalcitrant cyanuric acid substrate in aqueous $\mathrm{ZnO}$ suspensions, J. Phys. Chem. C 111 (2007) 18025-18032.

[188] D. Mijin, M. Savić, P. Snežana, A. Smiljanić, O. Glavaški, M. Jovanović, S. Petrović, A study of the photocatalytic degradation of metamitron in ZnO water suspensions, Desalination 249 (2009) 286-292.

[189] A.A. Abdel, S.A. Mahmoud, A.K. Aboul-Gheit, Sol-gel and thermally evaporated nanostructured thin $\mathrm{ZnO}$ films for photocatalytic degradation of trichlorophenol, Nanoscale Res. Lett. 4 (2009) 627-634.

[190] J. Domenech, A. Prieto, Stability of ZnO particles in aqueous suspensions under UV illumination, J. Phys. Chem. 90 (1986) 1123-1126.

[191] N. Kislov, J. Lahiri, H. Verma, D.Y. Goswami, E. Stefanakos, M. Batzill, Photocatalytic degradation of methyl orange over single crystalline $\mathrm{ZnO}$ : orientation dependence of photoactivity and photostability of ZnO, Langmuir 25 (2009) 3310-3315

[192] B. Dindar, S. Içli, Unusual photoreactivity of zinc oxide irradiated by concentrated sunlight, J. Photochem. Photobiol. A: Chem. 140 (2001) 263-268.

[193] S.K. Pardeshi, A.B. Patil, A simple route for photocatalytic degradation of phenol in aqueous zinc oxide suspension using solar energy, Sol. Energy 82 (2008) 700-705.

[194] L. Zhang, H. Cheng, R. Zong, Y. Zhu, Photocorrosion suppression of ZnO nanoparticles via hybridization with grahite-like carbon and enhanced photocatalytic activity, J. Phys. Chem. C 113 (2009) 2368-2374.

[195] H. Zhang, R. Zhong, Y. Zhu, Photocorrosion inhibition and photoactivity enhancement for zinc oxide via hybridization with monolayer polyaniline, J. Phys. Chem. C 113 (2009) 4605-4611.

[196] A. Sclafani, L. Palmisano, M. Schiavello, V. Augugliaro, S. Coluccia, L. Marchese, The photodecomposition of ethanoic acid adsorbed over semiconductor and insulator oxides. Part. I. Pure oxides, New J. Chem. 12 (1988) 129-135.

[197] S. Daniele, M.N. Ghazzal, L.G. Hubert-Pfalzgraf, C. Duchamp, C. Guillard, G. Ledoux, Preparations of nano-particles, nano-composites and fibers of $\mathrm{ZnO}$ from an amide precursor: photocatalytic decomposition of $\left(\mathrm{CH}_{3}\right)_{2} \mathrm{~S}_{2}$ in a continuous flow reactor, Mater. Res. Bull. 41 (2006) 2210-2218.

[198] M. El-Kemary, H. El-Shamy, I. El-Mehasseb, Photocatalytic degradation of ciprofloxacin drug in water using ZnO nanoparticles, J. Lumin. 130 (2010) 2327-2331.

[199] R. Velmurugan, M. Swaminathan, An efficient nanostructured ZnO for dye sensitized degradation of Reactive Red 120 dye under solar light, Sol. Energy Mater. Sol. Cells 95 (2011) 942-950.

[200] R. Kitture, S.J. Koppikar, R. Kaul-Ghanekar, S.N. Kale, Catalyst efficiency, photostability and reusability study of $\mathrm{ZnO}$ nanoparticles in visible light for dye degradation, J. Phys. Chem. Solids 72 (2011) 60-66.

[201] V. Shinde, T.P. Gujar, T. Noda, D. Fujita, A. Vinu, M. Grandcolas, J. Ye, Growth of shape- and size-selective zinc oxide nanorods by a microwave-assisted bath deposition method: effect on photocatalysis properties, Chem. Eur. J. 16 (2010) 10569-10575.

[202] F. Xu, P. Zhang, A. Navrotsky, Z.-Y. Yuan, T.-Z. Ren, M. Halasa, B.-L. Su, Hierarchically assembled porous ZnO nanoparticles: synthesis, surface energy, and photocatalytic activity, Chem. Mater. 19 (2007) 5680-5686.

[203] X. Li, K. Lv, K. Deng, J. Tang, R. Su, J. Sun, L. Chen, Synthesis and characterization of $\mathrm{ZnO}$ and $\mathrm{TiO}_{2}$ hollow spheres with enhanced photoreactivity, Mater. Sci. Eng. B 158 (2009) 40-47.

[204] M.S. Mohajerani, A. Lak, A. Simchi, Effect of morphology on the solar photocatalytic behavior of ZnO nanostructures, J. Alloys Compd. 485 (2009) 616-620.

[205] Y. Wang, X. Li, N. Wang, X. Quan, Y. Chen, Controllable synthesis of ZnO nanoflowers and their morphology-dependent photocatalytic activities, Sep. Purif. Technol. 62 (2008) 727-732.

[206] B. Li, Y. Wang, Facile synthesis and enhanced photocatalytic performance of flower-like ZnO hierarchical microstructures, J. Phys. Chem. C 114 (2010) 890-896.

[207] M. Hara, T. Kondo, M. Komoda, S. Ikeda, K. Shinohara, A. Tanaka, J.N. Kondo, K. Domen, $\mathrm{Cu}_{2} \mathrm{O}$ as a photocatalyst for overall water splitting under visible light irradiation, Chem. Commun. (1998) 357-358.

[208] Y. Zhang, B. Deng, T. Zhang, D. Gao, A.-W. Xu, Shape effects of $\mathrm{Cu}_{2} \mathrm{O}$ polyhedral microcrystals on photocatalytic activity, J. Phys. Chem. C 114 (2010) 5073-5079.

[209] H. Xu, W. Wang, W. Zhu, Shape evolution and size-controllable synthesis of $\mathrm{Cu}_{2} \mathrm{O}$ octahedra and their morphology-dependent photocatalytic properties, J. Phys. Chem. B 110 (2006) 13829-13834.

[210] J.-Y Ho, M.H. Huang, Synthesis of submicrometer-sized $\mathrm{Cu}_{2} \mathrm{O}$ crystals with morphological evolution from cubic to hexapod structures and their comparative photocatalytic activity, J. Phys. Chem. C 113 (2009) 14159-14164.

[211] Z. Zheng, B. Huang, Z. Wang, M. Guo, X. Qin, X. Zhang, P. Wang, Y. Dai, Crystal faces of $\mathrm{Cu}_{2} \mathrm{O}$ and their stabilities in photocatalytic reactions, J. Phys. Chem. C 113 (2009) 14448-14453.

[212] L. Huang, F. Peng, H. Yu, H. Wang, Preparation of cuprous oxides with different sizes and their behaviours of adsorption, visible-light driven photocatalysis and photocorrosion, Solid State Sci. 11 (2009) 129-138.
[213] B. Zhou, Z. Liu, H. Wang, Y. Yang, W. Su, Experimental study on photocatalytic activity of $\mathrm{Cu}_{2} \mathrm{O} / \mathrm{Cu}$ nanocomposites under visible light, Catal. Lett. 132 (2009) 75-80.

[214] L.-L. Ma, J.-L. Li, H.-Z. Sun, M.-Q. Qiu, J.-B. Wang, J.-Y. Chen, Y. Yu, Selfassembled $\mathrm{Cu}_{2} \mathrm{O}$ flowerlike architecture: polyol synthesis, photocatalytic activity and stability under simulated solar light, Mater. Res. Bull. 45 (2010) 961-968.

[215] A. Sclafani, L. Palmisano, G. Marcì, A.M. Venezia, Influence of platinum on catalytic activity of polycrystalline $\mathrm{WO}_{3}$ employed for phenol photodegradation in aqueous suspension, Sol. Energy Mater. Sol. Cells 51 (1998) 203-219.

[216] M.A. Gondal, M.N. Sayeed, A. Alarfaj, Activity comparison of $\mathrm{Fe}_{2} \mathrm{O}_{3}, \mathrm{NiO}, \mathrm{WO}_{3}$ $\mathrm{TiO}_{2}$ semiconductor catalysts in phenol degradation by laser enhanced photocatalytic process, Chem. Phys. Lett. 445 (2007) 325-330.

[217] K. Sayama, H. Hayashi, T. Arai, M. Yanagida, T. Gunji, H. Sugihara, Highly active $\mathrm{WO}_{3}$ semiconductor photocatalyst prepared from amorphous peroxotungstic acid for the degradation of various organic compounds, Appl. Catal. B: Environ. 94 (2010) 150-157.

[218] A. Watcharenwong, W. Chanmanee, N.R. de Tacconi, C.R. Chenthamarakshan, P. Kajitvichyanukul, K. Rajeshwar, Anodic growth of nanoporous $\mathrm{WO}_{3}$ films: morphology, photoelectrochemical response and photocatalytic activity for methylene blue and hexavalent chrome conversion, J. Electroanal. Chem. 612 (2008) 112-120.

[219] J. Luo, M. Hepel, Photoelectrochemical degradation of naphthol blue black diazo dye on $\mathrm{WO}_{3}$ film electrode, Electrochim. Acta 46 (2001) 2913-2922.

[220] M.A. Gondal, M.A. Dastageer, A. Khalil, Synthesis of nano- $\mathrm{WO}_{3}$ and its catalytic activity for enhanced antimicrobial process for water purification using laser induced photo-catalysis, Catal. Commun. 11 (2009) 214-219.

[221] K. Hayat, M.A. Gondal, M.M. Khaled, Z.H. Yamani, S. Ahmed, Laser induced photocatalytic degradation of hazardous dye (Safranin-O) using self synthesized nanocrystalline $\mathrm{WO}_{3}$, J. Hazard. Mater. 186 (2011) 1226-1233.

[222] H. Kim, K. Senthil, K. Yong, Photoelectrochemical and photocatalytic properties of tungsten oxide nanorods grown by thermal evaporation, Mater. Chem. Phys. 120 (2010) 452-455.

[223] D. Chen, J. Ye, Hierarchical $\mathrm{WO}_{3}$ hollow shells: dendrite, sphere and dumbbell and their photocatalytic properties, Adv. Funct. Mater. 18 (2008) 1922-1928.

[224] M. Shahid, D.S. Rhen, I. Shakir, S.P. Patole, J.B. Yoo, S.-J. Yang, D.J. Kang, Facile synthesis of single crystalline vanadium pentoxide nanowires and their photocatalytic behavior, Mater. Lett. 64 (2010) 2458-2461.

[225] B. Li, Y. Xu, G. Rong, M. Jing, Y. Xie, Vanadium pentoxide nanobelts and nanorolls: from controllable synthesis to investigation of their electrochemical properties and photocatalytic activities, Nanotechnology 17 (2006) 2560-2566.

[226] J.K. Leland, A.J. Bard, Photochemistry of colloidal semiconducting iron oxide polymorphs, J. Phys. Chem. 91 (1987) 5076-5083.

[227] P. Mazellier, M. Bolte, Heterogeneous light-induced transformation of 2,6 dimethylphenol in aqueous suspensions containing goethite, J. Photochem. Photobiol. A: Chem. 132 (2000) 129-133.

[228] J. Bandara, J.A. Mielczarski, A. Lopez, J. Kiwi, 2. Sensitized degradation of chlorophenols on iron oxides induced by visible light. Comparison with titanium oxide, Appl. Catal. B: Environ. 34 (2001) 321-333.

[229] Y. Wang, C.S. Liu, F.B. Li, C.P. Liu, J.B. Liang, Photodegradation of polycyclic aromatic hydrocarbon pyrene by iron oxide in solid phase, J. Hazard. Mater. 162 (2009) 716-723.

[230] T. Kawahara, K. Yamada, H. Tada, Visible light photocatalytic decomposition of 2-naphthol by anodic-biased $\alpha-\mathrm{Fe}_{2} \mathrm{O}_{3}$ film, J. Colloid Interface Sci. 294 (2006) 504-507.

[231] L. Li, Y. Chu, Y. Liu, L. Dong, Template-free synthesis and photocatalytic properties of novel $\mathrm{Fe}_{2} \mathrm{O}_{3}$ hollow spheres, J. Phys. Chem. C 111 (2007) 2123-2127.

[232] X. Xie, H. Yang, F. Zhang, L. Li, J. Ma, H. Jiao, J. Zhang, Synthesis of hollow microspheres constructed with $\alpha-\mathrm{Fe}_{2} \mathrm{O}_{3}$ nanorods and their photocatalytic and magnetic properties, J. Alloys Compd. 477 (2009) 90-99.

[233] S. Lian, E. Wang, L. Gao, D. Wu, Y. Song, L. Xu, Surfactant-assisted solvothermal preparation of submicrometer-sized hollow hematite particles and their photocatalytic activity, Mater. Res. Bull. 41 (2006) 1192-1198.

[234] Y. Bessekhouad, D. Robert, J.-V. Weber, Photocatalytic activity of $\mathrm{Cu}_{2} \mathrm{O} / \mathrm{TiO}_{2}$ $\mathrm{Bi}_{2} \mathrm{O}_{3} / \mathrm{TiO}_{2}$ and $\mathrm{ZnMn}_{2} \mathrm{O}_{4} / \mathrm{TiO}_{2}$ heterojunctions, Catal. Today 101 (2005) 315-321.

[235] Z. Ai, Y. Huang, S. Lee, L. Zhang, Monoclinic $\alpha-\mathrm{Bi}_{2} \mathrm{O}_{3}$ photocatalyst for efficient removal of gaseous NO and $\mathrm{HCHO}$ under visible light irradiation, J. Alloys Compd. 509 (2011) 2044-2049.

[236] J. Eberl, H. Kisch, Visible light photo-oxidations in the presence of $\alpha-\mathrm{Bi}_{2} \mathrm{O}_{3}$, Photochem. Photobiol. Sci. 11 (2008) 1400-1406.

[237] L. Zhang, W. Wang, J. Yang, Z. Chen, W. Zhang, L. Zhou, S. Liu, Sonochemical synthesis of nanocrystallite $\mathrm{Bi}_{2} \mathrm{O}_{3}$ as a visible-light-driven photocatalyst, Appl. Catal. A: Gen. 308 (2006) 105-110.

[238] G. Lin, D. Tan, F. Luo, D. Chen, Q. Zhao, J. Qiu, Z. Xu, Fabrication and photocatalytic property of $\alpha-\mathrm{Bi}_{2} \mathrm{O}_{3}$ nanoparticles by femtosecond laser ablation in liquid, J. Alloys Compd. 507 (2010) L43-L46.

[239] C. Wang, C. Shao, Y. Liu, L. Zhang, Photocatalytic properties $\mathrm{BiOCl}$ and $\mathrm{Bi}_{2} \mathrm{O}_{3}$ nanofibers prepared by electrospinning, Scripta Mater. 59 (2008) 332-335.

[240] L. Zhou, W. Wang, H. Xu, S. Sun, M. Shang, $\mathrm{Bi}_{2} \mathrm{O}_{3}$ hierarchical nanostruc tures: controllable synthesis, growth mechanism, and their application in photocatalysis, Chem. Eur. J. 15 (2009) 1776-1782.

[241] K. Hayat, M.A. Gondal, M.M. Khaled, S. Ahmed, Effect of operational key parameters on photocatalytic degradation of phenol using nano nickel oxide synthesized by sol-gel method, J. Mol. Catal. A: Chem. 336 (2011) 64-71. 
[242] X. Song, L. Gao, Facile synthesis and hierarchical assembly of hollow nickel oxide architectures bearing enhanced photocatalytic properties, J. Phys. Chem. C 112 (2008) 15299-15305.

[243] H. Kominami, K. Oki, M. Kohno, S.-I. Onoue, Y. Kera, B. Ohtani, Novel solvothermal synthesis of niobium(V) oxide powders and their photocatalytic activity in aqueous suspensions, J. Mater. Chem. 11 (2001) 604-609.

[244] A.G.S. Prado, L.B. Bolzon, C.P. Pedroso, A.O. Moura, L.L. Costa, $\mathrm{Nb}_{2} \mathrm{O}_{5}$ as efficient and recyclable photocatalyst for indigo carmine degradation, Appl. Catal. B: Environ. 82 (2008) 219-224.

[245] Y. Zhu, F. Yu, Y. Man, Q. Tian, Y. He, N. Wu, Preparation and performances of nanosized $\mathrm{Ta}_{2} \mathrm{O}_{5}$ powder photocatalyst, J. Solid State Chem. 178 (2005) 224-229.

[246] J.A. Navío, G. Colón, J.M. Herrmann, Photoconductive and photocatalytic properties of $\mathrm{ZrTiO}_{4}$. Comparison with the parent oxides $\mathrm{TiO}_{2}$ and $\mathrm{ZrO}_{2}$, J. Photochem. Photobiol. A: Chem. 108 (1997) 179-185.

[247] C. Karunakaran, S. Senthilvelan, Photocatalysis with $\mathrm{ZrO}_{2}$ : oxidation of aniline, J. Mol. Catal. A: Chem. 233 (2005) 1-8.

[248] G. Al-Sayyed, J.C. D’Oliveira, P. Pichat, Semiconductor-sensitized photodegradation of 4-chlorophenol in water, Photochem. Photobiol. A: Chem. 58 (1991) 99-114.

[249] J.A. Navío, G. Colón, M. Macías, P.J. Sánchez-Soto, V. Augugliaro, $\mathrm{ZrO}_{2}-\mathrm{SiO}_{2}$ mixed oxides: surface aspects, photophysical properties and photoreactivity for 4-nitrophenol oxidation in aqueous phase, J. Mol. Catal. A: Chem. 109 (1996) 239-248.

[250] S.G. Botta, J.A. Navío, M.C. Hidalgo, G.M. Restrepo, M.I. Litter, Photocatalytic properties of $\mathrm{ZrO}_{2}$ and $\mathrm{Fe} / \mathrm{ZrO}_{2}$ semiconductors prepared by a sol-gel technique, J. Photochem. Photobiol. A: Chem. 129 (1999) 89-99.

[251] A.A. Ashkarran, S.A.A. Afshar, S.M. Aghigh, M. Kavianipour, Photocatalytic activity of $\mathrm{ZrO}_{2}$ nanoparticles prepared by electrical arc discharge method in water, Polyhedron 29 (2010) 1370-1374.

[252] J.M. Coronado, A.J. Maira, A. Martínez-Arias, J.C. Conesa, J. Soria, EPR study of the radicals formed upon UV irradiation of ceria-based photocatalysts, J. Photochem. Photobiol. A: Chem. 150 (2002) 213-221.

[253] M.D. Hernández-Alonso, A.B. Hungría, A. Martínez-Arias, M. FernándezGarcía, J.M. Coronado, J.C. Conesa, J. Soria, EPR study of the photoassisted formation of radicals on $\mathrm{CeO}_{2}$ nanoparticles employed for toluene photooxidation, Appl. Catal. B: Environ. 50 (2004) 167-175.

[254] P. Ji, J. Zhang, F. Chen, M. Anpo, Study of adsorption and degradation of acid orange 7 on the surface of $\mathrm{CeO}_{2}$ under visible light irradiation, Appl. Catal. B: Environ. 85 (2009) 148-154.

[255] P. Ji, J. Zhang, F. Chen, M. Anpo, Ordered mesoporous $\mathrm{CeO}_{2}$ synthesized by nanocasting from cubic Ia3d mesoporous MCM-48 silica: formation, characterization and photocatalytic activity, J. Phys. Chem. C 112 (2008) 17809-17813.

[256] Y. Zhai, S. Zhang, H. Pang, Preparation, characterization and photocatalytic activity of $\mathrm{CeO}_{2}$ nanocrystalline using ammonium bicarbonate as precipitant, Mater. Lett. 61 (2007) 1863-1866.

[257] Y. Hou, L. Wu, X. Wang, Z. Ding, Z. Li, X. Fu, Photocatalytic performance of $\alpha-$, $\beta$-, and $\gamma-\mathrm{Ga}_{2} \mathrm{O}_{3}$ for the destruction of volatile aromatic pollutants in air, J. Catal. 250 (2007) 12-18.

[258] B. Zhao, P. Zhang, Photocatalytic decomposition of perfluorooctanoic acid with $\beta-\mathrm{Ga}_{2} \mathrm{O}_{3}$ wide bandgap photocatalyst, Catal. Commun. 10 (2009) 1184-1187.

[259] D. Meissner, R. Memming, B. Kastening, Photoelectrochemistry of cadmium sulfide. 1. Reanalysis of photocorrosion and flat-band potential, J. Phys. Chem. 92 (1988) 3476-3483.

[260] Y. Yang, N. Ren, Y. Zhang, Y. Tang, Nanosized cadmium sulfide in polyelectrolyte protected mesoporous sphere: a stable and regeneratable photocatalyst for visible-light-induced removal of organic pollutants, J. Photochem. Photobiol. A: Chem. 201 (2009) 111-120.

[261] J.S. Hu, L.L. Ren, Y.G. Guo, H.P. Liang, A.M. Cao, L.J. Wan, C.L. Bai, Mass production and high photocatalytic activity of ZnS nanoporous nanoparticles, Angew. Chem. Int. Ed. 44 (2005) 1269-1273.

[262] K. Li, F. Huang, X. Lin, Pristine narrow-bandgap $\mathrm{Sb}_{2} \mathrm{~S}_{3}$ as a highefficiency visible-light responsive photocatalyst, Scripta Mater. 58 (2008) 834-837.

[263] M. Sun, D. Li, W. Li, Y. Chen, Z. Chen, Y. He, X. Fu, New photocatalyst, $\mathrm{Sb}_{2} \mathrm{~S}_{3}$, for degradation of methyl orange under visible-light irradiation, J. Phys. Chem. C 112 (2008) 18076-18081.

[264] A. Kudo, K. Omori, H. Kato, A novel aqueous process for preparation of crystal form-controlled and highly crystalline $\mathrm{BiVO}_{4}$ powder from layered vanadates at room temperature and its photocatalytic and photophysical properties, J. Am. Chem. Soc. 121 (1999) 11459-11467.

[265] S. Tokunaga, H. Kato, A. Kudo, Selective preparation of monoclinic and tetragonal $\mathrm{BiVO}_{4}$ with scheelite structure and their photocatalytic properties, Chem. Mater. 13 (2001) 4624-4628.

[266] J.Q. Yu, A. Kudo, Effects of structural variation on the photocatalytic performance of hydrothermally synthesized $\mathrm{BiVO}_{4}$, Adv. Funct. Mater. 16 (2006) 2163-2169.

[267] H.M. Zhang, J.B. Liu, H. Wang, W.X. Zhang, H. Yan, Rapid microwave-assisted synthesis of phase controlled $\mathrm{BiVO}_{4}$ nanocrystals and research on photocatalytic properties under visible light irradiation, J. Nanopart. Res. 10 (2008) 767-774.

[268] A. Zhang, J. Zhang, N. Cui, X. Tie, Y. An, L. Li, Effects of pH hydrothermal synthesis and characterization of visible-light-driven $\mathrm{BiVO}_{4}$ photocatalyst, J. Mol. Catal. A: Chem. 304 (2009) 28-32.
[269] S. Kohtani, S. Makino, A. Kudo, K. Tokumura, Y. Ishigaki, T. Matsunaga, O. Nikaido, K. Hayakawa, R. Nakagaki, Photocatalytic degradation of 4-nnonylphenol under irradiation from solar simulator: comparison between $\mathrm{BiVO}_{4}$ and $\mathrm{TiO}_{2}$ photocatalysts, Chem. Lett. 31 (2002) 660-661.

[270] S. Kohtani, M. Koshiko, A. Kudo, K. Tokumura, Y. Ishigaki, A. Toriba, K. Hayakawa, R. Nakagaki, Photodegradation of 4-alkylphenols using $\mathrm{BiVO}_{4}$ photocatalyst under irradiation with visible light from a solar simulator, Appl. Catal. B: Environ. 46 (2003) 573-586.

[271] S. Kohtani, J. Hiro, N. Yamamoto, A. Kudo, K. Tokumura, R. Nakagaki, Adsorptive and photocatalytic properties of $\mathrm{Ag}$-loaded $\mathrm{BiVO}_{4}$ on the degradation of 4-n-alkylphenols under visible light irradiation, Catal. Commun. 6(2005) 185

[272] X. Zhang, Z. Ai, F. Jia, L. Zhang, X. Fan, Z. Zou, Selective synthesis and visiblelight photocatalytic activities of $\mathrm{BiVO}_{4}$ with different crystalline phases, Mater. Chem. Phys. 103 (2007) 162-167.

[273] W. Yin, W. Wang, L. Zhou, S. Sun, L. Zhang, CTAB-assisted synthesis of monoclinic $\mathrm{BiVO}_{4}$ photocatalyst and its highly efficient degradation of organic dye under visible-light irradiation, J. Hazard. Mater. 173 (2010) 194-199.

[274] L. Zhang, D.R. Chen, X.L. Jiao, Monoclinic structured $\mathrm{BiVO}_{4}$ nanosheets hydrothermal preparation, formation mechanism, and coloristic and photocatalytic properties, J. Phys. Chem. B 110 (2006) 2668-2673.

[275] L. Zhou, W.Z. Wang, S.W. Liu, L.S. Zhang, H.L. Xu, W. Zhu, A sonochemical route to visible-light-driven high-activity $\mathrm{BiVO}_{4}$ photocatalyst, J. Mol. Catal. A: Chem. 252 (2006) 120-124.

[276] L. Zhou, W.Z. Wang, L.S. Zhang, H.L. Xu, W. Zhu, Single-crystalline $\mathrm{BiVO}_{4}$ microtubes with square cross-sections: microstructure, growth mechanism, and photocatalytic property, J. Phys. Chem. C 111 (2007) 13659-13664.

[277] X. Hu, C. Hu, Preparation and visible-light photocatalytic activity of $\mathrm{Ag}_{3} \mathrm{VO}_{4}$ powders, J. Solid State Chem. 180 (2007) 725-732.

[278] Y. Zhang, H. Ding, F. Liu, S. Wei, S. Liu, D. He, F. Xiao, Synthesis of nanosized $\mathrm{Ag}_{3} \mathrm{VO}_{4}$ particles and their photocatalytic activity for degradation of rhodamine B under visible light, Chin. J. Catal. 29 (2008) 783-787.

[279] C.-M. Huang, G.-T. Pan, Y.-C.M. Li, M.-H. Li, T.C.-K. Yang, Crystalline phases and photocatalytic activities of hydrothermal synthesis $\mathrm{Ag}_{3} \mathrm{VO}_{4}$ and $\mathrm{Ag}_{4} \mathrm{~V}_{2} \mathrm{O}_{7}$ under visible light irradiation, Appl. Catal. A: Gen. 358 (2009) 164-172.

[280] J. Ye, Z. Zou, M. Oshikiri, A. Matsushita, M. Shimoda, M. Imai, T. Shishido, A novel hydrogen-evolving photocatalyst $\mathrm{InVO}_{4}$ active under visible light irradiation, Chem. Phys. Lett. 356 (2002) 221-226.

[281] L. Zhang, H. Fu, C. Zhang, Y. Zhu, Synthesis, characterization, and photocatalytic properties of $\mathrm{InVO}_{4}$ nanoparticles, J. Solid State Chem. 179 (2006) 804-811.

[282] Z. Ai, L. Zhang, S. Lee, Efficient visible light photocatalytic oxidation of NO on aerosol flow-synthesized nanocrystalline $\mathrm{InVO}_{4}$ hollow microspheres, J. Phys. Chem. C 114 (2010) 18594-18600.

[283] S. Mahapatra, G. Madras, T.N. Guru Row, Synthesis, characterization and photocatalytic activity of lanthanide (Ce, Pr and Nd) orthovanadates, Ind. Eng. Chem. Res. 46 (2007) 1013-1017.

[284] S. Mahapatra, S.K. Nayak, G. Madras, T.N. Guru Row, Microwave synthesis and photocatalytic activity of nano lanthanide (Ce, Pr, and Nd) orthovanadates, Ind. Eng. Chem. Res. 47 (2008) 6509-6516.

[285] J. Tang, Z. Zou, J. Ye, Photocatalytic decomposition of organic contaminants by $\mathrm{Bi}_{2} \mathrm{WO}_{6}$ under visible light irradiation, Catal. Lett. 92 (2004) 53-56.

[286] J. Yu, J. Xiong, B. Cheng, Y. Yu, J. Wang, Hydrothermal preparation and visiblelight photocatalytic activity of $\mathrm{Bi}_{2} \mathrm{WO}_{6}$ powders, J. Solid State Chem. 178 (2005) 1968-1972.

[287] Z. Zhang, W. Wang, M. Shang, W. Yin, Low-temperature combustion synthesis of $\mathrm{Bi}_{2} \mathrm{WO}_{6}$ nanoparticles as a visible-light-driven photocatalyst, J. Hazard. Mater. 177 (2010) 1013-1018.

[288] F. Amano, A. Yamakata, K. Nogami, M. Osawa, B. Ohtani, Visible light responsive pristine metal oxide photocatalyst: enhancement of activity by crystallization under hydrothermal treatment, J. Am. Chem. Soc. 130 (2008) 17650-17651.

[289] J. Ren, W. Wang, L. Zhang, J. Chang, S. Hu, Photocatalytic inactivation of bac teria by photocatalyst $\mathrm{Bi}_{2} \mathrm{WO}_{6}$ under visible light, Catal. Commun. 10 (2009) 1940-1943.

[290] S. Obregón Alfaro, A. Martínez-de la Cruz, L.M. Torres-Martínez, S.W. Lee Remove of marine plankton by photocatalysts with Aurivillius-type structure, Catal. Commun. 11 (2010) 326-330.

[291] C. Zhang, Y. Zhu, Synthesis of square $\mathrm{Bi}_{2} \mathrm{WO}_{6}$ nanoplates as high-activity visible-light-driven photocatalysts, Chem. Mater. 17 (2005) 3537-3545.

[292] H. Fu, C. Pan, W. Yao, Y. Zhu, Visible-light-induced degradation of rhodamine $\mathrm{B}$ by nanosized $\mathrm{Bi}_{2} \mathrm{WO}_{6}$, J. Phys. Chem. B 109 (2005) 22432-22439.

[293] S. Zhang, C. Zhang, Y. Man, Y. Zhu, Visible-light-driven photocatalyst of $\mathrm{Bi}_{2} \mathrm{WO}_{6}$ nanoparticles prepared via amorphous complex precursor and photocatalytic properties, J. Solid State Chem. 179 (2006) 62-69.

[294] H. Fu, L. Zhang, W. Yao, Y. Zhu, Photocatalytic properties of nanosized $\mathrm{Bi}_{2} \mathrm{WO}_{6}$ catalysts synthesized via a hydrothermal process, Appl. Catal. B: Environ. 66 (2006) 100-110

[295] H. Fu, W. Yao, L. Zhang, Y. Zhu, The enhanced photoactivity of nanosized $\mathrm{Bi}_{2} \mathrm{WO}_{6}$ catalyst for the degradation of 4-chlorophenol, Mater. Res. Bull. 43 (2008) 2617-2625

[296] M. Shang, W. Wang, S. Sun, L Zhou, L Zhang, $\mathrm{Bi}_{2} \mathrm{WO}_{6}$ nanocrystals with high photocatalytic activities under visible light, J. Phys. Chem. C 112 (2008) 10407-10411.

[297] L. Wu, J. Bi, Z. Li, X. Wang, X. Fu, Rapid preparation of $\mathrm{Bi}_{2} \mathrm{WO}_{6}$ photocatalyst with nanosheet morphology via microwave-assisted solvothermal synthesis, Catal. Today 131 (2008) 15-20. 
[298] H. Xie, D. Shen, X. Wang, G. Shen, Microwave hydrothermal synthesis and visible-light photocatalytic activity of $\mathrm{Bi}_{2} \mathrm{WO}_{6}$ nanoplates, Mater. Chem. Phys. 103 (2007) 334-339.

[299] L. Zhang, W. Wang, L. Zhou, H. Xu, $\mathrm{Bi}_{2} \mathrm{WO}_{6}$ nano- and microstructures: shape control and associated visible-light driven photocatalytic activities, Small 3 (2007) 1618-1625.

[300] F. Amano, K. Nogami, R. Abe, B. Ohtani, Facile hydrothermal preparation and photocatalytic activity of bismuth tungstate polycrystalline flake-ball particles, Chem. Lett. 36 (2007) 1314.

[301] F. Amano, K. Nogami, R. Abe, B. Ohtani, Preparation and characterization of bismuth tungstate polycrystalline flake-ball particles for photocatalytic reactions, J. Phys. Chem. C 112 (2008) 9320-9326.

[302] F. Amano, K. Nogami, M. Osawa, B. Ohtani, Visible light-responsive bismuth tungstate photocatalysts: effects of hierarchical architecture on photocatalytic activity, J. Phys. Chem. C 113 (2009) 1536-1542.

[303] G. Li, D. Zhang, J.C. Yu, M.K.H. Leung, An efficient bismuth tungstate visiblelight-driven photocatalyst for breaking down nitric oxide, Environ. Sci. Technol. 44 (2010) 4276-4281.

[304] L. Zhang, W. Wang, Z. Chen, L. Zhou, H. Xu, W. Zhu, Fabrication of flower-like $\mathrm{Bi}_{2} \mathrm{WO}_{6}$ superstructures as high performance visible-light driven photocatalysts, J. Mater. Chem. 24 (2007) 2526-2532.

[305] Y. Li, J. Liu, X. Huang, Synthesis and visible-light photocatalytic property of $\mathrm{Bi}_{2} \mathrm{WO}_{6}$ hierarchical octahedron-like structures, Nanoscale Res. Lett. 3 (2008) 365-371.

[306] J. Wu, F. Duan, Y. Zheng, Y. Xie, Synthesis of $\mathrm{Bi}_{2} \mathrm{WO}_{6}$ nanoplate-built hierarchical nest-like structures with visible-light-induced photocatalytic activity, J. Phys. Chem. C 111 (2007) 12866-12871.

[307] S. Zhu, T. Xu, H. Fu, J. Zhao, Y. Zhu, Synergetic effect of $\mathrm{Bi}_{2} \mathrm{WO}_{6}$ photocatalyst with $\mathrm{C}_{60}$ and enhanced photoactivity under visible irradiation, Environ. Sci. Technol. 41 (2007) 6234-6239.

[308] J.Q. Yu, A. Kudo, Hydrothermal synthesis and photocatalytic property of 2-dimensional bismuth molybdate nanoplates, Chem. Lett. 34 (2005) 1528-1529.

[309] Y. Shimodaira, H. Kato, H. Kobayashi, A. Kudo, Photophysical properties and photocatalytic activities of bismuth molybdates under visible light irradiation, J. Phys. Chem. B 110 (2006) 17790-17797.

[310] J. Bi, L. Wu, J. Li, Z.H. Li, X.X. Wang, X.Z. Fu, Simple solvothermal routes to synthesize nanocrystalline $\mathrm{Bi}_{2} \mathrm{MoO}_{6}$ photocatalysts with different morphologies, Acta Mater. 55 (2007) 4699-4705

[311] X. Zhao, T. Xu, W. Yao, Y. Zhu, Photodegradation of dye pollutants catalyzed by $\gamma-\mathrm{Bi}_{2} \mathrm{MoO}_{6}$ nanoplate under visible light irradiation, Appl. Surf. Sci. 255 (2009) 8036-8040.

[312] H.H. Li, C.Y. Liu, K.W. Li, H. Wang, Preparation, characterization and photocatalytic properties of nanoplate $\mathrm{Bi}_{2} \mathrm{MoO}_{6}$ catalysts, J. Mater. Sci. 43 (2008) 7026-7034.

[313] L. Zhou, W.Z. Wang, L.S. Zhang, Ultrasonic-assisted synthesis of visible-light induced $\mathrm{Bi}_{2} \mathrm{MoO}_{6}(\mathrm{M}=\mathrm{W}$, Mo) photocatalysts, J. Mol. Catal. A 268 (2007) 195-200.

[314] L. Zhang, T. Xu, X. Zhao, Y. Zhu, Controllable synthesis of $\mathrm{Bi}_{2} \mathrm{MoO}_{6}$ and effect of morphology and variation in local structure on photocatalytic activities, Appl. Catal. B: Environ. 98 (2010) 138-146.

[315] Y. Zheng, F. Duan, J. Wu, L. Liu, M. Chen, Y. Xie, Enhanced photocatalytic activity of bismuth molybdates with the preferentially exposed $\{010\}$ surface under visible light irradiation, J. Mol. Catal. A: Chem. 303 (2009) 9-14.

[316] A. Martínez-de la Cruz, S. Obregón Alfaro, E. López Cuéllar, U. Ortiz Méndez, Photocatalytic properties of $\mathrm{Bi}_{2} \mathrm{MoO}_{6}$ nanoparticles prepared by an amorphous complex precursor, Catal. Today 129 (2007) 194-199.

[317] L. Xie, J. Ma, G. Xu, Preparation of a novel $\mathrm{Bi}_{2} \mathrm{MoO}_{6}$ flake-like nanophotocatalyst by molten salt method and evaluation for photocatalytic decomposition of rhodamine B, Mater. Chem. Phys. 110 (2008) 197-200.

[318] W. Yin, W. Wang, S. Sun, Photocatalytic degradation of phenol over cage-like $\mathrm{Bi}_{2} \mathrm{MoO}_{6}$ hollow spheres under visible-light irradiation, Catal. Commun. 11 (2010) 647-650.

[319] C. Belver, C. Adán, M. Fernández-García, Photocatalytic behaviour of $\mathrm{Bi}_{2} \mathrm{MO}_{6}$ polymetalates for rhodamine B degradation, Catal. Today 143 (2009) 274-281.

[320] X. Zhao, Y. Zhu, Synergetic degradation of rhodamine B at a porous $\mathrm{ZnWO}_{4}$ film electrode by combined electro-oxidation and photocatalysis, Environ. Sci. Technol. 40 (2006) 3367-3372.

[321] H. Fu, J. Lin, L. Zhang, Y. Zhu, Photocatalytic activities of a novel $\mathrm{ZnWO}_{4}$ catalyst prepared by a hydrothermal process, Appl. Catal. A: Chem. 306 (2006) 58-67.

[322] J. Lin, J. Lin, Y. Zhu, Controlled synthesis of the $\mathrm{ZnWO}_{4}$ nanostructure and effects on the photocatalytic performance, Inorg. Chem. 46 (2007) 8372-8378.

[323] Y. Wu, S. Zhang, L. Zhang, Y. Zhu, Photocatalytic activity of nanosized $\mathrm{ZnWO}_{4}$, prepared by the sol-gel method, Chem. Res. Chin. U. 23 (2007) 465-468.

[324] G. Huang, Y. Zhu, Synthesis and photocatalytic performance of $\mathrm{ZnWO}_{4}$ catalyst, Mater. Sci. Eng. B 139 (2007) 201-208.

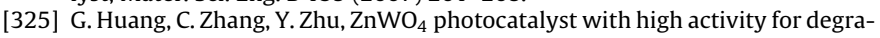
dation of organic contaminants, J. Alloys Compd. 432 (2007) 269-276.

[326] H. Fu, C. Pan, L. Zhang, Y. Zhu, Synthesis, characterization and photocatalytic properties of nanosized $\mathrm{Bi}_{2} \mathrm{WO}_{6}, \mathrm{PbWO}_{4}$ and $\mathrm{ZnWO}_{4}$ catalysts, Mat. Res. Bull. 42 (2007) 696-706.

[327] X. Zhao, W. Yao, Y. Wu, S. Zhang, H. Yang, Y. Zhu, Fabrication and photoelectrochemical properties of porous $\mathrm{ZnWO}_{4}$ film, J. Solid State Chem. 179 (2006) 2562-2570.
[328] R. Shi, Y. Wang, D. Li, J. Xu, Y. Zhu, Synthesis of $\mathrm{ZnWO}_{4}$ nanorods with [1 00 0] orientation and enhanced photocatalytic properties, Appl. Catal. B: Environ. 100 (2011) 173-178.

[329] D. Ye, D. Li, W. Zhang, M. Sun, Y. Hu, Y. Zhang, X. Fu, A new photocatalyst $\mathrm{CdWO}_{4}$ prepared with a hydrothermal method, J. Phys. Chem. C 112 (2008) 17351-17356.

[330] T. Yan, L. Li, W. Tong, J. Zheng, Y. Wang, G. Li, CdWO ${ }_{4}$ polymorphs: selective preparation, electronic structures, and photocatalytic activities, J. Solid State Chem. 184 (2011) 357-364.

[331] F. Dong, Y. Huang, S. Zou, J. Liu, S.C. Lee, Ultrasonic spray pyrolysis fabrication of solid and hollow $\mathrm{PbWO}_{4}$ spheres with structure-directed photocatalytic activity, J. Phys. Chem. C 115 (2011) 241-247.

[332] Z. Shan, Y. Wang, H. Ding, F. Huang, Structure-dependent photocatalytic activities of $\mathrm{MWO}_{4}(\mathrm{M}=\mathrm{Ca}, \mathrm{Sr}, \mathrm{Ba})$, J. Mol. Catal. A: Chem. 302 (2009) 54-58.

[333] C. Wang, X. Wang, J. Zhao, B. Mai, G. Sheng, P. Peng, J. Fu, Synthesis, characterization and photocatalytic property of nano-sized $\mathrm{Zn}_{2} \mathrm{SnO}_{4}$, J. Mater. Sci. 37 (2002) 2989-2996.

[334] X. Lou, X. Jia, J. Xu, S. Liu, Q. Gao, Hydrothermal synthesis, characterization and photocatalytic properties of $\mathrm{Zn}_{2} \mathrm{SnO}_{4}$ nanocrystal, Mater. Sci. Eng. A 432 (2006) 221-225.

[335] E.L. Foletto, S.L. Jahn, R.F.P.M. Moreira, Hydrothermal preparation of $\mathrm{Zn}_{2} \mathrm{SnO}_{4}$ nanocrystals and photocatalytic degradation of a leather dye, J. Appl. Electrochem. 40 (2010) 59-63.

[336] J. Zeng, M.D. Xin, K.W. Li, H. Wang, H. Yan, W.J. Zhang, Transformation process and photocatalytic activities of hydrothermally synthesized $\mathrm{Zn}_{2} \mathrm{SnO}_{4}$ nanocrystals, J. Phys. Chem. C 112 (2008) 4159-4167.

[337] X. Fu, X. Wang, J. Long, Z. Ding, T. Yan, G. Zhang, Z. Zhang, H. Lin, X. Fu, Hydrothermal synthesis, characterization, and photocatalytic properties of $\mathrm{Zn}_{2} \mathrm{SnO}_{4}$, J. Solid State Chem. 182 (2009) 517-524.

[338] Z. Ai, S. Lee, Y. Huang, W. Ho, L. Zhang, Photocatalytic removal of NO and $\mathrm{HCHO}$ over nanocrystalline $\mathrm{Zn}_{2} \mathrm{SnO}_{4}$ microcubes for indoor air purification, J. Hazard. Mater. 179 (2010) 141-150.

[339] W. Wang, J. Bi, L. Wu, Z. Li, X. Wang, X. Fu, Hydrothermal synthesis and performance of a novel nanocrystalline $\mathrm{Pb}_{2} \mathrm{Sn}_{2} \mathrm{O}_{6}$ photocatalyst, Nanotechnology 19 (2008) 505705.

[340] D. Chen, S. Ouyang, J. Ye, Photocatalytic degradation of isopropanol over $\mathrm{PbSnO}_{3}$ nanostructures under visible light irradiation, Nanoscale Res. Lett. 4 (2009) 274-280.

[341] J. Tang, Z. Zou, M. Katagiri, T. Kako, J. Ye, Photocatalytic degradation of MB on $\mathrm{MIn}_{2} \mathrm{O}_{4}(\mathrm{M}=$ alkali earth metal) under visible light: effects of crystal and electronic structure on the photocatalytic activity, Catal. Today 93-95 (2004) $885-889$.

[342] J. Tang, Z. Zou, J. Ye, Kinetics of MB degradation and effect of pH on the photocatalytic activity of $\mathrm{MIn}_{2} \mathrm{O}_{4}(\mathrm{M}=\mathrm{Ca}, \mathrm{Sr}, \mathrm{Ba})$ under visible light irradiation, Res. Chem. Intermed. 31 (2005) 513-519.

[343] J. Tang, Z. Zou, J. Ye, Effects of substituting $\mathrm{Sr}^{2+}$ and $\mathrm{Ba}^{2+}$ for $\mathrm{Ca}^{2+}$ on the structural properties and photocatalytic behaviors of $\mathrm{CaIn}_{2} \mathrm{O}_{4}$, Chem. Mater. 16 (2004) 1644-1649.

[344] J. Tang, Z. Zou, J. Yin, J. Ye, Photocatalytic degradation of methylene blue on $\mathrm{CaIn}_{2} \mathrm{O}_{4}$ under visible light irradiation, Chem. Phys. Lett. 382 (2003) $175-179$.

[345] X. Chen, H. Xue, Z. Li, L. Wu, X. Wang, X. Fu, Ternary wide band gap pblock metal semiconductor $\mathrm{ZnGa}_{2} \mathrm{O}_{4}$ for photocatalytic benzene degradation, J. Phys. Chem. C 112 (2008) 20393-20397.

[346] X. Zhang, J. Huang, K. Ding, Y. Hou, X. Wang, X. Fu, Photocatalytic decomposition of benzene by porous nanocrystalline $\mathrm{ZnGa}_{2} \mathrm{O}_{4}$ with a high surface area, Environ. Sci. Technol. 43 (2009) 5947-5951.

[347] J. Huang, X. Wang, Y. Hou, X. Chen, L. Wu, X. Fu, Degradation of benzene over a zinc germanate photocatalyst under ambient conditions, Environ. Sci. Technol. 42 (2008) 7387-7391.

[348] J. Huang, K. Ding, X. Wang, X. Fu, Nanostructuring cadmium germanate catalysts for photocatalytic oxidation of benzene at ambient conditions, Langmuir 25 (2009) 8313-8319.

[349] W.Zhang, J.Zhang, Z. Chen, T. Wang, Photocatalytic degradation of methylene blue by $\mathrm{ZnGa}_{2} \mathrm{O}_{4}$ thin films, Catal. Commun. 10 (2009) 1781-1785.

[350] W. Zhang, J. Zhang, X. Lan, Z. Chen, T. Wang, Photocatalytic performance of $\mathrm{ZnGa}_{2} \mathrm{O}_{4}$ for degradation of methylene blue and its improvement by doping with Cd, Catal. Commun. 11 (2010) 1104-1108.

[351] X. Lin, F. Huang, W. Wang, Y. Wang, Y. Xia, J. Shi, Photocatalytic activities of $\mathrm{M}_{2} \mathrm{Sb}_{2} \mathrm{O}_{7}(\mathrm{M}=\mathrm{Ca}, \mathrm{Sr})$ for degrading methyl orange, Appl. Catal. A: Gen. 313 (2006) 218-223.

[352] H. Xue, Z. Li, L. Wu, Z. Ding, X. Wang, X. Fu, Nanocrystalline ternary wide band gap p-block metal semiconductor $\mathrm{Sr}_{2} \mathrm{Sb}_{2} \mathrm{O}_{7}$ : hydrothermal syntheses and photocatalytic benzene degradation, J. Phys. Chem. C 112 (2008) 5850-5855.

[353] H. Xue, Z. Li, H. Dong, L. Wu, X. Wang, X. Fu, 3D hierarchical architectures of $\mathrm{Sr}_{2} \mathrm{Sb}_{2} \mathrm{O}_{7}$ : hydrothermal syntheses, formation mechanisms, and application in aqueous-phase photocatalysis, Cryst. Growth Des. 8 (2008) 4469-4475.

[354] X. Hu, J.C. Yu, J. Gong, Q. Li, Rapid mass production of hierarchically porous $\mathrm{ZnIn}_{2} \mathrm{~S}_{4}$ submicrospheres via a microwave-solvothermal process, Cryst. Growth Des. 7 (2007) 2444-2448.

[355] Z. Chen, D. Li, W. Zhang, Y. Shao, T. Chen, M. Sun, X. Fu, Photocatalytic degradation of dyes by $\mathrm{ZnIn}_{2} \mathrm{~S}_{4}$ microspheres under visible light irradiation, J. Phys. Chem. C 113 (2009) 4433-4440.

[356] H. Yu, X. Quan, Y. Zhang, N. Ma, S. Chen, H. Zhao, Electrochemically assisted photocatalytic inactivation of Escherichia coli under visible light using a $\mathrm{ZnIn}_{2} \mathrm{~S}_{4}$ film electrode, Langmuir 24 (2008) 7599-7604. 
[357] T. Yan, L. Li, G. Li, Y. Wang, W. Hu, X. Guan, Porous $\operatorname{SnIn}_{4} \mathrm{~S}_{8}$ microspheres in a new polymorph that promotes dyes degradation under visible light irradiation, J. Hazard. Mater. 186 (2011) 272-279.

[358] J. Tang, Z. Zou, J. Ye, Efficient photocatalytic decomposition of organic contaminants over $\mathrm{CaBi}_{2} \mathrm{O}_{4}$ under visible-light irradiation, Angew. Chem. Int. Ed. 43 (2004) 4463-4466.

[359] J. Tang, J. Ye, Photocatalytic and photophysical properties of visible-lightdriven photocatalyst $\mathrm{ZnBi}_{12} \mathrm{O}_{20}$, Chem. Phys. Lett. 410 (2005) 104-107.

[360] J. Tang, Z. Zou, J. Ye, Efficient photocatalysis on $\mathrm{BaBiO}_{3}$ driven by visible light, J. Phys. Chem. C 111 (2007) 12779-12785.

[361] T. Kako, Z. Zou, M. Katagiri, J. Ye, Decomposition of organic compounds over $\mathrm{NaBiO}_{3}$ under visible light irradiation, Chem. Mater. 19 (2007) 198-202.

[362] J. Kou, H. Zhang, Z. Li, S. Ouyang, J. Ye, Z. Zou, Photooxidation of polycyclic aromatic hydrocarbons over $\mathrm{NaBiO}_{3}$ under visible light irradiation, Catal. Lett. 122 (2008) 131-137.

[363] X. Chang, J. Huang, C. Cheng, W. Sha, X. Li, G. Ji, S. Deng, G. Yu, Photocatalytic decomposition of 4-t-octylphenol over $\mathrm{NaBiO}_{3}$ driven by visible light: catalytic kinetics and corrosion products characterization, J. Hazard. Mater. 173 (2010) 765-772.

[364] X. Chang, G. Ji, Q. Sui, J. Huang, G. Yu, Rapid photocatalytic degradation of PCP-Na over $\mathrm{NaBiO}_{3}$ driven by visible light irradiation, J. Hazard. Mater. 166 (2009) 728-733.

[365] L. Chen, S. Zhang, L. Wang, D. Xue, S. Yin, Preparation and photocatalytic properties of strontium titanate powders via sol-gel process, J. Cryst. Growth 311 (2009) 746-748.

[366] H.Y. He, Comparison study of photocatalytic properties of $\mathrm{SrTiO}_{3}$ and $\mathrm{TiO}_{2}$ powders in decomposition of methyl orange, Int. J. Environ. Res. 3 (2009) 57-60.

[367] T. Puangpetch, T. Sreethawong, S. Yoshikawa, S. Chavadej, Synthesis and photocatalytic activity in methyl orange degradation of mesoporous-assembled $\mathrm{SrTiO}_{3}$ nanocrystals prepared by sol-gel method with the aid of structuredirecting surfactant, J. Mol. Catal. A: Chem. 287 (2008) 70-79.

[368] N. Wang, D. Kong, H. He, Solvothermal synthesis of strontium titanate nanocrystallines from metatitanic acid and photocatalytic activities, Powder Technol. 207 (2011) 470-473.

[369] Z. Zheng, B. Huang, X. Qin, X. Zhang, Y. Dai, Facile synthesis of $\mathrm{SrTiO}_{3}$ hollow microspheres built as assembly of nanocubes and their associated photocatalytic activity, J. Colloid Interface Sci. 358 (2011) 68-72.

[370] W.F. Yao, H. Wang, X.H. Xu, S.X. Shang, Y. Hou, Y. Zhang, M. Wang, Synthesis and photocatalytic property of bismuth titanate $\mathrm{Bi}_{4} \mathrm{Ti}_{3} \mathrm{O}_{12}$, Mater. Lett. 57 (2003) 1899-1902.

[371] W. Yao, H. Wang, X. Xu, J. Zhou, X. Yang, Y. Zhang, S. Shang, Photocatalytic property of bismuth titanate $\mathrm{Bi}_{2} \mathrm{Ti}_{2} \mathrm{O}_{7}$, Appl. Catal. A: Gen. 259 (2004) 29-33.

[372] Y. Ku, L.-C. Wang, C.-M. Ma, Photocatalytic oxidation of isopropanol in aqueous solution using perovskite- structured $\mathrm{La}_{2} \mathrm{Ti}_{2} \mathrm{O}_{7}$, Chem. Eng. Technol. 30 (2007) 895-900.

[373] M.A. Valenzuela, P. Bosch, J. Jimenez-Becerrill, O. Quiroz, A.I. Paez, Preparation, characterization and photocatalytic activity of $\mathrm{ZnO}, \mathrm{Fe}_{2} \mathrm{O}_{3}$ and $\mathrm{ZnFe}_{2} \mathrm{O}_{4}$, J. Photochem. Photobiol. A: Chem. 148 (2002) 177-182.

[374] W.Q. Meng, F. Li, D.G. Evans, X. Duan, Photocatalytic activity of highly porous zinc ferrite prepared from a zinc-iron(III)-sulfate layered double hydroxide precursor, J. Porous Mater. 11 (2004) 97-105.

[375] X. Niu, H. Li, G. Liu, Preparation, characterization and photocatalytic properties of $\mathrm{REFeO}_{3}(\mathrm{RE}=\mathrm{Sm}, \mathrm{Eu}, \mathrm{Gd}), \mathrm{J}$. Mol. Catal. A: Chem. 232 (2005) 89-93.

[376] F. Gao, X. Chen, K. Yin, S. Dong, Z. Ren, F. Yuan, T. Yu, Z. Zou, J.-M. Liu, Visiblelight photocatalytic properties of weak magnetic $\mathrm{BiFeO}_{3}$ nanoparticles, Adv. Mater. 19 (2007) 2889-2892.

[377] Z. Liu, Y. Qi, C. Lu, High efficient ultraviolet photocatalytic activity of $\mathrm{BiFeO}_{3}$ nanoparticles synthesized by a chemical coprecipitation process, J. Mater. Sci: Mater. Electron. 21 (2010) 380-384.

[378] Y. Huo, Y. Jin, Y. Zhang, Citric acid assisted solvothermal synthesis of $\mathrm{BiFeO}_{3}$ microspheres with high visible-light photocatalytic activity, J. Mol. Catal. A: Chem. 331 (2010) 15-20.

[379] B. Muktha, J. Darriet, G. Madras, T.N. Guru Row, Crystal structures and photocatalysis of the triclinic polymorphs of $\mathrm{BiNbO}_{4}$ and $\mathrm{BiTaO}_{4}$, J. Solid State Chem. 179 (2006) 3919-3925.

[380] L. Zhang, I. Djerdj, M. Cao, M. Antonietti, M. Niederberger, Nonaqueous sol-gel synthesis of a nanocrystalline $\mathrm{InNbO}_{4}$ visible-light photocatalyst, Adv. Mater. 19 (2007) 2083-2086.

[381] G. Zhang, J. Yang, S. Zhang, Q. Xiong, B. Huang, J. Wang, W. Gong, Preparation of nanosized $\mathrm{Bi}_{3} \mathrm{NbO}_{7}$ and its visible-light photocatalytic property, J. Hazard. Mater. 172 (2009) 986-992.

[382] X. Li, T. Kako, J. Ye, 2-Propanol photodegradation over lead niobates under visible light irradiation, Appl. Catal. A: Gen. 326 (2007) 1-7.

[383] X. Li, J. Ye, Photocatalytic degradation of rhodamine $\mathrm{B}$ over $\mathrm{Pb}_{3} \mathrm{Nb}_{4} \mathrm{O}_{13} /$ fumed $\mathrm{SiO}_{2}$ composite under visible light irradiation, J. Phys. Chem. C 111 (2007) 13109-13116.

[384] Y. Maruyama, H. Irie, K. Hashimoto, Visible light sensitive photocatalyst, delafossite structured $\alpha-\mathrm{AgGaO}_{2}$, J. Phys. Chem. B 110 (2006) 23274-23278.

[385] S. Ouyang, N. Kikugawa, D. Chen, Z. Zou, J. Ye, A Systematical study on photocatalytic properties of $\mathrm{AgMO}_{2}(\mathrm{M}=\mathrm{Al}, \mathrm{Ga}, \mathrm{In})$ : effects of chemical compositions, crystal structures, and electronic structures, J. Phys. Chem. C 113 (2009) 1560-1566.

[386] H. Dong, Z. Li, X. Xu, Z. Ding, L. Wu, X. Wang, X. Fu, Visible light-induced photocatalytic activity of delafossite $\mathrm{AgMO}_{2}(\mathrm{M}=\mathrm{Al}, \mathrm{Ga}$, In) prepared via a hydrothermal method, Appl. Catal. B: Environ. 89 (2009) 551-556.
[387] S. Ouyang, H. Zhang, D. Li, T. Yu, J. Ye, Z. Zou, Electronic structure and photocatalytic characterization of a novel photocatalyst $\mathrm{AgAlO}_{2}$, J. Phys. Chem. B 110 (2006) 11677-11682.

[388] S. Ouyang, Z. Li, Z. Ouyang, T. Yu, J. Ye, Z. Zou, Correlation of crystal struc tures, electronic structures, and photocatalytic properties in a series of Ag-based oxides: $\mathrm{AgAlO}_{2}, \mathrm{AgCrO}_{2}$, and $\mathrm{Ag}_{2} \mathrm{CrO}_{4}$, J. Phys. Chem. C 112 (2008) 3134-3141.

[389] T. Kako, N. Kikugawa, J. Ye, Photocatalytic activities of $\mathrm{AgSbO}_{3}$ under visible light irradiation, Catal. Today 131 (2008) 197-202.

[390] S. Ouyang, N. Kikugawa, Z. Zou, J. Ye, Effective decolorizations and mineralizations of organic dyes over a silver germanium oxide photocatalyst under indoor-illumination irradiation, Appl. Catal. A: Gen. 366 (2009) 309-314.

[391] X. Chang, J. Huang, C. Cheng, Q. Sui, W. Sha, G. Ji, S. Deng, G. Yu, BiOX (X = Cl, $\mathrm{Br}, \mathrm{I})$ photocatalysts prepared using $\mathrm{NaBiO}_{3}$ as the $\mathrm{Bi}$ source: characterization and catalytic performance, Catal. Commun. 11 (2010) 460-464.

[392] X. Zhang, Z. Ai, F. Jia, L. Zhang, Generalized one-pot synthesis, characterization, and photocatalytic activity of hierarchical $\mathrm{BiOX}(\mathrm{X}=\mathrm{Cl}, \mathrm{Br}, \mathrm{I})$ nanoplate microspheres, J. Phys. Chem. C 112 (2008) 747-753.

[393] H. An, Y. Du, T. Wang, C. Wang, W. Hao, J. Zhang, Photocatalytic properties of $\mathrm{BiOX}(\mathrm{X}=\mathrm{Cl}, \mathrm{Br}$, and I), Rare Metals 27 (2008) 243-250.

[394] C. Wang, C. Shao, Y. Liuc, L. Zhang, Photocatalytic properties $\mathrm{BiOCl}$ and $\mathrm{Bi}_{2} \mathrm{O}_{3}$ nanofibers prepared by electrospinning, Scripta Mater. 59 (2008) 332-335.

[395] M.A. Gondal, X.F. Chang, Z.H. Yamani, UV-light induced photocatalytic decolorization of rhodamine $6 \mathrm{G}$ molecules over $\mathrm{BiOCl}$ from aqueous solution, Chem. Eng. J. 165 (2010) 250-257.

[396] F. Chen, H. Liu, S. Bagwasi, X. Shen, J. Zhang, Photocatalytic study of BiOC for degradation of organic pollutants under UV irradiation, J. Photochem. Photobiol. A: Chem. 215 (2010) 76-80.

[397] S. Wu, C. Wang, Y. Cui, T. Wang, B. Huang, X. Zhang, X. Qin, P. Brault, Synthesis and photocatalytic properties of $\mathrm{BiOCl}$ nanowire arrays, Mater. Lett. 64 (2010) 115-118.

[398] K.-L. Zhang, C.-M. Liu, F.-Q. Huang, C. Zheng, W.-D. Wang, Study of the elec tronic structure and photocatalytic activity of the BiOCl photocatalyst, Appl. Catal. B: Environ. 68 (2006) 125-129.

[399] X. Lin, T. Huang, F. Huang, W. Wang, J. Shi, Photocatalytic activity of a Bi-Based oxychloride $\mathrm{Bi}_{3} \mathrm{O}_{4} \mathrm{Cl}$, J. Phys. Chem. B 110 (2006) 24629-24634.

[400] Z. Jiang, F. Yang, G. Yang, L. Kong, M.O. Jones, T. Xiao, P.P. Edwards, The hydrothermal synthesis of $\mathrm{BiOBr}$ flakes for visible-light-responsive photocatalytic degradation of methyl orange, J. Photochem. Photobiol. A: Chem. 212 (2010) 8-13.

[401] J. Zhang, F. Shi, J. Lin, D. Chen, J. Gao, Z. Huang, X. Ding, C. Tang, Self-assembled 3-D architectures of $\mathrm{BiOBr}$ as a visible light-driven photocatalyst, Chem. Mater. 20 (2008) 2937-2941.

[402] Z. Ai, W. Ho, S. Lee, L. Zhang, Efficient photocatalytic removal of NO in indoor air with hierarchical bismuth oxybromide nanoplate microspheres under visible light, Environ. Sci. Technol. 43 (2009) 4143-4150.

[403] M. Shang, W. Wang, L. Zhang, Preparation of BiOBr lamellar structure with high photocatalytic activity by CTAB as $\mathrm{Br}$ source and template, J. Hazard. Mater. 167 (2009) 803-809.

[404] W.L. Huang, Electronic structures and optical properties of $\mathrm{BiOX}(\mathrm{X}=\mathrm{F}, \mathrm{Cl}, \mathrm{Br}$, I) via DFT calculations, J. Comput. Chem. 30 (2008) 1882-1891.

[405] X. Chang, J. Huang, Q. Tan, M. Wang, G. Ji, S. Deng, G. Yu, Photocatalytic degradation of PCP-Na over BiOI nanosheets under simulated sunlight irradiation, Catal. Commun. 10 (2009) 1957-1961.

[406] W. Su, J. Wang, Y. Huang, W. Wang, L. Wu, X.X. Wang, P. Liu, Synthesis and catalytic performances of a novel photocatalyst BiOF, Scripta Mater. 62 (2010) 345-348.

[407] W. Wang, F. Huang, X. Lin, $x \mathrm{BiOI}-(1-x) \mathrm{BiOCl}$ as efficient visible-light-driven photocatalysts, Scripta Mater. 56 (2007) 669-672.

[408] W. Wang, F. Huang, X. Lin, J. Yang, Visible-light responsive photocatalysts $x \operatorname{BiOBr}-(1-x)$ BiOI, Catal. Commun. 9 (2008) 8-12

[409] T. Yan, J. Long, Y. Chen, X. Wang, D. Li, X. Fu, Indium hydroxide: a highly active and low deactivated catalyst for photoinduced oxidation of benzene, C. R. Chim. 11 (2008) 101-106

[410] T. Yan, X. Wang, J. Long, P. Liu, X. Fu, G. Zhang, X. Fu, Urea-based hydrotherma growth, optical and photocatalytic properties of single-crystalline $\operatorname{In}(\mathrm{OH})_{3}$ nanocubes, J. Colloid Interface Sci. 325 (2008) 425-431.

[411] T. Yan, J. Long, X. Shi, D. Wang, Z. Li, X. Wang, X. Fu, Efficient photocatalytic degradation of volatile organic compounds by porous indium hydroxide nanocrystals, Environ. Sci. Technol. 44 (2010) 1380-1385.

[412] Z. Li, Z. Xie, Y. Zhang, L. Wu, X. Wang, X. Fu, Wide band gap p-block meta oxyhydroxide InOOH: a new durable photocatalyst for benzene degradation, J. Phys. Chem. C 111 (2007) 18348-18352.

[413] Z. Lei, G. Ma, M. Liu, W. You, H. Yan, G. Wu, T. Takata, M. Hara, K. Domen, C. Li, Sulfur-substituted and zinc-doped $\operatorname{In}(\mathrm{OH})_{3}$ : a new class of catalyst fo photocatalytic $\mathrm{H}_{2}$ production from water under visible light illumination, J. Catal. 237 (2006) 322-329.

[414] Z. Li, T. Dong, Y. Zhang, L. Wu, J. Li, X. Wang, X. Fu, Studies on $\operatorname{In}(\mathrm{OH})_{y} \mathrm{~S}_{z}$ solid solutions: syntheses, characterizations, electronic structure and visible-light-driven photocatalytic activities, J. Phys. Chem. C 111 (2007) 4727-4733.

[415] S. Ge, L. Zhang, Efficient visible light driven photocatalytic removal of RhB and NO with low temperature synthesized $\operatorname{In}(\mathrm{OH})_{x} \mathrm{~S}_{y}$ hollow nanocubes: a comparative study, Environ. Sci. Technol. 45 (2011) 3027-3033.

[416] J. Luan, Z. Zou, M. Lu, S. Zheng, Y. Chen, Growth, structural and photophysical properties of $\mathrm{Bi}_{2} \mathrm{GaTaO}_{7}$, J. Cryst. Growth 273 (2004) 241-247. 
[417] J. Luan, X. Hao, S. Zheng, G. Luan, X. Wu, Structural, photophysical and photocatalytic properties of $\mathrm{Bi}_{2} \mathrm{MTaO}_{7}(\mathrm{M}=\mathrm{La}$ and Y), J. Mater. Sci. 41 (2006) 8001-8012.

[418] J. Luan, Z. Zou, M. Lu, G. Luan, Y. Chen, Structural and photocatalytic properties of the new solid photocatalyst $\mathrm{In}_{2} \mathrm{BiTaO}_{7}$, Res. Chem. Intermed. 32 (2006) 31-42.

[419] J. Luan, S. Zheng, X. Hao, G. Luan, X. Wu, Z. Zou, Photophysical and photocatalytic properties of novel $\mathrm{M}_{2} \mathrm{BiNbO}_{7}(\mathrm{M}=\mathrm{In}$ and $\mathrm{Ga}$ ), J. Braz. Chem. Soc. 17 (2006) 1368-1376.

[420] J. Luan, H. Cai, S. Zheng, X. Hao, G. Luan, X. Wu, Z. Zou, Structural and photocatalytic properties of novel $\mathrm{Bi}_{2} \mathrm{GaVO}_{7}$, Mater. Chem. Phys. 104 (2007) 119-124.

[421] J. Luan, H. Cai, X. Hao, J. Zhang, G. Luan, X. Wu, Z. Zou, Structural characterization and photocatalytic properties of novel $\mathrm{Bi}_{2} \mathrm{FeVO}_{7}$, Res. Chem. Intermed. 33 (2007) 487-500.

[422] J. Luan, W. Zhao, J. Feng, H. Cai, Z. Zheng, B. Pan, X. Wu, Z. Zou, Y. Li, Structural, photophysical and photocatalytic properties of novel $\mathrm{Bi}_{2} \mathrm{AlVO}_{7}$, J. Hazard. Mater. 164 (2009) 781-789.

[423] J. Luan, B. Pan, Y. Paz, Y. Li, X. Wu, Z. Zou, Structural, photophysical and photocatalytic properties of new $\mathrm{Bi}_{2} \mathrm{SbVO}_{7}$ under visible light irradiation, Phys. Chem. Chem. Phys. 11 (2009) 6289-6298.

[424] J. Luan, L. Zhang, K. Ma, Y. Li, Z. Zou, Preparation and property characterization of new $\mathrm{Y}_{2} \mathrm{FeSbO}_{7}$ and $\mathrm{In}_{2} \mathrm{FeSbO}_{7}$ photocatalysts, Solid State Sci. 13 (2011) 185-194.

[425] J. Luan, M. Li, K. Ma, Y. Li, Z. Zou, Photocatalytic activity of novel $\mathrm{Y}_{2}$ InSbO $_{7}$ and $\mathrm{Y}_{2} \mathrm{GdSbO}_{7}$ nanocatalysts for degradation of environmental pollutant rhodamine B under visible light irradiation, Chem. Eng. J. 167 (2011) 162-171.

[426] J. Luan, M. Lu, S. Zheng, Z.Zou, Optical, structural and photophysical properties of $\mathrm{Ga}_{2} \mathrm{BiTaO}_{7}$ compound, J. Mater. Sci. 40 (2005) 4905-4909.

[427] J. Luan, K. Ma, B. Pan, Y. Li, X. Wu, Z. Zou, Synthesis and catalytic activity of new $\mathrm{Gd}_{2} \mathrm{BiSbO}_{7}$ and $\mathrm{Gd}_{2} \mathrm{YSbO}_{7}$ nanocatalysts, J. Mol. Catal. A: Chem. 321 (2010) $1-9$.

[428] J. Luan, Z. Zheng, H. Cai, X. Wu, G. Luan, Z. Zou, Structural characterization and photocatalytic properties of novel $\mathrm{Bi}_{2} \mathrm{YVO}_{8}$, Mater. Res. Bull. 43 (2008) 3332-3344.
[429] T. Kako, Z. Zou, J. Ye, Photocatalytic oxidation of 2-propanol in the gas phase over cesium bismuth niobates under visible light irradiation, Res. Chem. Intermed. 31 (2005) 359-364.

[430] H.G. Kim, D.W. Hwang, J.S. Lee, An undoped, single-phase oxide photocatalyst working under visible light, J. Am. Chem. Soc. 126 (2004) 8912-8913.

[431] T. Kako, J. Ye, Photocatalytic decomposition of acetaldehyde over rubidium bismuth niobates under visible light irradiation, Mater. Trans. 46 (2005) 2699-2703.

[432] B. Muktha, M.H. Priya, G. Madras, T.N. Guru Row, Synthesis, structure, and photocatalysis in a new structural variant of the aurivillius phase: $\mathrm{LiBi}_{4} \mathrm{M}_{3} \mathrm{O}_{14}$ ( $\mathrm{M}=\mathrm{Nb}, \mathrm{Ta})$, J. Phys. Chem. B 109 (2005) 11442-11449.

[433] T. Hatakeyama, S. Takeda, F. Ishikawa, A. Ohmura, A. Nakayama, Y. Yamada, A. Matsushita, J. Ye, Photocatalytic activities of $\mathrm{Ba}_{2} \mathrm{RBiO}_{6}(\mathrm{R}=\mathrm{La}, \mathrm{Ce}, \mathrm{Nd}, \mathrm{Sm}$, Eu, Gd, Dy) under visible light irradiation, J. Ceram. Soc. Jpn. 118 (2010) 91-95.

[434] L.L. Garza-Tovar, L.M. Torres-Martínez, D. Bernal Rodríguez, R. Gómez, G. del Angel, Photocatalytic degradation of methylene blue on $\mathrm{Bi}_{2} \mathrm{MNbO}_{7}$ $(\mathrm{M}=\mathrm{Al}, \mathrm{Fe}, \mathrm{In}, \mathrm{Sm})$ sol-gel catalysts, J. Mol. Catal. A: Chem. 247 (2006) 283-290.

[435] L.M. Torres-Martínez, I. Juárez-Ramírez, J.S. Ramos-Garza, F. Vázquez-Acosta, S.W. Lee, Sol-gel preparation of $\mathrm{Bi}_{2} \mathrm{InTaO}_{7}$ and its photocatalytic behavior for organic compounds degradation, Mater. Sci. Forum 658 (2010) 491-494.

[436] X. Li, S. Ouyang, N. Kikugawa, J. Ye, Novel $\mathrm{Ag}_{2} \mathrm{ZnGeO}_{4}$ photocatalyst for dye degradation under visible light irradiation, Appl. Catal. A: Gen. 334 (2008) 51-58.

[437] X. Lin, T. Huang, F. Huang, W. Wang, J. Shi, Photocatalytic activity of a Bi-based oxychloride $\mathrm{Bi}_{4} \mathrm{NbO}_{8} \mathrm{Cl}$, J. Mater. Chem. 17 (2007) 2145-2150.

[438] X. Lin, Z. Shan, K. Li, W. Wang, J. Yang, F. Huang, Photocatalytic activity of a novel Bi-based oxychloride catalyst $\mathrm{Na}_{0.5} \mathrm{Bi}_{1.5} \mathrm{O}_{2} \mathrm{Cl}$, Solid State Sci. 9 (2007) 944-949.

[439] Z. Shan, W. Wang, X. Lin, H. Ding, F. Huang, Photocatalytic degradation of organic dyes on visible-light responsive photocatalyst $\mathrm{PbBiO}_{2} \mathrm{Br}$, J. Solid State Chem. 181 (2008) 1361-1366. 